\title{
Final Report on Fiscal Year 1992 Activities for the Environmental Monitors Line-Loss Study
}

Date Published

September 1993

Prepared for the U.S. Department of Energy Office of Environmental Restoration and Waste Management

(2) Westingtouse
Hanford Company Richland, Washington 99352

Hanford Operations and Engineering Contractor for the

U.S. Department of Energy under Contract DE-AC06-87RL10930 


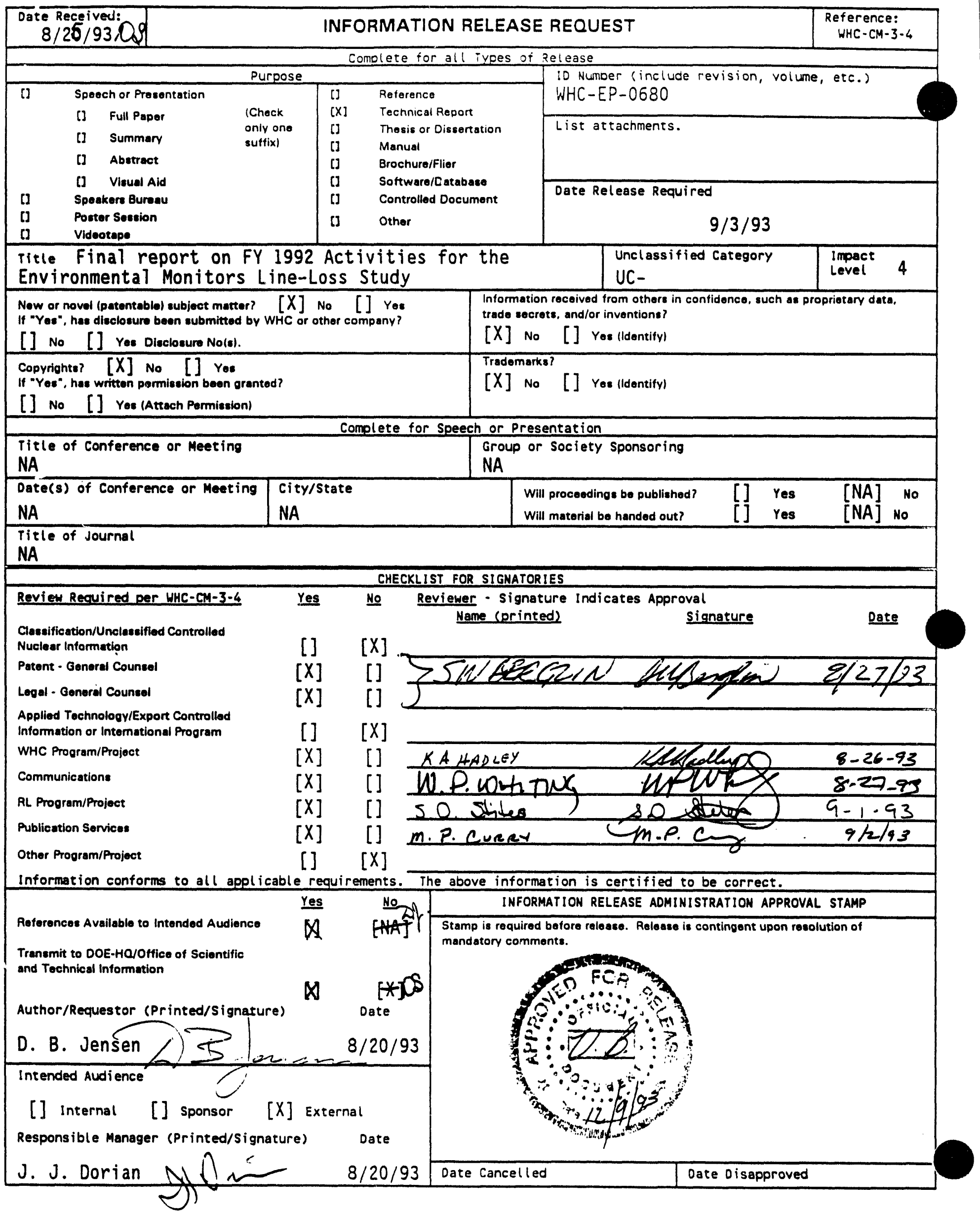




\title{
FINAL REPORT ON FY 1992 ACTIVITIES FOR THE ENVIRONMENTAL MONITOKS LINE-LOSS STUDY
}

January 18, 1993

\author{
Prepared For: \\ Westinghouse Hanford Company \\ P. O. Box 1970 \\ Richland, WA 99352
}
Prepared By:
Science Applications International Corporation 1845 Terminal Drive Richland, WA 99352


WHC-EP-0680

This page intentionally left blank. 
Document Title:

Final Report on FY 1992 Activities for the Environmental Monitors Line-Loss Study

Prepared By:

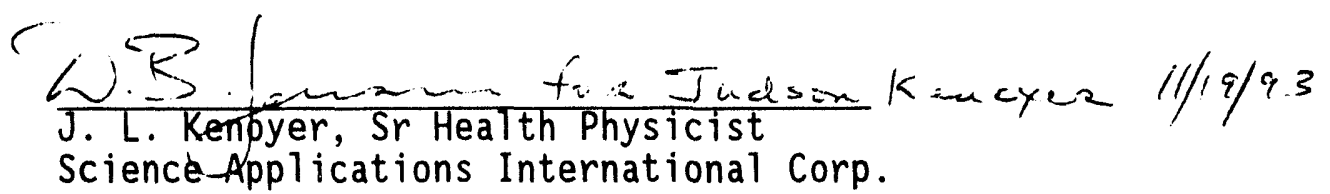

Reviewed By:

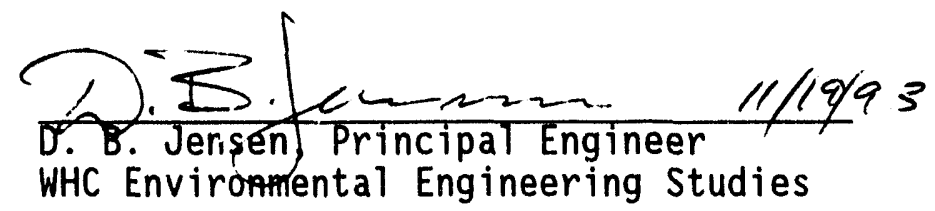

Approved By:

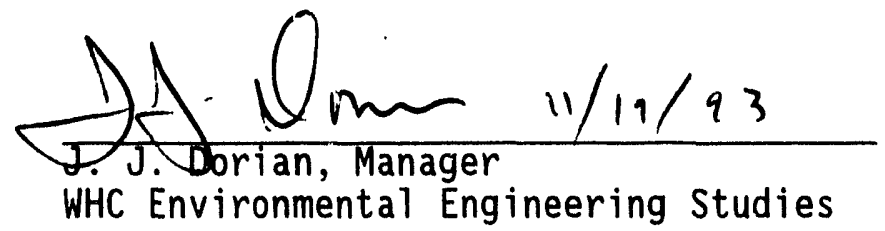


WHC-EP-0680

This page intentionally left blank. 


\section{TABLE OF CONTEYTS}

1.0 INTRODUCTION $\ldots \ldots \ldots \ldots \ldots \ldots \ldots \ldots \ldots \ldots \ldots \ldots \ldots \ldots \ldots \ldots .11$

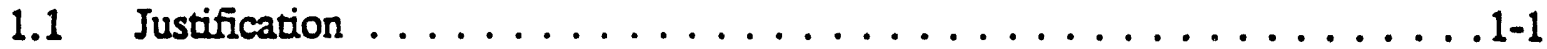

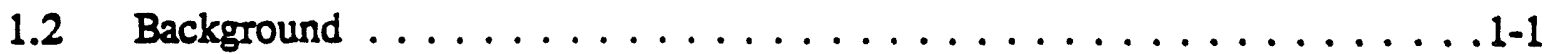

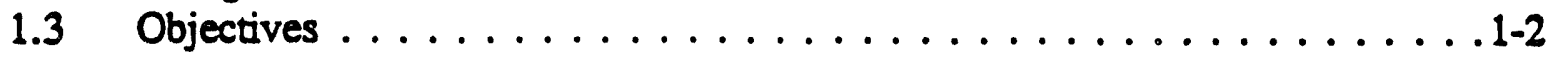

2.0 WORK PERFORMED DURING FY 1992 AND FIRST QUARTER OF FY

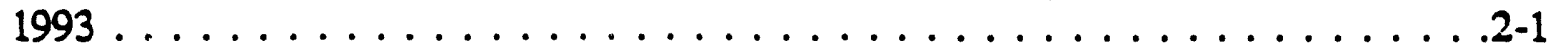

2.1 Description of Sampling and Measurement Systems and Procedures . . . . 2-1

2.1 .1 Cascade Impactor . . . . . . . . . . . . . . . . . . 2-1

2.1.1.1 PR Stack ..............2-1

2.1.1.2 PUREX Main Stack . . . . . . . . . . 2-4

2.1.1.3 AP-Tank Farm Stack . . . . . . . . . 2-6

2.1.2 Laser Spectrometer . . . . . . . . . . . . . . . . . . . . 2-9

2.1.2.1 PR Stack . . . . . . . . . . . . 2-9

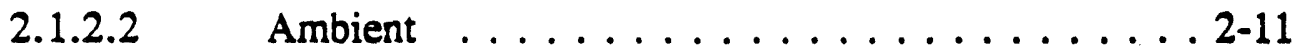

2.2 Data . . . . . . . . . . . . . . . . . . 2-11

2.2 .1 Acquisition . . . . . . . . . . . . . . 2-12

2.2.1.1 Cascade Impactor . . . . . . . . . 2-12

2.2.1.2 Laser Spectrometer . . . . . . . . . . . 2-13

2.2.2 Data Analyses and Assessments . . . . . . . . . 2-14

2.2.2.1 Cascade Impactor . . . . . . . . . . 2-14

2.2.2.2 Laser Spectrometer . . . . . . . . . . . 2-17

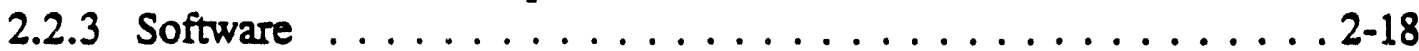

2.3 Results . . . . . . . . . . . . . . . . . . . . 2-18

2.3.1 Cascade Impactor . . . . . . . . . . . . . . . . 2-19

2.3.2 Laser Spectrometer . . . . . . . . . . . . . . . 2-25

2.3.3 Software . . . . . . . . . . . . . . 2-32

2.3.4 Comparisons and Assessments . . . . . . . . . . 2-33

2.4 Development of General Test Methods and Procedures for Line-Loss

Determinations . . . . . . . . . . . . . . . . 2-35

2.4.1 Preliminary Actions $\ldots \ldots \ldots \ldots \ldots \ldots \ldots \ldots .2-35$

2.4.2 Sample Acquisition . . . . . . . . . . . . . 2-38

2.4.3 Sample Analyses and Measurements . . . . . . . . 2-39

2.4.3.1 Cascade Impactor . . . . . . . . . . . . 2-39

2.4.3.2 Laser Spectrometer . . . . . . . . . . . . 2-40

2.4.4 Data Assessment . . . . . . . . . . . . . . 2-41

2.4.4.1 Cascade Impactor . . . . . . . . . . . 2-41

2.4.4.2 Laser Spectrometer . . . . . . . . . . . . 2-41

2.4.4.3 Comparison of Cascade Impactor and Laser

Spectrometer Data . . . . . . . . . . . 2-41

2.4.5 Development of Conclusions . . . . . . . . . . . . . 2-42 


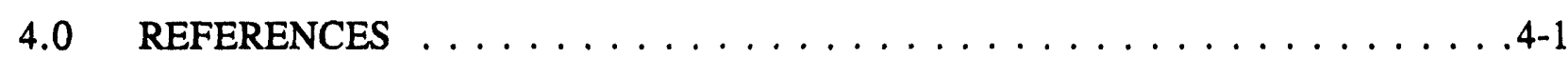

\section{LIST OF FIGURES}

2-1 PR-Stack Cascade Impactor Roof Location Sampling System $\ldots \ldots \ldots \ldots$. . . . .

2-2 PR-Stack Cascade Impactor CAM Sampling System . . . . . . . . . . . . . . 2-2

2-3 Cross-Section of Sampling Inlet Nozzle for the PR Stack . . . . . . . . . . . . . 2-4

2-4 Current PUREX Main Stack Effluent Sampling Program . . . . . . . . . . . . 2-5

2-5 PUREX Main Stack Cascade Impactor Sampling System . . . . . . . . . . . 2-5

2-6 Air Flow Splitter to be Used on the PUREX Main Stack with the Cascade Impactor System . . . . . . . . . . . . . . . . . . . 2-6

2-7 Current Effluent Monitoring System Downstream from the PUREX Main Stack Sampling Line . . . . . . . . . . . . . . . . . . . . . . . 2-7

2-8 Cascade Impactor System Downstream from the PUREX Main Stack Sampling

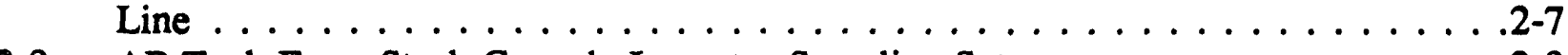

2-9 AP Tank Farm Stack Cascade Impactor Sampling Setup . . . . . . . . . . . . 2-8

2-10 AP Tank Farm Stack Cascade Impactor Sampling System . . . . . . . . . . . 2-9

2-11 Current Effluent Sampling System Downstream from Sampling Line . . . . . 2-10

2-12 Intermediate Sampling System Downstream from AP Tank Farm Stack . . . . . 2-10

2-13 AP Tank Farm Cascade Impactor Sampling System Downstream from the Sampling Line . . . . . . . . . . . . . . . . . . 2-11

2-14 Particle Size Frequency Distributions for Four Samples $\ldots \ldots \ldots \ldots$. . . . 2-29

2-15 Size Distribution Data for the PR-Stack Measurements . . . . . . . . . 2-30

A1-1 Andersen Cascade Impactor $\ldots \ldots \ldots \ldots \ldots \ldots \ldots \ldots \ldots$. . . . . . . . . . . . .

A1-2 Cascade Impactor Cross-Section $\ldots \ldots \ldots \ldots \ldots \ldots \ldots \ldots \ldots \ldots$ A1-4

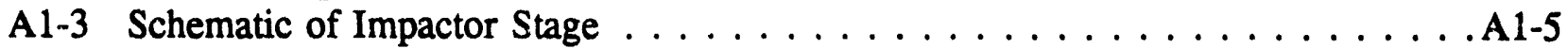

A1-4 Fractional Efficiency Curves . . . . . . . . . . . . . . A1-10

A1-5 Particle Size Diameter Graph . . . . . . . . . . . . . . A1-12

A2-1 A2200 Laser Particle Counter $\ldots \ldots \ldots \ldots \ldots \ldots \ldots \ldots \ldots \ldots$. . . . . . . . . .

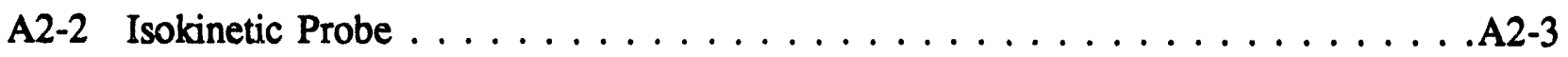

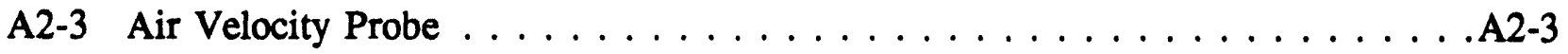

A2-4 Relative Humidity/Temperature Sensor $\ldots \ldots \ldots \ldots \ldots \ldots \ldots \ldots$. . . . . . . . 


\section{LIST OF TABLES}

2-1 Cascade Impactor Data from the PR Stack (Sample Sets \#1, 2, and 3) . . . . 2-20

2-2 Cascade Impactor Data from the PR Stack (Sample Sets \#4 and \#5 . . . . . . 2-21

2-3 Laser Particle Sample Data for PR Stack . . . . . . . . . . . . . . . . . . . 2-26

2-4 Particle Counts in Different Size Ranges for PR-Stack Measurements . . . . . . 2-28

2-5 PR-Stack Sample Locations . . . . . . . . . . . . . . . . . . . . 2-28

2-6 Particle Size Distributions . . . . . . . . . . . . . . . . . . . . . 2-32

2-7 Theoretical Percent Penetration of Particles for the PR Stack Sampling Line . . . 2-34

2-8 Checklist of Items Needed for PR-Stack Cascade Impactor Samples . . . . . . . 2-37

A1-1 Data Presentation . . . . . . . . . . . . . . . . . . . . . A1-9 
METRIC CONVERSION CHART

\begin{tabular}{|c|c|c|}
\hline \multicolumn{3}{|c|}{ INTO METRIC } \\
\hline If you know & Multiply by & To get \\
\hline \multicolumn{3}{|c|}{ Length } \\
\hline inches & 2.54 & centimeters \\
\hline feet & 30.48 & centimeters \\
\hline \multicolumn{3}{|c|}{ Volume } \\
\hline gallons & 3.786 & 1iters \\
\hline cubic feet & 0.02832 & cubic meters \\
\hline \multicolumn{3}{|c|}{ Temperature } \\
\hline Fahrenheit & $\begin{array}{l}\text { Subtract } 32 \text { then } \\
\text { multiply by } 5 / 9 \text { ths }\end{array}$ & Celsius \\
\hline \multicolumn{3}{|c|}{ Pressure } \\
\hline inches water & 1.87 & $\mathrm{~mm} \mathrm{Hg}$ \\
\hline inches water & 249 & Paschal (Pa) \\
\hline \multicolumn{3}{|c|}{ OUT OF METRIC } \\
\hline \multicolumn{3}{|c|}{ Length } \\
\hline centimeters & 0.3937 & inches \\
\hline meters & 3.28 & feet \\
\hline \multicolumn{3}{|c|}{ Volume } \\
\hline milliliters & $1.247 \times 10^{-3}$ & cubic feet \\
\hline liters & 0.264 & gallons. \\
\hline cubic meters & 35.31 & cubic feet \\
\hline \multicolumn{3}{|c|}{ Temperature } \\
\hline Celsius & $\begin{array}{l}\text { Multiply by } 9 / 5 \text { ths, then } \\
\text { add } 32\end{array}$ & Fahrenheit \\
\hline \multicolumn{3}{|c|}{ Pressure } \\
\hline $\mathrm{mm} \mathrm{Hg}$ & 0.5353 & inches water \\
\hline Paschal (Pa) & $4.02 \times 10^{-3}$ & inches water \\
\hline
\end{tabular}




\subsection{INTRODUCTION}

The work performed on this Environmental Monitors Line-Loss Study has been performed under Contract Numbers MLW-SVV-073750 and MFH-SVV-207554. Work on the task was initiated mid-December 1991, and this report documents and summarizes the work performed through January 18, 1993.

The sections included in this report summarize the work performed on the Environmental Monitors Line-Loss Study. The sections included in this report are arranged to reflect individual sub-tasks and include:

- descriptions of measurement systems and procedures used to obtain cascade impactor samples and laser spectrometer measurements from. multiple stacks and locations;

- information on data acquisition, analyses, assessment, and software;

- discussion of the analyses and measurement results from the cascade impactor and laser spectrometer systems and software used;

- discussion on the development of general test methods and procedures for lineloss determinations;

- an overall summary and specific conclusions that can be made with regard to efforts performed on this task during FY 1992 and FY 1993 (October 1, 1992 through January 18, 1993).

Supporting information for these sections is included in this report as appendices.

\subsection{Justification}

Deficiencies in air monitoring and sampling systems at WHC are identified in WHC Compliance Plan CP89-16. These deficiencies include line loss quantification, potential proportional sampling errors, quantification of sampling/measurement system bias, and overall system calibrations. These requirements are set forth in the Environmental Compliance Manual, WHC-CM-7-5, Part D. "Tiger Team" assessment number A/BMPF-3 also identifies line losses as a potential for large sampling errors. This has been a continuation of work started in FY 1991.

\subsection{Background,}

During FY 1991, work was performed on the Air Monitor Calibration and Line-Loss Study under Contract Number MLW-SVV-518974. The task was initiated in mid-February, 
1991 and was completed September 30, 1991. The objectives of this work were to obtain information on current industry sampling methods, line-loss studies, and calibration technology. Assessment of present WHC systems was documented against both the regulations and currently available technology. There were five objectives associated with this task as stated in the original work plan. These were:

1) conduct a technical review of current industry-wide gaseous effluent sampling and monitoring methods, line-loss studies, equipment and procedures,

2) assess the present WHC system designs, collection data and calibration methods for systems sampling and monitoring stack effluents,

3) outline and develop the methods for determining the accuracy of the WHC sampling and monitoring systems,

4) document test methods and procedures, including the technical bases, system accuracy, specific sources of error and test results,

5) initiate a line-loss study, if required, to determine system accuracy and equipment using existing contaminants and/or tracers on one WHC stack sampling and monitoring system as directed by the WHC Task Manager and within the budget limitations.

Efforts on these subtasks were summarized in a report titled "Final Report on FY 1991 Activities for the Air Monitor Calibration and Line-Loss Study" submitted to WHC on September 30, 1991 by SAIC personnel.

\subsection{Objectives}

The scope of this task was to obtain information on line losses for monitoring systems by empirical measurements. Assessment of both impactor sample results and laser measurements have been documented to provide methods for determining potential line losses in Hanford stack monitoring systems. The completed work is consistent with the Action Plans contained in Compliance Plan CP89-16. These were:

There were six objectives associated with this task as stated in the original work plan.

1) complete cascade impactor tests on PUREX PR Stack and determine projected line losses,

2) determine particle size distribution in selected stack(s) by laser spectrometry, 
3) complete cascade impactor tests on a second stack system and document results,

4) prepare test methods and procedures for line loss determinations,

5) plan, initiate, and complete a third impactor study, if required, using existing contaminants and/or tracers on one WHC stack,

6) prepare a final report. 
WHC-EP-0680

This page intentionally left blank. 


\subsection{WORK PERFORMED DURING FY 1992 AND FIRST QUARTER OF FY 1993}

Details of the work performed during FY 1992 and the beginning of FY 1993 are described in this section. Included are descriptions of the measurement systems constructed and/or modified and procedures written and implemented to obtain data to be used to quantify particle line losses in effluent sampling lines. Bases for decisions made during the work period are stated where appropriate. Cascade-impactor and laser-spectrometer systems were used to obtain particle size-distribution and line-loss data. Data was obtained on the PR Stack; measurements were obtained directly from the stack and also downstream of the effluent sampling line used by an alpha CAM. Plans to acquire data from the PUREX Main Stack and from the AP Tank Farm Stack were developed but they were not implemented during the work period; these plans are also presented in this report.

Details of data acquisition, analyses, and assessment are discussed and compared. A software program developed by Anand and McFarland (Anand and McFarland 1991) is also described.

Specific results of testing using the cascade impactor and the laser spectrometer are presented and discussed as well as results obtained using the "Deposition" software. The empirical results are compared to the software results. Finally, general test methods and procedures for the determination of particle line loss based on the data obtained during the year and the assessment of that data are discussed in detail.

\subsection{Description of Sampling and Measurement Systems and Procedures}

The effluent sampling and measurement systems used or planned to be used in this study are described in this section. Also included here are descriptions of procedures used to operate the instrumentation.

\subsubsection{Cascade Impactor}

The cascade impactors used in this task were manufactured by Andersen Instruments, Incorporated. They were the Non-Viable Ambient Particle Sizing Samplers and were operated at 1 actual cubic foot per minute (acfm). They are multi-stage (8), multi-orifice cascade impactors using filter paper as the collection substrates. These units are described in detail in Appendix A-1. The sampling systems in which these impactors were designed to be used during this task were for the PR Stack (296-A-1), the PUREX Main Stack (291-A-1), and the AP Tank Farm Stack (296-A-40).

\subsubsection{1 .PR Stack}

Cascade impactor samples were obtained directly from the PR Stack (from a PUREX roof location) and downstream from an alpha CAM sampling line location in the PR-Stack 
Instrument Building (Building 292-AA). Schematics of these two locations are shown in Figures 2-1 and 2-2.

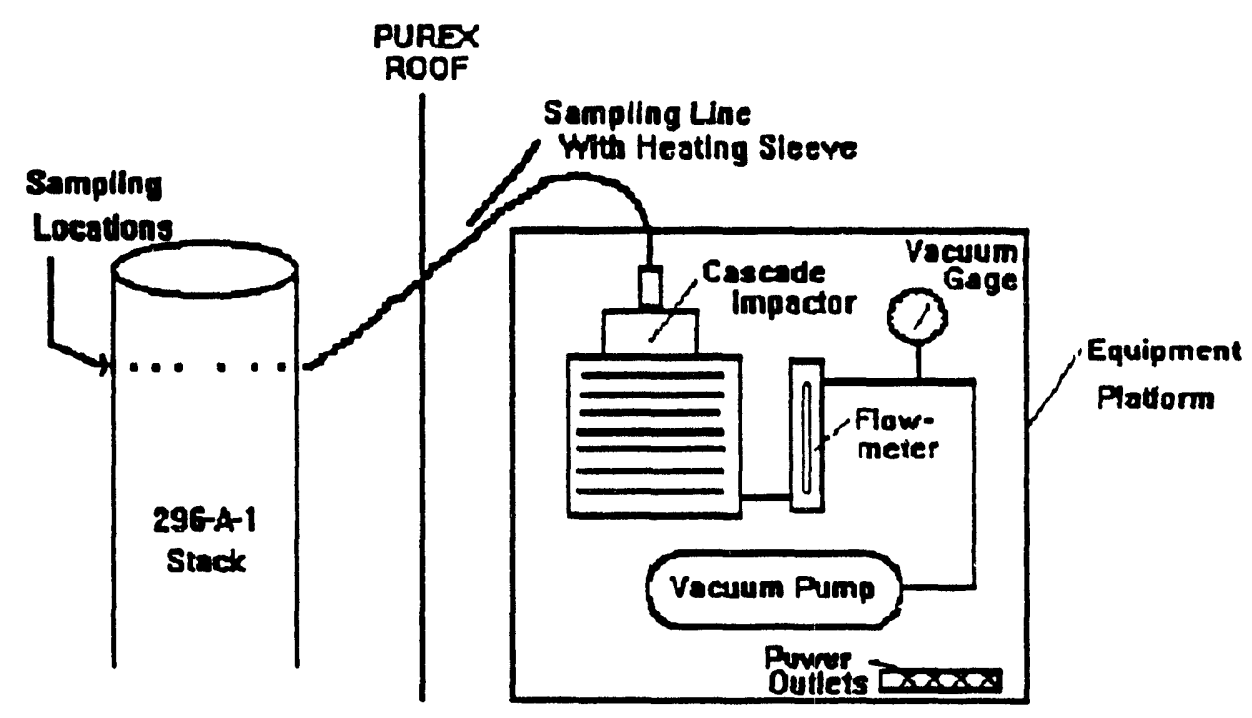

Figuro 2-1. PR-Stack Cascade Impactor Roof Location Sampling System

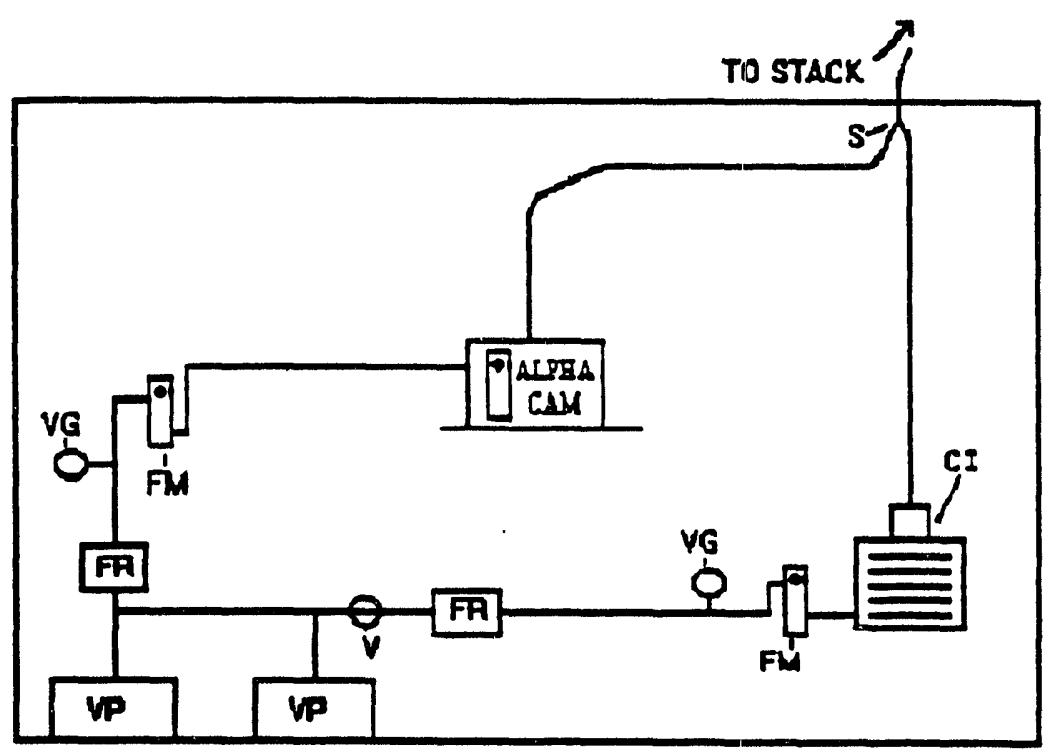

S - Splitter; VG - Vecuum gaugo; FM - Flow motor; FR - Flow regulator; V - Valvo; VP - Vecuum pump; Cl - Cascedo impector

Figure 2-2. PR-Stack Cascade Impactor CAM Sampling System

The cascade impactor system designed for sampling directly from the PR stack was positioned on a 3/4-in.-thick plywood base that is $2 \mathrm{ft} \times 2 \mathrm{ft}$ in surface dimensions. On that 
platform was placed the cascade impactor, flowmeter, vacuum gauge, two small vacuum pumps, a temperature controller, and a power outlet bar. The vacuum pumps and the temperature controller operated on 110 volts $\mathrm{AC}, 60 \mathrm{~Hz}$ power. After all of the parts of the system had been transported to the roof from the ground, they were secured to the platform. The sampling line ( $1 / 2$ in. outer diameter, 0.065 in. wall thickness; stainless steel) was inserted through the 1/2-in.-diameter hole in the side of the PR Stack and connected to the second part of the sampling line with a compression fitting. The inlet nozzle had an inner diameter of $3 / 8 \mathrm{in}$. with an approximate taper of $15^{\circ}$ at the entrance to an outer diameter of $1 / 2$ in. A diagram of the inlet nozzle is shown in Figure 2-3. The other part of the sampling line ran parallel to the PUREX Building roof until a gentle bend in it curved upward (with a radius of curvature of approximately 5 in.) and then it curved to a vertical tube that was connected to the top of the cascade impactor with another compression fitting. The sampling line was wrapped with heating tape and a plastic enclosure was secured over the cascade impactor and the rest of the system to protect the entire system from the weather. Samples were obtained during the winter months when ambient temperatures were in the 30s. A low temperature of near freezing was observed. The temperature of the sampling line was kept at approximately $80^{\circ} \mathrm{F}$ throughout the sampling period. Nine different sampling locations were used for the inlet nozzle during the sampling interval; these were based on the locations used by WHC Vent and Balance personnel when the velocity traverse measurements are obtained to characterize the velocity profile in the stack. These measurements are made once per quarter and are based on WHC Procedure 7-GN-56, Rev. 1, "Airflow Capacity and Distribution Tests." These locations represent positions recommended by the EPA in 40 CFR 60, Appendix A, Method 1 (U.S. EPA 1990). In Procedure 7-GN-56, 10 measurement locations are suggested; however, because of the shape of the inlet nozzle and the corresponding "width" of the inlet nozzle caused by the radius of curvature, the sample location normally used for the first measurement location could not be used for these samples-it was not physically possible. Therefore, the first two sample locations were combined and a sampling period of two times the period for a single location was used at a distance of $21 / 4$ in. inside the stack.

The sampling system in the PR Stack Instrument Building (292-AA) required a simple "modification" before the cascade impactor sampling system could be installed. An elbow and valve needed to be removed from the "spare" sampling line that is downstream from the air flow splitter. The other sampling line from the splitter goes to the alpha CAM. A diagram of this system may be found in Figure 1 in the Work Plan attached to this report as Appendix B-2. The cascade impactor was connected directly to the vertical portion of the sampling line downstream of the splitter with a compression fitting. As shown in Figure 2-2, a flowmeter and vacuum gauge are located downstream of the cascade impactor. Two facility vacuum pumps were used to meet the flowrate needs for the CAM and the cascade impactor. The normal flowrate for the alpha CAM is approximately 2 standard cubic feet per minute (scfm). This meets the flowrate required for isokinetic sampling through the sample rake in the PR Stack. When the CAM and cascade impactor are operated at the same time, the total flowrate must equal the flowrate previously determined for isokinetic flow conditions. The cascade impactor is designed to operate at $1 \mathrm{acfm}$. The flowrate through 


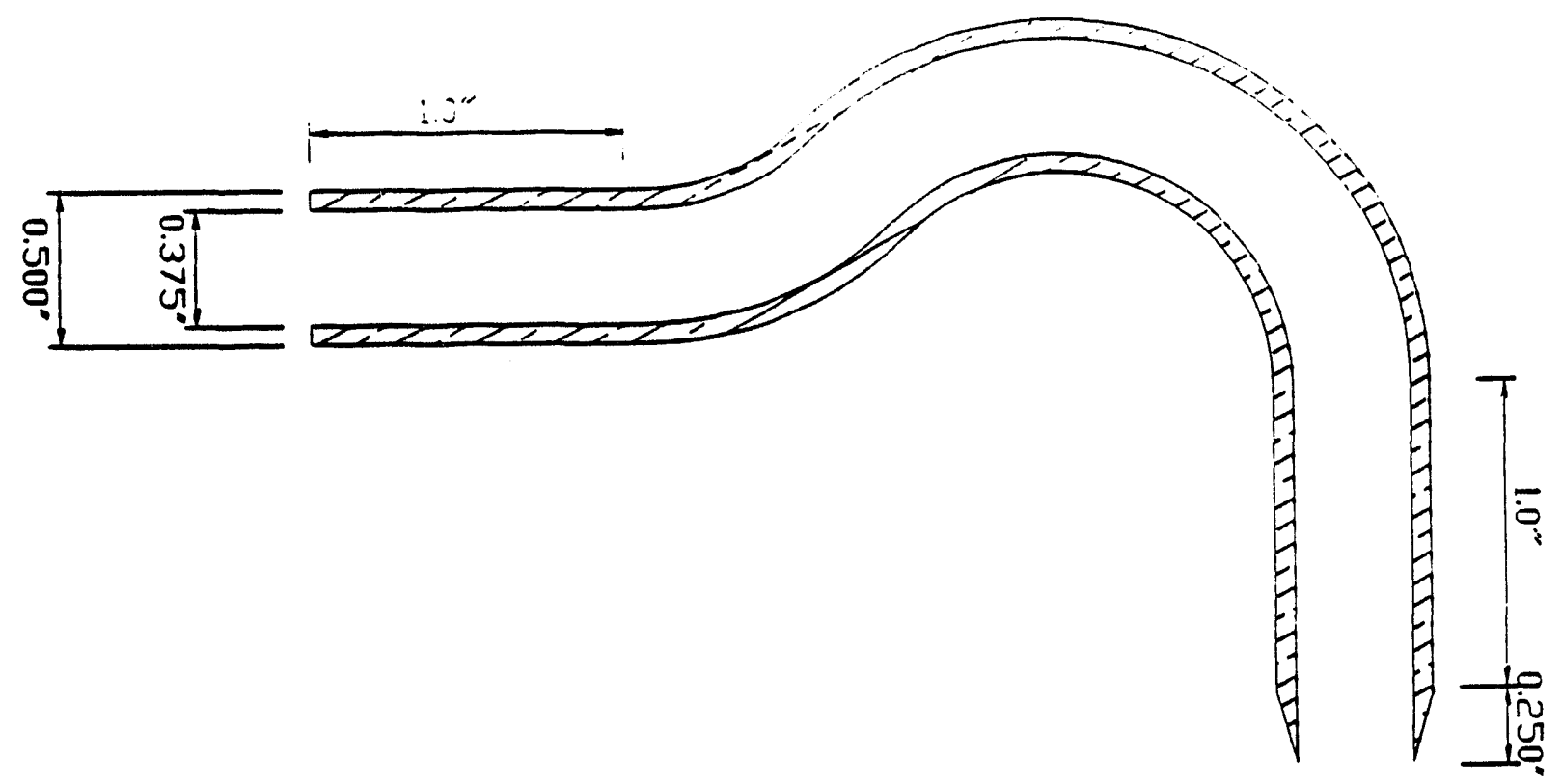

Figure 2-3. Cross-Section of Sampling Inlet Nozzle for the PR Stack

the CAM must be reduced accordingly and, therefore, the alarm set-point on the CAM must also be reduced proportionally to reflect this change. The flowmeter used with the cascade impactor is operated under a vacuum; therefore, the reading must be adjusted to compensate for this condition. Table I in the Work Plan (i.e., Appendix B-2) lists correction factors for this purpose. Table II in the same Work Plan lists calibration information for the flowmeter used. The temperature in the PR Instrument Building is controlled at approximately $75^{\circ} \mathrm{F}$; no heating tape is required on the sampling line inside the building. This sample is obtained during approximately the same time interval that the corresponding cascade impactor is operated on the PUREX Building roof.

\subsubsection{PUREX Main Stack}

Planning for the acquisition of cascade impactor samples from the PUREX Main Stack (291-A-1) was initiated in FY 1992. Figure 2-4 illustrates one of the current effluent sampling and monitoring systems on this stack. The line chosen to be used (after modifications) samples from the 60 -foot level of the stack. The line currently can be used to monitor $\mathrm{NO}_{x}$ levels in the stack by using $\mathrm{NO}_{x}$ monitors located in the 292-AB Building.

Figure 2-5 illustrates where the cascade impactor system would be located to obtain a sample directly from the stack. Scaffolding will need to be erected near the Main Stack so that samples can be obtained from the 60 -foot level. The line connected to the sampling rake inside the stack already has a compression fitting so that the line can be "installed" easily without cutting the line. The same type of cascade impactor system as used on the PR Stack will be used here. The system will be positioned on a $2 \mathrm{ft} \times 2 \mathrm{ft}, 3 / 4$-in.-thick plywood base. The base will accommodate the cascade impactor, flowmeter, vacuum gauge, two 


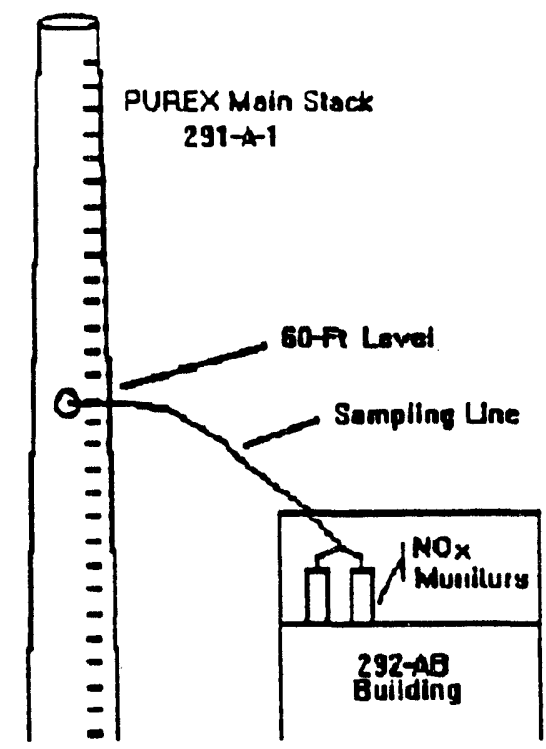

Figure 2-4. Current PUREX Main Stack Effluent Sampling Program

small vacuum pumps, a temperature controller, and a power outlet bar. The vacuum pumps and the temperature controller will operate on 110 volts AC, $60 \mathrm{~Hz}$ electrical power supplied from the ground.

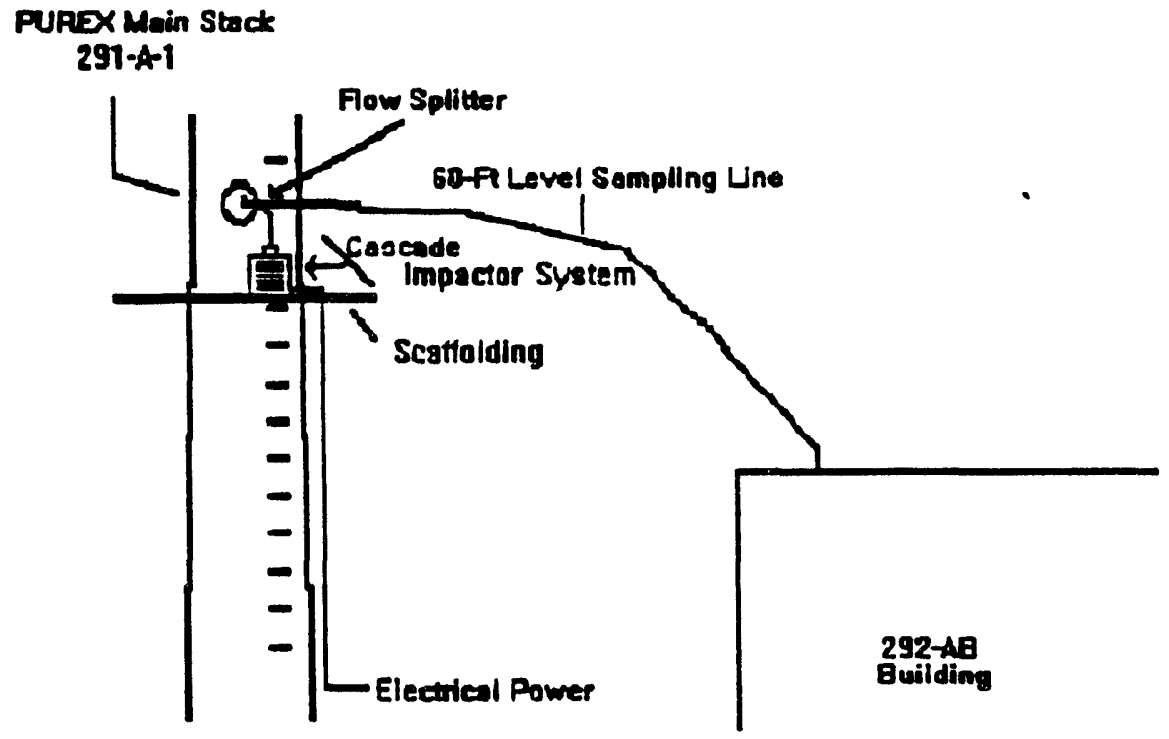

Figure 2-5. PUREX Main Stack Cascade Impactor Sampling System 
Figure 2-6 shows a schematic of the air flow splitter to be used to incorporate the cascade impactor into the current sampling system. This splitter has already been constructed and is made of stainless steel with the dimensions shown in the figure. Refer to Figure 2-5 as to the location of the splitter in the system.

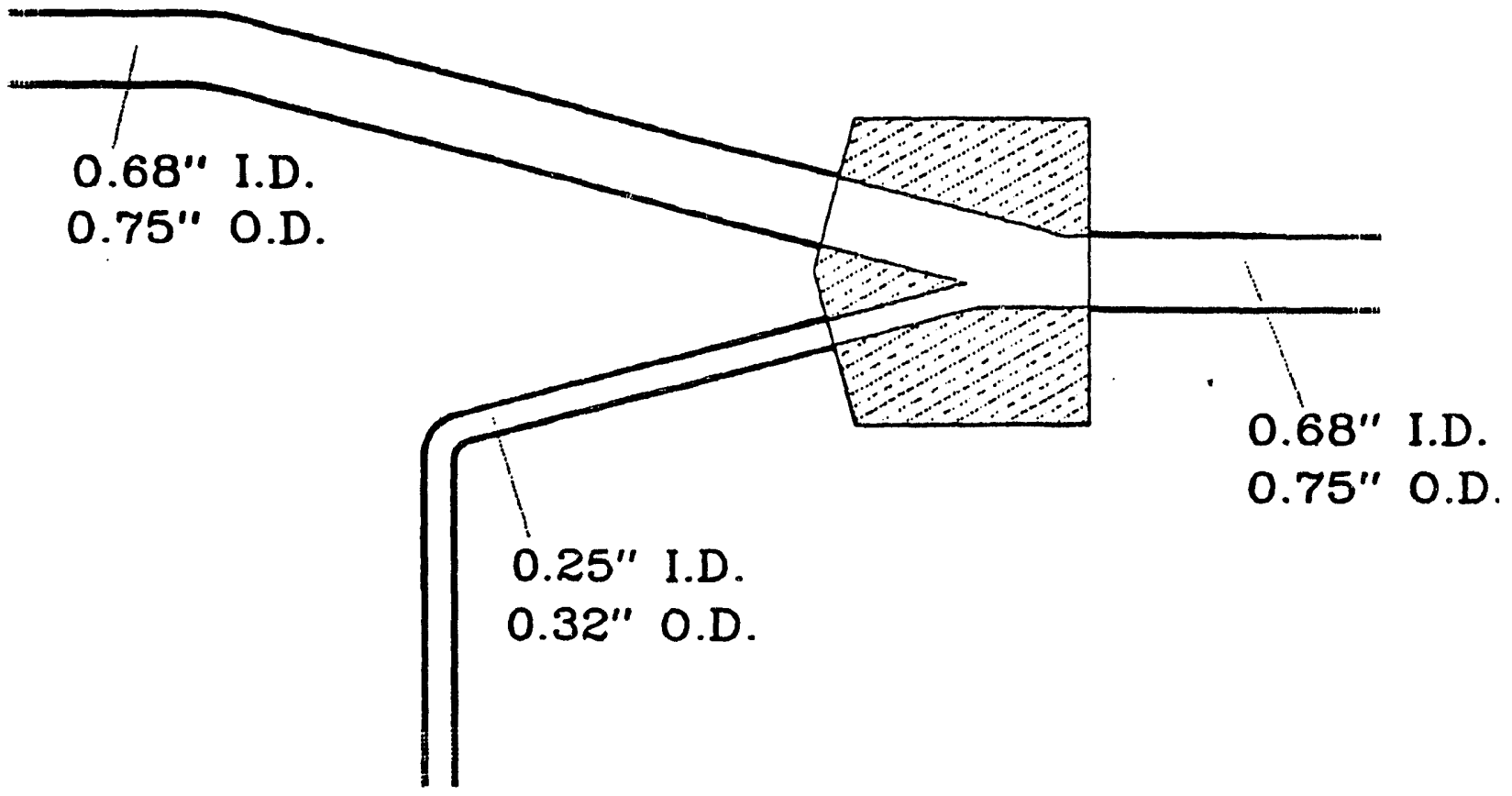

Figure 2-6. Air Flow Splitter to be Used on the PUREX Main Stack with the Cascade Impactor System

Figure 2-7 illustrates the current effluent monitoring system that exists downstream from the PUREX Main Stack sampling line. This system will be modified so that a cascade impactor can be used to obtain particle size distribution and line-loss information.

Figure 2-8 shows where a second cascade impactor system would be located downstream from the PUREX Main Stack sampling line. An air flow splitter is already in the monitoring line used by the $\mathrm{NO}_{\mathrm{x}}$ monitors. Part of the flow goes to the monitors and the rest of the gas flows through a bypass line. The total flowrate through the main sampling line is $8 \mathrm{scfm}$ to ensure isokinetic sampling from the stack. The cascade impactor system will be located downstream from the splitter in the 292-AB Building and will sample downstream of the air flow splitter at a flowrate of $1 \mathrm{acfm}$.

\subsubsection{AP-Tank Farm Stack}

Planning for the acquisition of cascade impactor samples from the AP-Tank Farm Stack (296-A-40) was initiated in FY 1992. No samples were obtained because of changes in 


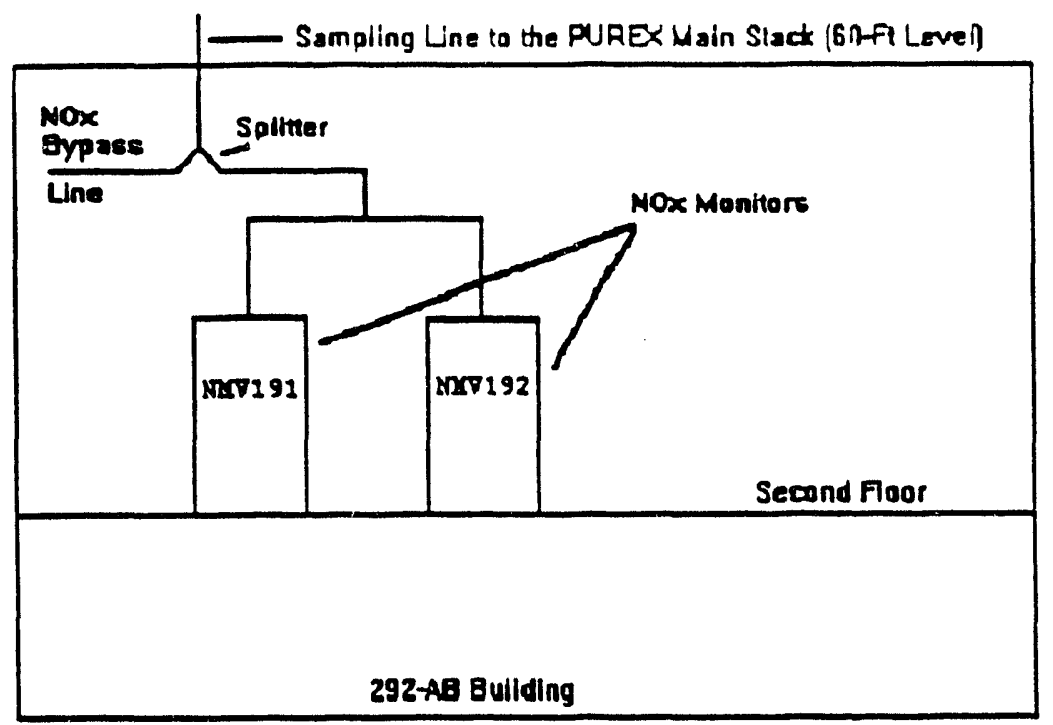

Figure 2-7. Current Effluent Monitoring System Downstream from the PUREX Main Stack Sampling Line

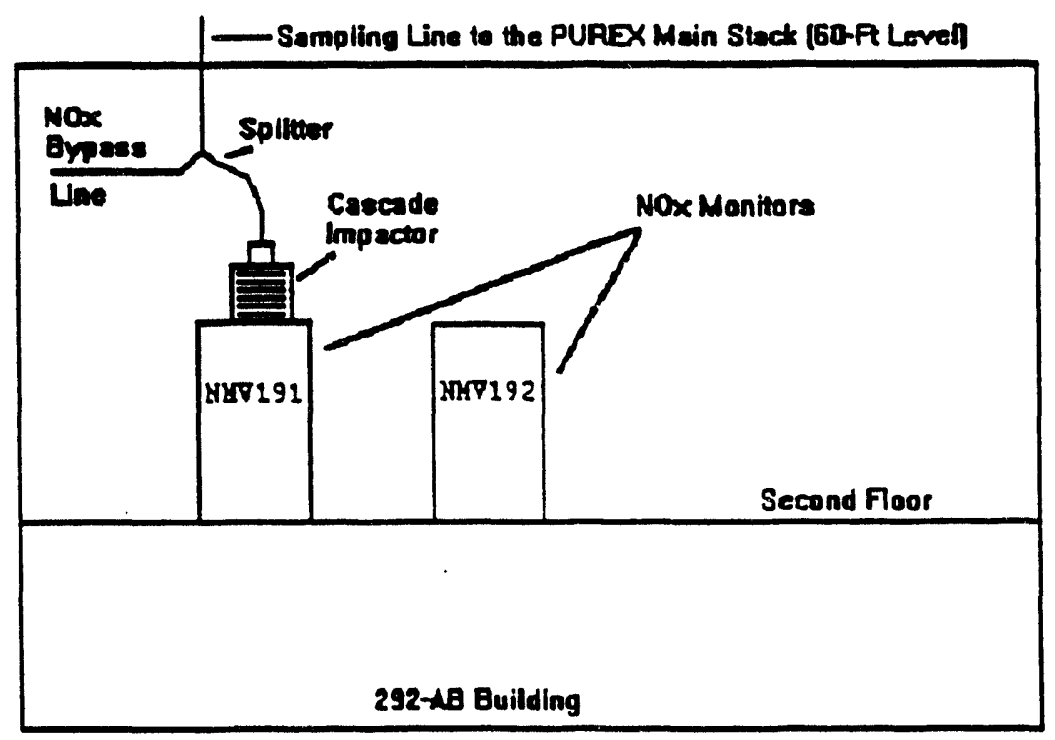

Figure 2-8. Cascade Impactor System Downstream from the PUREX Main Stack Sampling Line

the priorities established for the Cognizant Engineer and modifications required to be made in the current effluent sampling and monitoring system.

The same type of cascade impactor system as used to sample directly from the PR Stack and planned to sample from the PUREX Main Stack will be used to sample directly 
from this stack. Figure 2-9 illustrates how the system will be supported by scaffolding already in place by the stack. Figure $2-10$ is a diagram showing the location of the cascade impactor system parts that are secured to the 2-ft $\times 2$-ft $\times 3 / 4-$ in. wooden platform and how, as a whole system, they will be moved so that the single inlet probe will sample from different locations inside the stack.

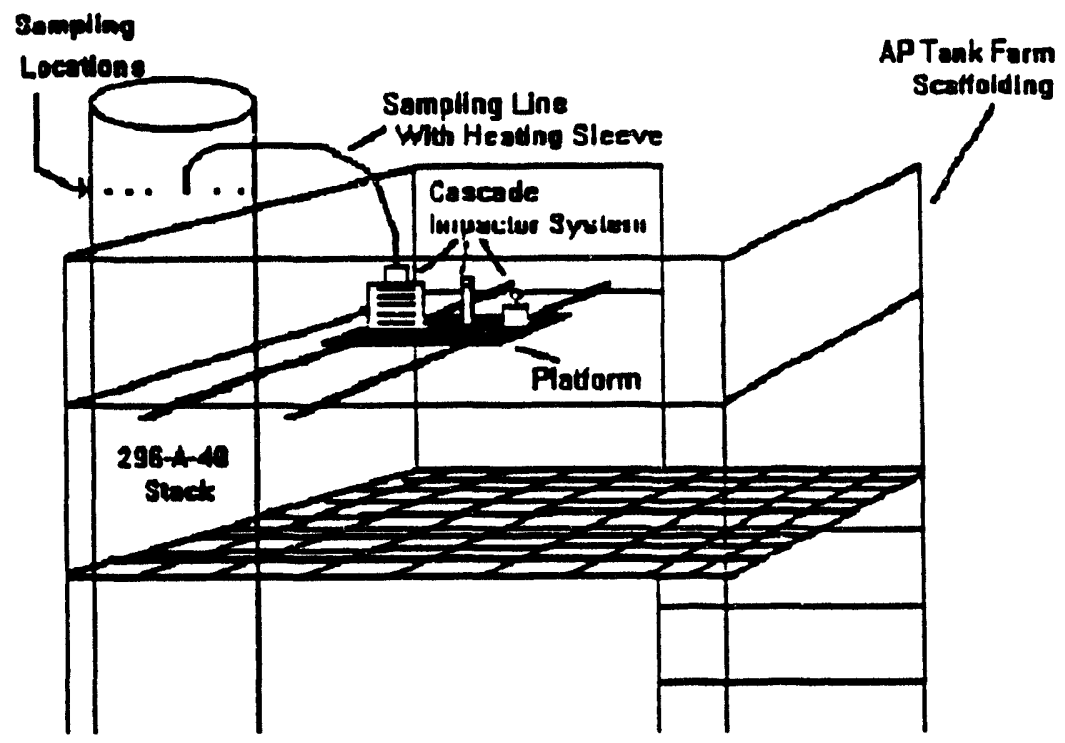

Figure 2-9. AP Tank Farm Stack Cascade Impactor Sampling Setup

In order to obtain cascade impactor samples downstream of the sampling line, modifications will need to be made in the current effluent sampling system.

Figure 2-11 shows a schematic of the current system which is located in the instrument cabinet near the stack. Currently a Beta-CAM, record sampler, two silver zeolite (AgZ) cartridges and associated sampling and monitoring equipment are located in the cabinet. Two separate lines sample from the stack. No air-flow splitter is currently used in the system. Figure 2-12 shows an "intermediate" sampling system which is similar to what now is currently used in the PR-Stack Instrument Building (292-AA). An air-flow splitter will be put into the sampling line for the CAM and would allow for two samples to be obtained simultaneously. The total air flowrate would ensure isokinetic sampling conditions for the sampling. This step is considered to be "intermediate" because a tee plus a valve would be put into the system and the system would be a closed one - where a cascade impactor or other sampling device could be "inserted" at any time. The tee and valve would be removed and be replaced with the cascade impactor. The flowmeter, vacuum gauge, flow regulator, and vacuum pump would be permanently installed in the system. Figure 2-13 shows the complete system with the cascade impactor sampling from one line from the air-flow splitter and the CAM sampling from the other line. Once this system is installed, it will be left in place until the sample acquisition would be completed. The readings of the flowmeter and 


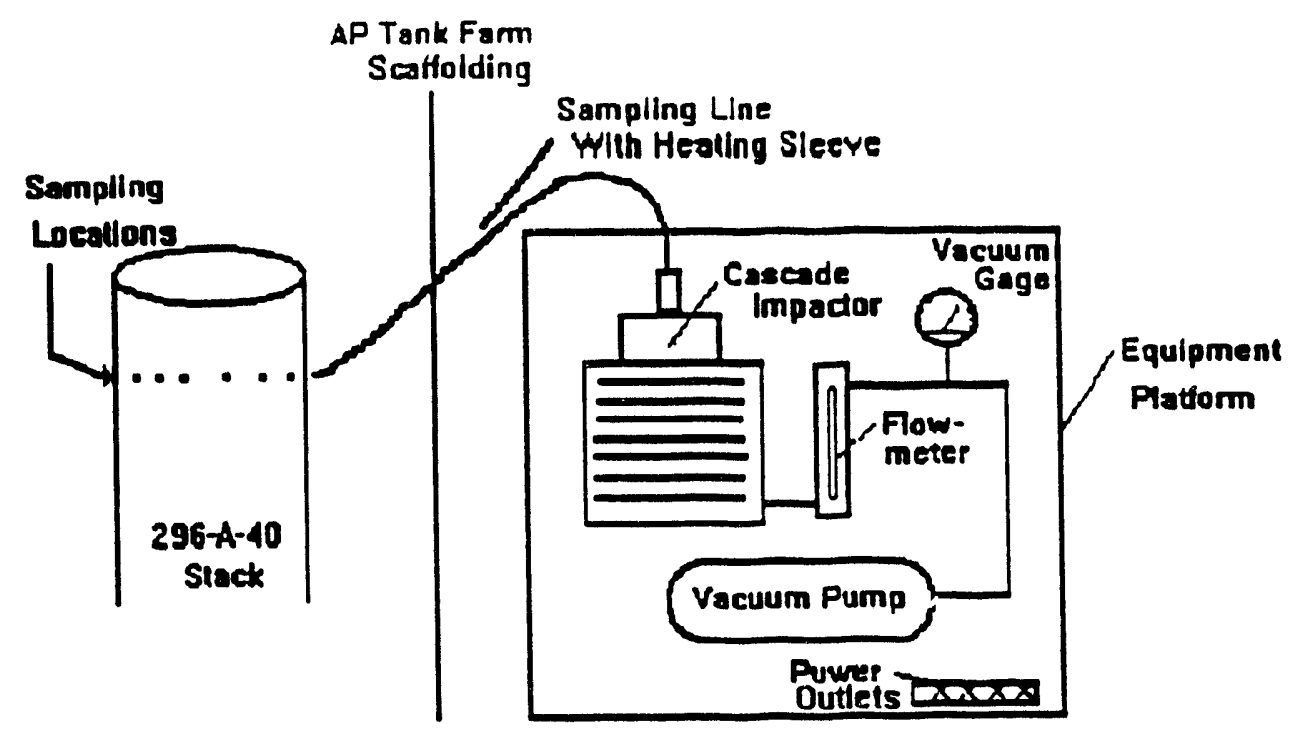

Figure 2-10. AP Tank Farm Stack Cascade Impactor Sampling System

vacuum gauge will be observed and documented periodically throughout the sampling period (e.g., once per week for 10 weeks).

\subsubsection{Laser Spectrometer}

The laser spectrometer used in this task was a factory-modified Model A2200 Airborne Particle Counter manufactured by MET One, Incorporated. It can determine the size distributions of airborne particulates in the 0.1-5.0 micron size range (i.e., projectedarea diameters). The unit was modified such that the vacuum pump was external to the system to assist in any decontamination if necessary and also to allow for two velocity probes instead of the standard single probe. This unit is described in detail in Appendix A-2.

\subsubsection{PR Stack}

Measurements using the laser spectrometer were made in the same locations where cascade impactor samples had been obtained: 1) directly from the PR Stack at a PUREX roof location; and 2) downstream from an alpha CAM sampling line location in the PR-Stack Instrument Building (292-AA). Figures 2-1 and 2-2 represent the locations at which cascade impactor samples were obtained. The impactors were replaced by the laser spectrometer for real-time measurements.

Measurements were obtained directly from the stack using the same inlet nozzle as used with the cascade impactor. An additional stainless steel extension was used to connect the inlet nozzle to the laser spectrometer because of the height difference between the 
cascade impactor and the laser spectrometer. No extemal flow meter or vacuum gauge was used; the external vacuum pump normally used with the laser spectrometer was used along with the unit's internal flow-sensing indicating device.

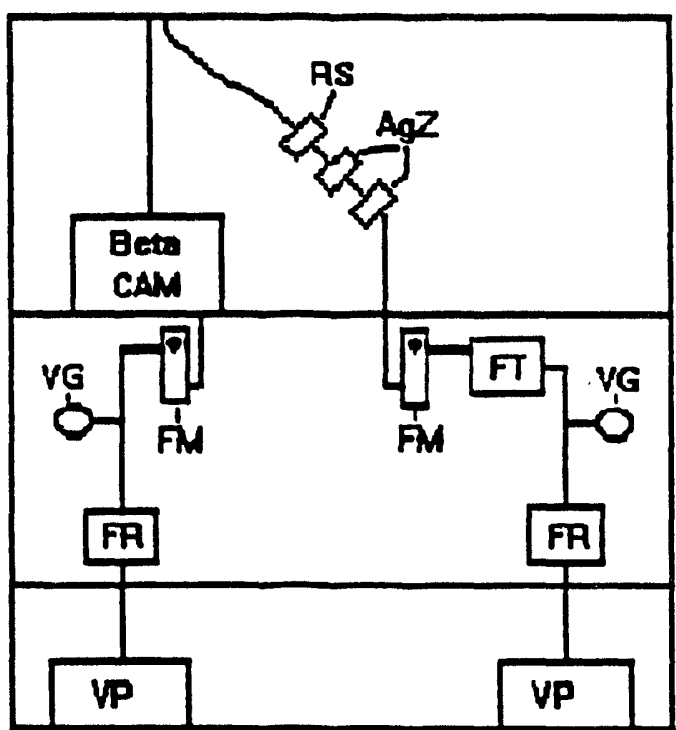

RS - Record semple; AgZ - Silver Zeolite cartridges;

VG - Vecuum geuga: FM - Fow moter; FT - Fow totelizor;

FR - Fow reouletor; VP - Vecuum pump

Figure 2-11. Curreat Efflueat Sampling System Downstream from Sampling Line

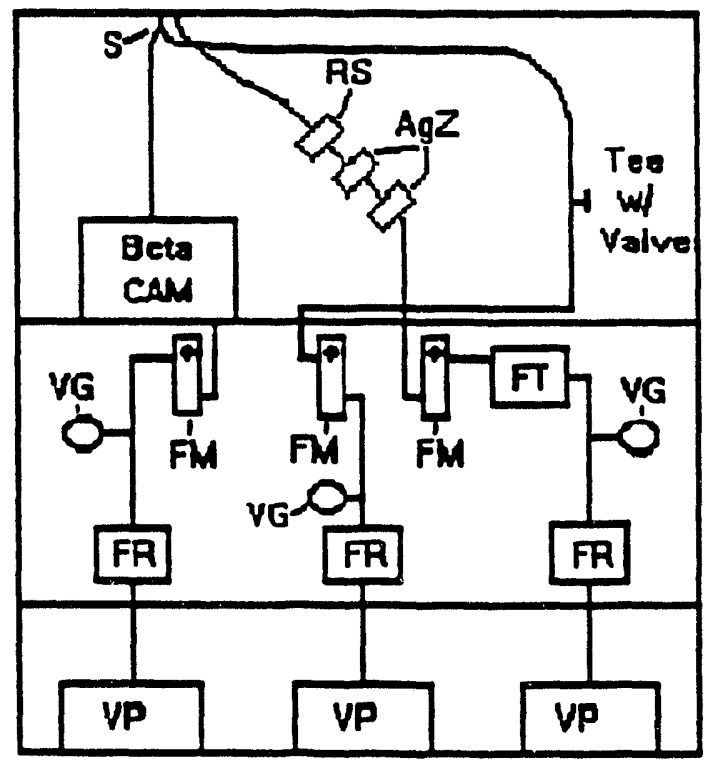

S - Splitter; RS - Record semple; AQZ - Silver Zoolite cartridges;

VG - Vecuum geugo; FM - Fow moter; FT - Fow totalizer;

FR - Fow rogulator; VP - Vacuum pump

Figure 2-12. Intermediate Sampling System Downstream from AP Tank Farm Stack 


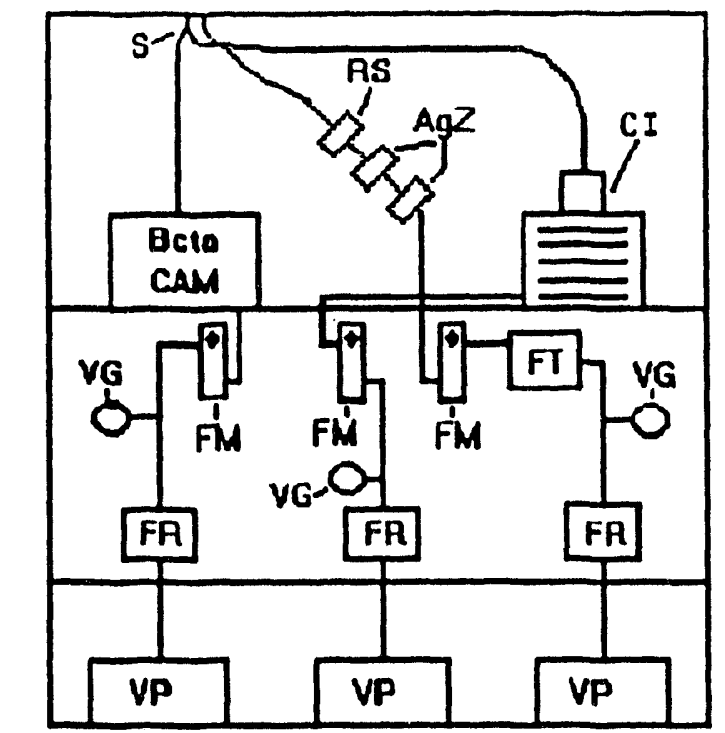

S - Splitter; RS - Record semple; AgZ - Silver Zeolite cartridges; VG - Vecuum gauge; FM - Flow meter; FT - Flow totalizer;

FR. Flow regulator; VP . Vecuum pump

Figure 2-13. AP Tank Farm Cascade Impactor Sampling System Downstream from the Sampling Line

Measurements from the CAM line were straightforward. The vacuum pump for the laser spectrometer was used for this location also; however, the facility vacuum pump in the 292-AA Building was used to exhaust the sampled gas downstream of the laser spectrometer but was not used to assist in the acquisition of the sample from the line. A stainless steel extension, which was approximately $2 \mathrm{ft}$ in length, was required from the valve/tee to the laser spectrometer because of physical constraints; the spectrometer was too wide to fit in the exact location that the cascade impactor had been located.

\subsubsection{Ambient}

Ambient particle size measurements were also made with the laser spectrometer from the location on the PUREX roof. The unit was positioned in the location near the PR Stack after the last stack sample had been obtained. The sampling line was disconnected from the unit and the air just above the unit was sampled. After the spectrometer lines and sensitive cavity were flushed for an adequate time, measurements were recorded.

\subsection{Data}

Details on the data obtained during FY 1992 are provided in this section. Information on the acquisition of data using the cascade impactor and laser spectrometer systems, the methods used for the analyses and assessment of the data, and the use of a specific software program to estimate particle line-loss are discussed. 


\subsubsection{Acquisition}

General details of the work plans developed to obtain cascade impactor samples and laser spectrometer measurements are discussed in this section. Some explanations and bases for decisions are also included.

\subsubsection{Cascade Impactor}

The specific work plan used to obtain a cascade impactor sample directly from the PR Stack is included as Appendix B-1 of this report. This work plan includes a general description of the work, information on preplanning and coordination, safety considerations, specific steps to perform prestart checks, steps required to install the cascade impactor sampling system, specific steps to periodically change the location of the sample probe, and steps to remove the sampling system. Included as part of the work plan are diagrams of the set-up, correction factors required for in-line flowmeter readings due to vacuum, flowmeter calibration data, and a data sheet to be used during sampling. This work plan was modified prior to each use of it during the fiscal year; the minor changes were made to improve over the previous procedures used to obtain the samples. The first cascade impaciur sample collected directly from the PR Stack was obtained over approximately 7 weeks with the sampling probe being moved to a new location inside the stack every 4 to 5 days. Each time the probe was moved, the flowrate and vacuum gauge readings were observed and documented. The sampling system's condition and location were also verified as being adequate at that time. Inspection personnel were required to initial a data sheet and record the date and time of the inspection each time. The second cascade impactor sample from the PR Stack was obtained over a period of approximately 10 weeks in order to obtain more material on the collection substrates for better counting statistics during analyses of the samples. After collection of the samples had been completed, the cascade impactor as a complete unit was transported to the 222-S Laboratory. The samples were subsequently analyzed by personnel in the laboratory for $239,240 \mathrm{Pu}$ and ${ }^{241} \mathrm{Am}$ content and total alpha activity. The activities in the sampling line and the pre-separator were differentiated for this second set of samples also. Both were rinsed and separate analyses were performed.

The specific work plan used to obtain a cascade impactor sample from the CAM sampling line for the PR Stack is included as Appendix B-2 of this report. The work plan includes the same general categories that the work plan for sampling directly from the PR stack includes. In general, sampling from this location is simpler than sampling directly from the stack; once the cascade impactor is connected, the cascade impactor system does not have to be moved. This system was installed on the same day as the system used to sample directly from the stack and was also removed on the same day that the stack system was removed. The connections, flowrate and vacuum gauge readings are checked within approximately 10 minutes after the system on the roof has been moved and the instrument readings observed and documented. The CAM sampling system's condition was also verified as being adequate at the time of inspection. Personnel were required to initial a data sheet and record the date and time of the inspection each time with this system also. 
A work plan was developed to be used to obtain cascade impactor samples from the PUREX Main Stack (291-A-1) but was not implemented during FY 1992. A copy of this plan is included as Appendix B-3 of this report. Acquisitions of samples directly from the stack at the 60-ft level and downstream of the sampling line at a location inside the 292-AB Building are discussed in the work plan. The same type of cascade impactor systems will be used to obtain these samples as was used to obtain samples from the PR Stack. Scaffolding is required to be erected next to the Main Stack to provide a platform for the cascade impactor system and for access to that system. An air flow splitter has been constructed for use in obtaining the sample from the stack where part of the air flow is directed to the cascade impactor and the remainder of it goes through the established sampling line. Downstream of the sampling line in the 292-AB Building is a second air flow splitter and another cascade impactor system will operate downstream of it.

A work plan was developed to be used to obtain cascade impactor samples from the AP Tank Farm Stack (296-A-40); this plan was not implemented during FY 1992. A copy of this plan is included as Appendix B-4 of this report. The acquisitions of samples directly from the stack and downstream of the sampling line are discussed in this work plan. Scaffolding is already present next to the AP Tank Farm Stack. The platform on which the cascade impactor system sets requires minor modifications to it so that is can be ' oved along the scaffolding when required. Major modifications, however, are required inside the instrument cabinet which houses the current effluent monitoring equipment. An air flow splitter located upstream of the Beta CAM inside the cabinet is required. A stainless steel sampling line would extend from the "unused" leg of the splitter (the other leg would go to the (AM) and be fitted with a valve and tee with a line going to a flowmeter, vacuum gauge, flow regulator, and vacuum pump. All of these items do not currently exist in the instrument cabinet. The valve and tee can be replaced by a cascade impactor when samples are needed. Sampling will be performed over several weeks to obtain adequate material for analyses.

\subsubsection{Laser Spectrometer}

The specific work plan used to obtain laser spectrometer measurements directly from the PR Stack is included as Appendix B-5 of this report. This work plan was developed from the work plan used to obtain cascade impactor samples directly from the PR Stack. The main difference between the two work plans was that real-time measurements were obtained with the laser spectrometer while the cascade impactor was required to sample for several weeks to obtain adequate material for analyses. The same locations inside the stack were used with both systems. Particle concentrations in the effluent allowed for laser measurement periods of three minutes in length; that is, by using three minutes to collect each set of data, no set of data for the total number of particles ( $>0.1$ micron) exceeded the upper limit of the counter - 999,999. Four sets of data were obtaired at each location inside the stack with one minute between the collections. The laser spectrometer ran continuously so that it was assumed that the flow rate remained constant. The last three sets of the four sets of data obtained were used to calculate means and standard deviations for each position. 
The first data set was not used in the calculations because the "system" was allowed to equilibrate (i.e., the stack, flows, spectrometer, etc) after physically disturbing the set up.

The specific work plan used to obtain laser spectrometer measurements from the CAM sampling line for the PR Stack is included as Appendix B-6 of this report. This work plan was developed from the work plan used to obtain cascade impactor samples at this location. Once the spectrometer was connected into the effluent monitoring system, it was allowed to sample for approximately 10 minutes before data was obtained to characterize the effluent. Several sets of data were obtained with 1-minute intervals between data sets while the effluent system was operated in a normal mode. After these data were obtained, two sets of data were obtained while the sampling line was being tapped to make it vibrate. This was done to investigate the hypothesis that material on the inside of the sampling line was present and could break or flake off and be transported through the line.

\subsubsection{Data Analyses and Assessments}

Data were obtained using two different types of systems: cascade impactors, and a laser spectrometer. Methods for data analysis and types of data assessments employed are discussed in this section.

\subsubsection{Cascade Impactor}

A description of the Andersen cascade impactor, calibration of the unit, and analysis and interpretation of data are included in Appendix A-1. The example given in the Appendix discusses gravimetric data, but radioactive counting data are handled and evaluated in the same manner. The counting data can be plotted on "logarithmic-probit" graph paper (refer to Figure A1-5) and the activity median aerodynamic diameter and associated geometric standard deviation then determined from the plot for the aerosol distribution. The total amounts of radioactivity collected by the entire unit upstream and downstrearr. of the sampling line can be compared as well as the amounts of radioactivity on individual stages.

\section{2-S Laboratory Data}

After the cascade impactors were operated for the time period of 6-10 weeks to collect an adequate amount of material for analyses, the units were transported to the 222-S Laboratory for those analyses. Each impactor generated 10 samples for analyses: the preseparator wash, 8 collection substrates for different stages within the impactor, and 1 filter used for a final "backup" filter to collect all particles that had not been collected on the stages. Sampling lines used between the impactor and the stack can also be rinsed and analyzed for radioactivity.

Following disassembly of the impactors, the filter papers were placed in an alpha proportional counter for determination of total alpha activity. (Note: this analysis was performed on the last set of samples only.) The filter papers were then dissolved (either by 
thermal ashing or chemical digestion) in order to obtain liquid samples that could be processed (i.e., separation by ion exchange) and electrodeposited onto counting planchets. The samples then underwent alpha energy analysis, which was performed on all sets of electrodeposited samples. The analytical procedures used by 222-S Laboratory personnel were the following: "Separation of Pu and Am by Ion Exchange" (Catlow 1989), "Electrodeposition of Actinides" (Catlow 1991), "Alpha Energy Analysis Using the Canberra Jupiter System" (Dowell 1991), and "Total Alpha Counting by Alpha Proportional Counters" (Jones 1991).

\section{Revised Data}

The initial cascade impactor counting data reported from the 222-S laboratory included the activities (in pCi) for: 1) ${ }^{239,240} \mathrm{Pu}$; and 2) ${ }^{241} \mathrm{Am}$ on each cascade impactor sample for the following measurements:

- $\quad$ CAM Line Measurement \#1 (i.e., Sample Set \#1)

- $\quad$ CAM Line Measurement \#2 (i.e., Sample Set \#2)

- $\quad$ Roof Measurement \#1 (i.e., Sample Set \#3)

- $\quad$ CAM Line Measurement \#3 (i.e., Sample Set \#4)

- $\quad$ Roof Measurement \#2 (i.e., Sample Set \#5).

The CAM Line Measurement $\# 2$ and the Roof Measurement \#1 were performed concurrently. The CAM Line Measurement $\# 3$ and the Roof Measurement $\# 2$ was also performed concurrently.

Difficulties were encountered during the assessment of the alpha energy analysis data for the cascade impactor samples because a number of samples (i.e., collection substrates) contained radioactivity less than the laboratory detection limit for the analyses (i.e., $<0.5$ $\mathrm{pCi}$ /sample). Personnel from the 222-S Laboratory were very helpful in helping in the evaluation of the counting data and provided the raw data for further evaluation of each sample. Separate assessment procedures were developed to use with the raw data; these are discussed below.

To provide the best possible assessment of the cascade impactor data, the raw counting data and the data reduction report from the computer analysis of the data were obtained for the roof measurement and second CAM line measurement.

The data reduction reported included information on the counting time (each sample was counted for $30,000 \mathrm{~s}$ ), the peak locations, the calculated activity for each identified radionuclide, and detector calibration information including channel to energy conversion 
equations and counting efficiency. The counting efficiency values included the percent recovery during the chemical separation process as determined from the sample spikes.

The raw counting data included the number of counts recorded in each of 512 channels from the alpha energy analysis. Peaks (typically 20 to 40 channels wide) corresponding to the energies of alpha particles present in the samples were observable in the data. The energies corresponding to the peaks could be determined from the energy calibration information provided in the data reduction report. This allowed the identification of the radionuclides that corresponded to the peaks. The following radionuclides were identified: ${ }^{239,240} \mathrm{Pu},{ }^{238} \mathrm{Pu},{ }^{241} \mathrm{Am},{ }^{236} \mathrm{Pu}$, and ${ }^{243} \mathrm{Am}$ (the latter two were sample recovery spikes).

In some cases, information was missing from the data reduction report when it was not possible for the computer code to perform the necessary calculations. For example, calculated activities were not calculated if it was not possible to adequately identify a peak. Because of these limitations and the fact that a small number of counts were recorded in many peaks due to the low activities, activity estimates were determined manually from the raw data. These estimates are presented in Table 2-1. To derive these estimates, peak locations were identified based on both the energy calibration information and the pattern of counts in the channels corresponding to the peaks of interest. The counts in each defined peak were summed to determine the total peaks. The number of background counts in each peak was assumed to be zero based on discussions with laboratory personnel. Therefore, the number of counts used to perform the activity estimates was equal to the total counts identified in each peak.

Calculation of radionuclide activities in each sample was performed using the following equation:

$$
A(p C i)=[C \times K] \div[E \times T]
$$

where $\mathrm{C}=$ the number of counts in the peak corresponding to the radionuclide

$K=\mathbf{a}$ conversion factor for disintegrations per minute to $\mathrm{pCi}$

$\mathrm{E}=$ the counting efficiency (counts recorded in the peak per disintegrations in the sample)

$T=$ the counting time $(30,000 s)$.

Detector efficiencies were determined from the data reduction report, if reported. In cases where efficiencies could not be determined from the information in the data reduction report, default values were used based on evaluation of data reduction reports that did provide the necessary. information. The average default values used were: ${ }^{239,240} \mathrm{Pu}, 0.20$ cpm/dpm; ${ }^{238} \mathrm{Pu} 0.15 \mathrm{cpm} / \mathrm{dpm} ;{ }^{241} \mathrm{Am}, 0.16 \mathrm{cpm} / \mathrm{dpm}$. 
The most useful information from this analysis was the estimated $239.2+0 \mathrm{Pu}$ activities; the other radionuclides present in the gaseous effluent (i.e., ${ }^{238} \mathrm{Pu}$ and ${ }^{241} \mathrm{Am}$ ) were not present in the samples in sufficient quantities to permit detailed evaluations of particle size distributions. The ${ }^{239,240} \mathrm{Pu}$ activity estimates calculated in this manner were, in general, comparable to the activities reported by the 222-S laboratory. However, the calculations provided two important improvements to the data: 1) correction of typographical errors contained in the laboratory reports, and 2) estimates of activities initially reported as less than the minimum detectable activity (MDA) of the analysis process. The latter point is especially important because of the very low activities present in many of the samples. We were able to provide activity estimates for some of the samples originally reported to be less than the MDA for the following reasons:

- The computer algorithm used by the 222-S laboratory is set to identify only well defined peaks, which typically did not occur for the cascade impactor samples because of the low activities.

- We were searching for only a few specific alpha particle energies, which allowed a more detailed evaluation of the counting data than is possible with the computer algorithm.

- In some cases when measured activities are less than the laboratory calculated MDA, the measured activities do reliably (i.e., at a lower confidence level) indicate the presence of radioactivity (i.e., measured values less than the MDA do not necessarily mean that radioactivity was not identified at a high confidence level) (Brodsky 1992).

Despite these improvements, it was still not possible to determine reliable activity estimates for some of the samples, even though it appeared from the counting data that $239,240 \mathrm{Pu}$ was present on the samples. A complete discussion of the data is presented in Section 2.3 of this report.

\subsubsection{Laser Spectrometer}

The laser spectrometer used on this task is described in detail in Appendix A-2 of this report. The unit samples at a flowrate of 1 cubic foot per minute (cfm) and counts the number of particles in different size ranges (i.e., by projected-area diameter). A hard copy of the data is printed shortly after the desired sampling period has ended. The size ranges for the model used are 0 to $0.10,0.11$ to $0.20,0.21$ to $0.30,0.31$ to $0.50,0.51$ to 1.00 , 1.01 to 5.00 and greater than 5.00 microns in diameter. Data can also be acquired cumulatively; that is, number of particles $>0.1,>0.2,>0.3,>0.5,>1.0$, and $>5.0$ microns in diameter.

Data was analyzed and compared in several ways. The total number of counts upstream and downstream of the sampling line were compared in all size ranges. The 
particle size distributions of all measurements were determined from plotting the counting data on logarithmic-probit graph paper using the same methods as were used with the cascade impactor data. Refer to Appendix A-1 for details. Mass median diameters were calculated using estimates of the count median diameters and geometric standard deviations. Another reference (Ropp 1985) was useful in the interpretation of the particle size distributions.

\subsubsection{Software}

A software program titled "DEPOSITION" has been developed by N. K. Anand and A. R. McFarland of the Department of Mechanical Engineering at Texas A\&M University. This program calculates particle penetration through aerosol transport lines and is described thoroughly in NUREG/GR-0006 (Anand and McFarland 1991). The version of the software used for calculations under this task was Version 1.02 published in October, 1991. The purpose of using this software was to compare the results with the empirical numbers obtained with the cascade impactors and laser spectrometer.

Aerosol transport lines should be designed to minimize particle losses in those lines. A typical transport line consists of an inlet, bends, and straight tubes and the orientation of the straight tubes can be horizontal, vertical, or inclined. Particles can be deposited on the internal walls of any of these components. The primary mechanisms for particle deposition in transport lines are gravitational settling, turbulent diffusion, inertial impaction, and Brownian diffusion. For larger particles ( $>1$ micron in aerodynamic diameter), the gravitational settling plays a very important role. It is more important in horizontal tubes than in vertical tubes. For smaller particles ( $<0.1$ micron), Brownian diffusion is the dominant mechanism for deposition of particles. The influence of turbulent diffusion on particle deposition increases with the particle velocity and size.

Guidance in NUREG/GR-0006 and in the program was followed to incorporate the dimensions, flowrates, and other physical variables associated with the PR Stack sampling line into the calculation of aerosol penetration using the software program. Aerosol penetration is defined as the ratio of aerosol concentration at the exit of a transport line to the aerosol concentration at the inlet of the transport line.

\subsection{Results}

Results from the cascade impactor samples obtained and the laser spectrometer measurements made during FY 1992 are included in this section. Data is listed in tables and observations and conclusions are made on that data. Comparisons of the cascade impactor results, the laser spectrometer results, and the results obtained with the "DEPOSITION" software are made in Section 2.3.4. 


\subsubsection{Cascade Impactor}

Listed in Table 2-1 are the data for three cascade impactor sets of collection substrates. Listed in Table 2-2 are the data for two additional cascade impactor sets of collection substrates. Sample Set $\# 1$ is from the cascade impactor used to sample from the CAM line during the time period of $9 / 12 / 91$ through 11/15/91 (i.e., 50 days). Sample Set \#2 represents data obtained by sampling from the same CAM line as for Sample Set $\# 1$, using the same impactor but during the time frame of $2 / 12 / 92$ through $3 / 30 / 92$ (i.e., 47 days). Sample Set \#3 is from a second cascade impactor used during the same time period as the impactor for Sample Set $\# 2$ and represents data from sampling the effluent directly from the PR Stack. Each collection substrate was analyzed for ${ }^{239,240} \mathrm{Pu}$ and ${ }^{241} \mathrm{Am}$. Effective-cutoff diameters (ECDs) for each stage (and pre-separator) are also listed in Tables 2-1 and 2-2. Some of the samples were analyzed by 222-S Laboratory personnel at being below the minimum detectable limits for the specific counting systems used for those samples. Sample Set \#4 and Sample Set \#5 were obtained during the time frame of 8/13/92 through 10/27/92 (i.e., 75 days). Sample Set \#4 was obtained using a cascade impactor positioned at the same location used to obtain Sample Sets $\# 1$ and $\# 2$ (i.e., in the CAM line). Sample Set "5 was obtained using a cascade impactor positioned at the same location used to obtain Sample Set \#3 (i.e., directly from the PR Stack). The following are comments on the interpretation and assessment of this data.

\section{Sample Set \#1 rs. Sample Set \#2 (Table 2.1)}

Eacts

- $\quad$ Sample Set \#1 was obtained 9/12/91 through $11 / 15 / 91$ (50 days).

- $\quad$ Sample Set $\# 2$ was obtained $2 / 12 / / 92$ through 3/30/92 (47 days).

- Both sample sets were from the CAM line.

- The cascade impactor used for each of these sample sets was operated at approximately the same flow rate.

- $\quad$ Collection surfaces in Sample Set \#1 were all fiber glass; collection surfaces in Sample Set $\# 2$ were Whatman paper $\# 41$ except for the final collection filter which was fiber glass.

- The "WASH" included the amount of activity collected in the pre-separator for each of the sample sets. 
Table 2-1. Cascade Impactor Data from the PR Stack (Sample Sets \#1, 2, and 3)

\begin{tabular}{|c|c|c|c|c|c|c|c|}
\hline \multirow{3}{*}{$\begin{array}{l}\text { Simple } \\
\text { ID }\end{array}$} & \multirow{3}{*}{$\begin{array}{c}\text { ECD } \\
\text { (Micrens) }\end{array}$} & \multicolumn{4}{|c|}{ CAM Line } & \multicolumn{2}{|c|}{ Roof } \\
\hline & & \multicolumn{2}{|c|}{$\begin{array}{c}{ }^{230.240} \mathrm{Pu} \\
\text { pCi/Sumple }\end{array}$} & \multicolumn{2}{|c|}{ pCi/Sample } & \multirow{2}{*}{$\begin{array}{c}230,200 \mathrm{Pu} \\
\text { pCi/Sample } \\
\text { Sample Set } \mathbf{H}^{b}\end{array}$} & \multirow{2}{*}{$\begin{array}{c}{ }^{241} \text { Am } \\
\text { pCi/Sumple } \\
\text { Sample Set } 13^{\mathrm{L}}\end{array}$} \\
\hline & & Sample Set $\| 1$ & Sumple Set $12 b$ & Sample Set $\| 1$ & Sample Set $12^{b}$ & & \\
\hline Wash & $>10$ & 76.2 & $77.2(72.9)^{d}$ & 33.8 & 22.5 & $33.1(29.2)$ & 8.43 \\
\hline 1 & 9 & 14.6 & $1.55(0.13)$ & 6.38 & $<0.53^{c}$ & $<5.0^{f}(0.08)$ & $<0.57^{c}$ \\
\hline 2 & 5.8 & 2.32 & $1.78(0.51)$ & $<0.69^{\circ}$ & $<0.72^{\mathrm{c}}$ & $2.11(1.10)$ & $<0.61^{\mathrm{c}}$ \\
\hline 3 & 4.7 & 2.52 & $<0.47^{c}(--)$ & 2.03 & $<0.72^{c}$ & $0.62(0.51)$ & 4.68 \\
\hline 4 & 3.3 & 1.70 & $0.59(0.64)$ & $<0.86^{c}$ & 0.58 & $0.58(0.42)$ & $<0.58^{\circ}$ \\
\hline 5 & 2.1 & 1.26 & $<0.47^{\circ}(--)$ & 1.44 & $<0.79^{c}$ & $0.54(0.44)$ & $<0.62^{\mathrm{c}}$ \\
\hline 6 & 1.1 & 1.36 & $<0.56^{\mathrm{c}}(0.30)$ & 1.05 & $<0.57^{c}$ & $3.5(0.31)$ & $<0.58^{i}$ \\
\hline 7 & 0.7 & $<0.56^{\mathrm{c}}$ & $<0.5^{c}(0.20)$ & $<7.80^{c}$ & $<0.86^{c}$ & $<0.47^{c}(-)$ & $<0.58^{\circ}$ \\
\hline 8 & 0.4 & $<0.53^{\mathfrak{c}}$ & $<0.52^{c}(0.28)$ & $<0.69^{\circ}$ & $<0.61^{c}$ & $<0.47^{\circ}(0.08)$ & $<0.81^{\mathrm{c}}$ \\
\hline Filter & $\mathbf{0}$ & 1.56 & $0.64(0.44)$ & $<10^{c}$ & $<1.32^{c}$ & $<0.75^{\mathrm{c}}(0.60)$ & 1.02 \\
\hline
\end{tabular}

- ECD = Effective-Cutoff Diameter.

- Sample Sets 12 and 13 were obtained during the same time interval.

c " <" values are below the detection limits for the counting systems used for the specific samples.

d The numbers in parentheses have been recalculuted using procedures discussed in Section 2.2.2.1. 
Table 2-2. Cascade Impactor Data from the PR Stack (Semple Sets $\mathbf{4 4}$ and $\mathbf{4 5}$ )

\begin{tabular}{|c|c|c|c|c|c|c|c|}
\hline \multirow{2}{*}{$\begin{array}{l}\text { Sample } \\
\text { ID }\end{array}$} & \multirow{2}{*}{$\begin{array}{c}\text { ECD* } \\
\text { (Microns) }\end{array}$} & \multicolumn{2}{|c|}{$\begin{array}{l}230.200 \mathrm{Pu} \\
\text { pCi/Somple }\end{array}$} & \multicolumn{2}{|c|}{$\begin{array}{c}201 \mathrm{Am} \\
\text { pCisample }\end{array}$} & \multicolumn{2}{|c|}{$\begin{array}{c}\text { Total Alpha Activity } \\
\text { PCi/Sample }\end{array}$} \\
\hline & & CAME & Roof & CAMK & Roort & CAM' & Roart \\
\hline Line & $>10$ & - & 10.07 & - & 2.79 & - & 11.4 \\
\hline Pre-Sep & $>10$ & b & 9.84 & 6.54 & 2.19 & 23.0 & 10.3 \\
\hline 1 & 9 & 1.25 & 1.48 & 0.48 & 0.188 & 4.42 & 5.31 \\
\hline 2 & 5.8 & 0.74 & 0.96 & 0.37 & 0.398 & 1.45 & 1.39 \\
\hline 3 & 4.7 & 0.26 & 0.59 & f & 0.45 & 1.83 & 1.45 \\
\hline 4 & 3.3 & 1.53 & 1.36 & f & I & 2.65 & 3.29 \\
\hline 5 & 2.1 & 0.55 & 0.34 & 0.62 & r & 2.15 & 3.22 \\
\hline 6 & 1.1 & f & 1.01 & 0.54 & f & 1.90 & 1.77 \\
\hline 7 & 0.7 & 0.47 & 0.48 & 1.15 & f & 0.82 & 0.70 \\
\hline 8 & 0.4 & 0.178 & 0.21 & 0.24 & f & 1.01 & 0.70 \\
\hline Filter & 0 & 1 & 0.33 & $\mathrm{f}$ & 1 & 3.22 & 2.34 \\
\hline
\end{tabular}

- $E C D=$ Effoctive-Cutoff Diameter.

- Activities have been calculated from raw data using procedures discussed in Section 2.2.2.1.

- Sample Set \#4.

d Sample Set 45.

- "- = not applicable to CAM system.

'No discernible peak.

- Date is highly uncertain.

Data is spurious; no peaks are discernible and spectrum does not represent the expected data. 


\section{Observations}

- The ${ }^{239,240} \mathrm{Pu}$ activity "WASH" for each sample set is approximately the same and represents a large percentage of the total activity collected (i.e., about $75 \%$ and $95 \%$ for Sample Sets $\# 1$ and $\# 2$, respectively).

- The ${ }^{241}$ Am activity collected in the "WASH" in Sample Set $\# 2$ is about 30\% less than for Sample Set \#1 but each contributes a major percentage of the total activity for each sample set.

- When the "WASH" and collection stage \#1 activities are added for each of the sample sets, greater than $90 \%$ of the total activity collected for each set is represented. This means that greater than $90 \%$ of the activity is associated with particles larger than 9 microns in aerodynamic diameter.

\section{Sample Set 2 vs. Sample Set \#3 (Tables 2.1 and 2.2)}

\section{Eacts}

- Both Sample Sets were obtained 2/12/92 through 3/30/92 (47 days).

- The cascade impactors used for these sample sets were operated at approximately the same flow rate.

- Sample Set $\$ 2$ was from the CAM line.

- Sample Set $\# 3$ was from the stack.

- The "WASH" for Sample Set $\# 2$ was for the pre-separator; for Sample Set $\# 3$, it represented the pre-separator and the sampling line from the impactor to the stack.

\section{Observations}

- The total activity (Pu and Am) collected from the stack is approximately $50 \%$ of that collected from the CAM line.

- More of the ${ }^{241}$ Am sample counts are at "less than detectable" levels for Sample Sets $\# 2$ and $\# 3$ compared to Sample Set $\# 1$.

- Comparison of collection stages $\# 2$ through $\# 6$ (Pu-activities) for the two sample sets can be interpreted as showing a particle loss (based on activity) of approximately $25 \%$ in the CAM sample line for particles that are between 1 and 6 microns in aerodynamic diameter. 


\section{Sample Set \#4 vs. Sample Set $\neq 5$ (Table 2.2)}

\section{Eacts}

- Both Sample Sets were obtained 8/13/92 through 10/27/92 (75 days).

- Sample Set \#4 was from the CAM line.

- Sample Set \#5 was from the stack.

- The flowrate of the cascade impactor used to obtain Sample Set \#4 was approximately $90 \%$ of the flowrate of the cascade impactor used to obtain Sample Set \#5. The data listed have not been adjusted for this difference in flowrate.

- The sampling line and the pre-separator used in Sample Set \#5 (roof location) were analyzed separately.

- An analysis for total alpha activity was performed on each sample as well as the analyses for ${ }^{239,240 \mathrm{Pu}}$ and ${ }^{241} \mathrm{Am}$.

\section{Observations}

- The most reliable data from these data sets are for the total alpha activities because of problems that arose with the isotopic analyses for ${ }^{239,240} \mathrm{Pu}$ and ${ }^{241} \mathrm{Am}$.

- The data for the analyses of ${ }^{239.240 \mathrm{Pu} \text { and }}{ }^{241} \mathrm{Am}$ are weak due to the analyses techniques and have, in general, large uncertainties associated with them.

- Large particles are indicated by both data sets.

- After adjustment for flowrate differences, the total amount of activity collected downstream of the sample line is approximately $10 \%$ greater than that collected directly from the stack.

- Some particle line loss is observed when comparing stage to stage, but the variability in the data and the "generation" of material makes it very difficult to estimate the level accurately. 


\section{General Interpretations and Conclusions from the Data}

- The variability in the lower detection limits for the different counters used makes it very difficult to interpret the data if the current 222-S Laboratory procedures are followed.

- Larger particles were present in all of the cascade impactor samples whether the samples were from the CAM line or the stack. It would be anticipated that particles passing through the stack HEPA filters would be primarily in the smaller size fractions ( $<10$ microns). If the particles were associated with inert airborne particles, it would be anticipated that a large proportion of the activity would be associated with the smaller size fraction since agglomeration is a surface area function and the smaller size fractions have a larger surfaceto-volume ratio. We could speculate that the presence of the major portion of the activity appearing in the larger size fraction may indicate that the activity has accumulated somewhere downstream of the HEPA filters over a long period of time and that the material is now flaking/breaking away due to deterioration of the surface. The long-term accumulation of the activity may be corroborated by the presence of substantial amounts of ${ }^{24 !} \mathrm{Am}$ as a daughter product of ${ }^{241} \mathrm{Pu}$, an impurity associated with ${ }^{239} \mathrm{Pu}$.

- The higher level of activity that was seen in samples from the CAM sampling line compared to samples from the stack could mean that material is both inside the sampling line and the stack and is available to flake/break off of the interior surface of the two transporting systems. Dilution flow is greater in the stack; this may account for the activity difference.

- It is very difficult to accurately determine the activity median aerodynamic diameter and associated geometric standard deviation of a size distribution when a large percentage of the radioactivity is deposited in the pre-separator.

- Most of the ${ }^{241} \mathrm{Am}$ samples analyzed were below the reported laboratory detection limits for the counting systems (i.e., 41 of the 51 samples) and this hampers the data interpretation within each sample set and also comparison among samples.

- Conclusions made regarding particle sizes and possible line losses involved based on the total activity data are difficult to make and may not be as reliable as other conclusions. This is due to the fact that the size distributions of the americium and the plutonium aerosols may be different.

- More useful information could be obtained if detectors with lower levels of detection were used, if the counting intervals were extended to increase the 
sensitivity of the counting systems, and/or if more sensitive data assessment procedures are used.

- Using the "revised" data, one can show a decrease in the mass median aerodynamic diameter from the roof sample to the CAM sample from 4 microns to 2 microns for the smaller fraction of particles (i.e., particles not collected by the pre-separator).

- It may be possible to interpret line-loss data by comparing specific stages of the cascade impactors that have sampled upstream and downstream of the line under evaluations.

\subsubsection{Laser Spectrometer}

On June 17, 1992, particle-size measurements were made on the PR Stack (296-A-1) using a laser spectrometer. The instrument employed was a factory-modified Model A2200 manufactured by Met One, Inc. Real-time measurements were obtained directly from the PR Stack (from a roof access location) and also from a location downstream from the sampling line used by an alpha Continuous Air Monitor (CAM). The location of the "CAM" samples was in the PR-Stack Instrument Building (292-AA). The work plans followed during these measurements were WP-P-92-030 and WP-P-92-029, respectively for these locations; these work plans are included in this report as Appendices B-5 and B-6. These two locations had been used in the past from which cascade impactor samples were obtained.

It should be noted that it is difficult to directly compare the laser spectrometer data to the cascade impactor data. The laser spectrometer measures a "projected-area" diameter and the cascade impactor measures an aerodynamic diameter. These may be compared by using the equation

$$
D_{p r} \times(\rho)^{1 / 2}=D_{a}
$$

$$
\text { where } \begin{aligned}
\mathrm{D}_{\mathrm{pr}} & =\text { Projected-Area Diameter } \\
\mathrm{D}_{\mathrm{a}} & =\text { Aerodynamic Diameter } \\
\rho & =\text { particle density }
\end{aligned}
$$

if the density of the particle is known and if they are homogeneous particles. However, the make-up of the particles is not known so that the density of the particles can not be estimated and the probability is low that the particles are homogeneous, thus comparison are speculative.

The measurements made directly from the stack were obtained from. 9 different positions across the inside area of the stack. Three sets of data were averaged for each location and the data is summarized in Table 2-3. Represented in this table are particle counts for different particle-size intervals (i.e., $>0.1,>0.2,>0.3,>0.5,>1.0$, and $>5.0$ 
Table 2-3. Laser Particle Sample Data for PR Siack

\begin{tabular}{|c|c|c|c|c|c|c|c|c|c|c|c|c|}
\hline \multirow{2}{*}{ Position } & \multicolumn{2}{|c|}{$>0.1 \mathrm{~km}$} & \multicolumn{2}{|c|}{$>0.2 \mu \mathrm{m}$} & \multicolumn{2}{|c|}{$>0.3 \mathrm{\mu m}$} & \multicolumn{2}{|c|}{$>0.5 \mathrm{~mm}$} & \multicolumn{2}{|c|}{$>1.0 \mathrm{~mm}$} & \multicolumn{2}{|c|}{$>5.0 \mathrm{~mm}$} \\
\hline & $\mathbf{x}$ & SD & $\mathbf{x}$ & SD & $\mathbf{x}$ & SD & $\mathbf{x}$ & SD & $\mathbf{x}$ & SD & $\mathbf{x}$ & SI) \\
\hline 1 & 477851 & 15172 & 254629 & 1323 & 49119 & 1150 & 5139 & 476 & 1496 & 182 & 297 & 13 \\
\hline 2 & 536024 & 16554 & 268243 & 9005 & 47855 & 794 & 4736 & 146 & 1240 & 84 & 227 & 53 \\
\hline 3 & 524987 & 24604 & 255046 & 3065 & 44001 & 788 & 4228 & 594 & 1111 & 341 & 180 & 74 \\
\hline 4 & 602730 & 64511 & 316021 & 50126 & 56870 & 12499 & 5302 & 1384 & 956 & 95 & 154 & 23 \\
\hline 5 & 623356 & 139294 & 337396 & 75130 & 59067 & 14949 & 5151 & 1495 & 841 & 32 & 82 & 9 \\
\hline 6 & 607149 & 109599 & 329444 & 72210 & 51058 & 9632 & 4133 & 456 & 765 & 59 & 88 & 20 \\
\hline 7 & 901711 & 163471 & 556043 & 113692 & 116520 & 27198 & 13249 & 4914 & 1161 & 292 & 132 & 44 \\
\hline 8 & 461618 & 15059 & 246203 & 3929 & 40197 & 765 & 3633 & 104 & 726 & 77 & 64 & 15 \\
\hline 9 & 488133 & 16720 & 244846 & 2171 & 40191 & 1414 & 3813 & 176 & 814 & 45 & 88 & 20 \\
\hline Mean & 580395 & $\cdots$ & 311986 & $\cdots$ & 56097 & - & 5487 & -- & 1012 & - & 146 & $\cdots$ \\
\hline CAM I & 385039 & 25750 & 210008 & 2833 & 43192 & 331 & 6600 & 109 & 1457 & 19 & 123 & 2 \\
\hline CAM 2 & 447131 & 22805 & 243273 & 4299 & 85755 & 14524 & 43276 & 13645 & 28221 & 10240 & 9803 & 2502 \\
\hline Ambient & 2126412 & - & 1888140 & - & 794415 & - & 104226 & - & 23046 & - & 4839 & -- \\
\hline
\end{tabular}

Notes:

- All data normalized to $3 \mathrm{a}^{3}$ volume.

- Mean $=$ mean of the numbers for the 9 positions.

- CAM 1 = sample from CAM sample line under normal operating conditions.

- CAM 2 = sample from CAM sample line during line vibration.

- Ambient = sample taken on the PUREX roof from the environmen.

$\mathbf{X}=$ Mean of the aumber of counts observed in the counting interval.

- SD = Standard Deviation of the counts observed. 
microns in diameter). The means of the particle counts for the 9 positions are also listed Table 2-3. Other sets of data listed in Table 2-3 are for "CAM 1," "CAM 2," and "Ambient". The "CAM 1" data refers to measurements obtained from the CAM sampling line under normal-operating conditions. The "CAM $2^{n}$ data refers to measurements obtained from the CAM sampling line during a time that the line was being tapped to make it vibrate. The "Ambient" dat represent data that was obtained on the roof of the PUREX Building after the sampling line from the PR Stack had been disconnected and a suitable volume pulled through the instrument to obtain a sample from the environment. Particle counts in different size ranges for the PR-Stack measurements are listed in Table 2-4. The size ranges of interest are the following: $0.11-0.20,0.21-0.30,0.31-0.50,0.51-1.0,1.01-5.0$, and $>5.0$ microns. The number of particles $/ 3 \mathrm{ft}^{3}$ are listed for the four different sets of PRStack measurements obtained. Table 2-5 describes the location of the sample probe inside the PR Stack for the 9 sets of measurements. The data are also shown graphically. Figure 2-14 represents the data listed in Table 2-4 and shows the particle-size frequency distributions for the four sample sets. Figure 2-15 shows the particle-size distribution data for the PR-Stack measurements from which count median diameters (CMDs) and geometric standard deviations (GSDs) can be estimated. The curves represent an estimate of the best fit for the data for each sample set from 10-99\% less than stated diameters.

\section{Observations}

The variability in the particle counts in different size intervals for the 9 sampling locations in the PR Stack can be determined. The relative standard deviation (i.e., [(Standard Deviation)/(Mean)] x 100) for the six particle size intervals ranges from $15 \%$ to 65\%. The two most stable particle size ranges are for particles that are 0.11-0.2 and 1.1-5.0 microns. The least staile is the size range of 0.51-1.0 micron.

Comparisons can be made between the mean stack sample.particle counts (for the 9 sample locations) and the mean particle counts for the "CAM 1" sample. If one looks at different particle size ranges, an interesting observation can be made. For the particle size ranges of $0.11-0.2,0.21-0.30,0.31-0.5,0.51-1.0,1.01-5.0$, and $>5.0$ microns, the change in particle counts (from the "Stack" sample to the "CAM 1" sample are $-35 \%,-35 \%,-28 \%$, $+15 \%,+54 \%$, and $-16 \%$, respectively. This suggests that two mechanisms may be occurring at the same time. One could be a loss of particles through deposition in the sampling line (i.e., for 0.11 through 0.50 microns, and for $>5.0$ microns) and the other mechanism could be a "generation" of particles (i.e., for 0.50 through 5.0 microns).

The ambient sample can be compared to the stack sample to determine the effectiveness of the overall filtration system and look at the particle size distributions. If one looks at the total number of particles in each of these samples, quite a difference is seen. In terms of the number of particles $>0.1$ micron, over three times more particles were seen in the ambient sample than in the stack sample. The greatest differential when looking at the 
Table 2-. Particle Counts in Different Size Ranges for PR-Stack Measurements

\begin{tabular}{|c|c|r|r|r|}
\hline \multirow{2}{*}{ Size Range (mm) } & \multicolumn{4}{|c|}{ Particles/3ft $^{3}$} \\
\cline { 2 - 5 } & Stack & CAM 1 & \multicolumn{1}{|c|}{ CAM 2 } & Ambient \\
\hline$>5.0$ & 146 & 123 & 9803 & 4839 \\
\hline $1.01-5.0$ & 866 & 1334 & 18418 & 18207 \\
\hline $0.51-1.0$ & 4475 & 5143 & 15055 & 81180 \\
\hline $0.31-0.5$ & 50610 & 36592 & 42479 & 690189 \\
\hline $0.21-0.3$ & 255889 & 166816 & 157518 & 1093725 \\
\hline $0.11-0.2$ & 268409 & 175034 & 203858 & 238272 \\
\hline
\end{tabular}

Table 2-5. PR-Stack Sample Locations

\begin{tabular}{|c|c|}
\hline Sample Number & $\begin{array}{c}\text { Location Inside } \\
\text { Stack }\end{array}$ \\
\hline 1 & $21 / 4^{\prime \prime}$ \\
2 & $31 / 2^{\prime \prime}$ \\
3 & $51 / 2^{\prime \prime}$ \\
4 & $81 / 4^{\prime \prime}$ \\
5 & $153 / 4^{\prime \prime}$ \\
6 & $181 / 2^{\prime \prime}$ \\
7 & $201 / 2^{\prime \prime}$ \\
8 & $22^{\prime \prime}$ \\
9 & $233 / 8^{\prime \prime}$ \\
\hline
\end{tabular}

data with respect to specific size intervals is for particles larger than 5.0 microns in diameter; there were over 30 times more particles of this size in the ambient sample than in the stack sample. This was to be expected.

The data from "CAM 1" and "CAM 2" can also be compared. The only operational parameter that was different between these two samples was that during the "CAM $2^{\text {" sample }}$ the line was being tapped periodically. The difference in the results was astounding. Approximately 80 times more particles larger than 5 microns in diameter were seen when the line was tapped. Significant increases were also seen in the 0.51 through 1.0 and 1.1 through 5.0 micton ranges. This supports the hypothesis that material that has been deposited in the sampling line can be made to break or flake off and will be collected downstream on an air sample. 


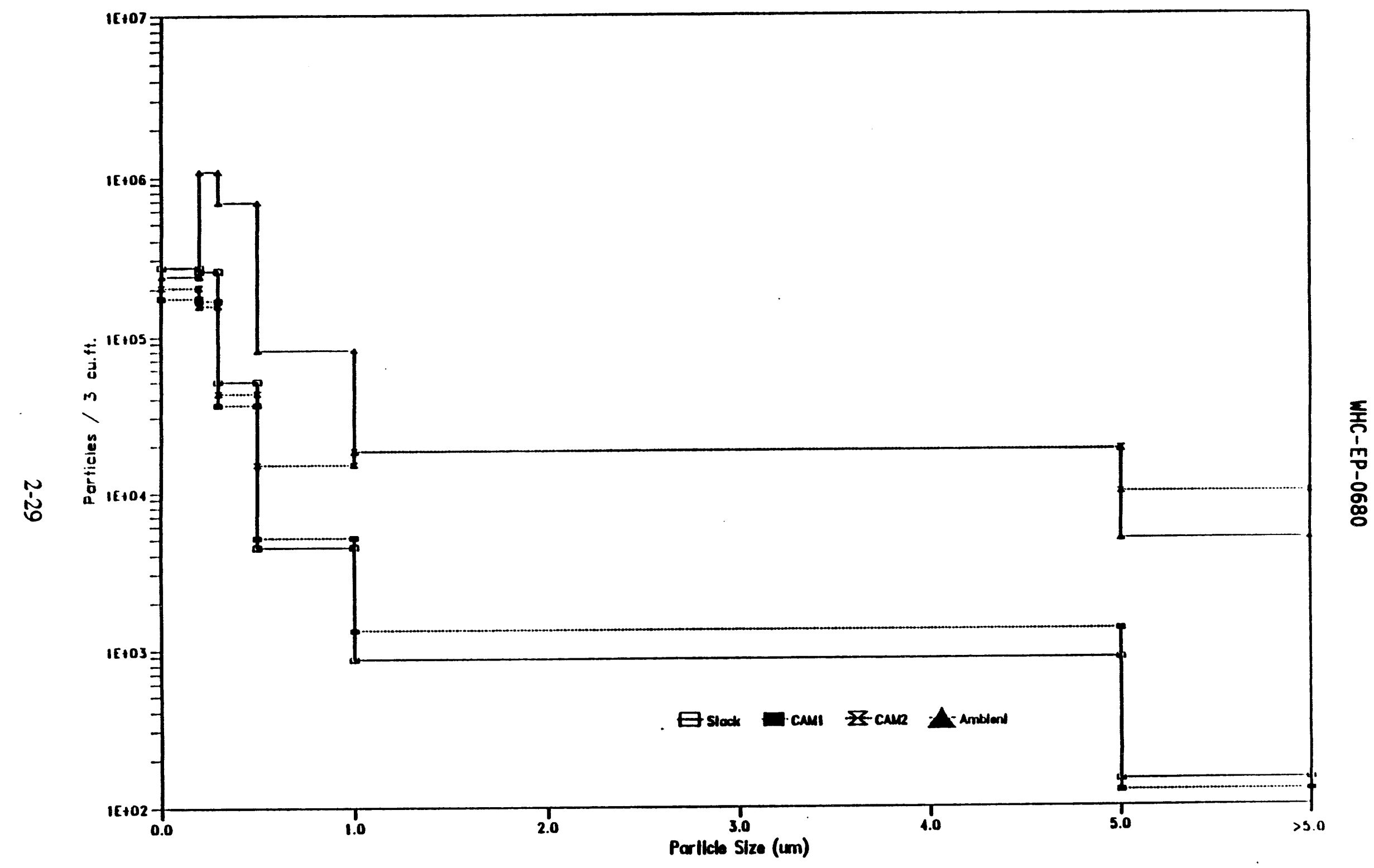

Figure 2-14. Particle Size Prequency Distributions for Four Samples 


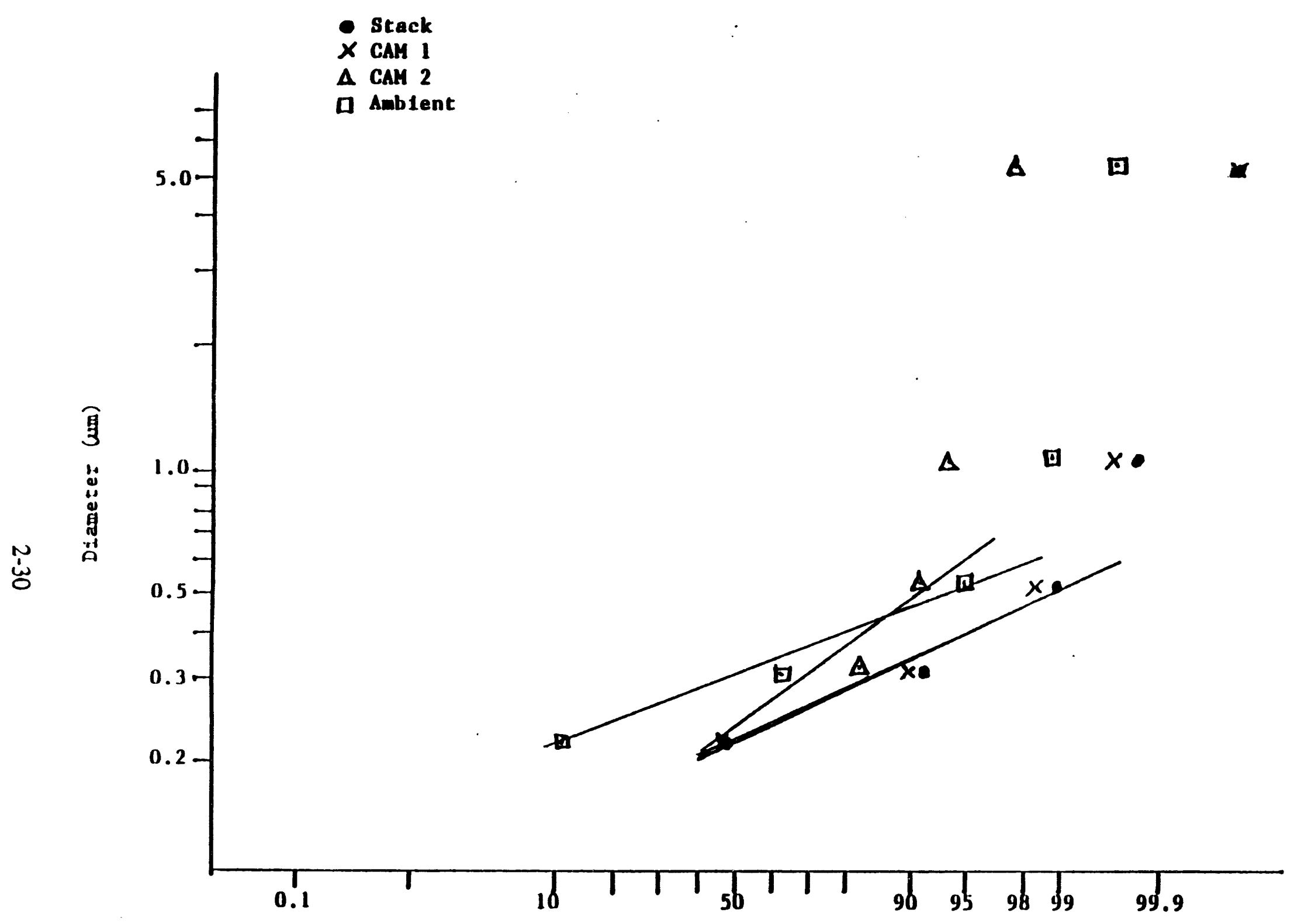

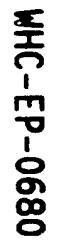

I I.egs than Stated Dlameter

Figure 2-15. Size Distribution Data for the PR-Stack Measurements 
Figure 2-15 shows the particle size distributions of the four sets of samples obtained from the PR. Stack. Count median diameters, geometric standard deviations, and mass median diameters for the particle distributions are listed in Table 2-6. The count median diameters for the stack, "CAM 1", and "CAM 2" particle distributions are approximately the same; however, the geometric standard deviations for these distributions are different, and this makes the calculated mass median diameters significantly different. In all of the samples taken (even the ambient sample), a certain fraction of the population was of a larger diameter than would be expected for the population to be identified as a $\log$-normal distribution. All size distributions appear to be at least bimodal. The CMDs and the GSDs were estimated from the smaller-sized fraction of the particle distribution so that the observations and conclusions would be conservative.

\section{Conclusions}

- The determination of particle line loss is not a straightforward or simple one, especially when multiple mechanisms are occurring simultaneously.

- Particles in all size ranges measured by the laser particle size spectrometer are more than likely being deposited in the sampling line during the transport from the PR Stack to the alpha CAM. A particle line loss of approximately 30-35\% was measured in certain size intervals.

- There are particles being "generated" during the sampling. The larger numbers of particles seen in specific size intervals of the "CAM 1" sample compared to the corresponding size intervals of the "Stack" sample could mean that material is inside the sampling line and is available to flake/break off of the interior surface of the transporting system. This hypothesis is certainly substantiated when comparing "CAM 2" data to "CAM 1" data.

- Tapping the sampling line during sampling does appear to significantly increase the number concentration of particles, especially those that are 0.5 micron and larger. This is not likely due to an inleakage of ambient aerosol during the sampling because the measurements show a higher concentration of

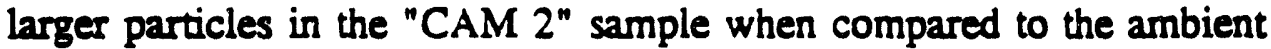
sample.

- The length of the section tapped is only a small segment of the total transport line and is located at the end of the line. It is likely that deposition of material has occurred throughout the line with the largest amount of deposition being nearer the stack. Any vibration over time, shaking, or rapping of the transport line could result in erroneous measurement of radionuclide release if the radionuclide deposits in the transport line and is subsequently reintroduced into the stack sample through this line. 
WHC-EP-0680

Table 2-6. Particle Size Distributions

\begin{tabular}{|c|c|c|}
\hline Sample & CMD $(\mu \mathrm{m})(\mathrm{GSD})$ & MMD $(\mu \mathrm{m})^{1}$ \\
\hline Stack & $0.20(1.40)$ & 0.28 \\
\hline CAM 1 & $0.21(1.43)$ & 0.31 \\
\hline CAM 2 & $0.22(1.70)$ & 0.52 \\
\hline Ambient & $0.29(1.38)$ & 0.40 \\
\hline
\end{tabular}

1 Using MMD $=$ CMD exp [3 $\ln ^{2}$ GSD].

Note: $C M D=$ Count median diameter.

GSD = Geometric standard deviation.

MMD = Mass median diameter.

-

The measurement of the particle size distribution is affected by the location at which the sample is obtained. An increase in the mass median diameter of the particle can be seen downstream of the stack due to a significant number of larger particles being present in the sample.

- From the results of the laser spectrometer measurements and the previously obtained cascade impactor measurements, an effort to obtain more information on the chemical and isotopic composition of the material on the inside of the sampling line may be justified. A filter sample could be obtained during extended vibration or tapping of the line and the sample then analyzed by 222-S Laboratory personnel. The results could provide information on what material and isotopes have been deposited in the line.

\subsubsection{Software}

Results of using the "DEPOSITION" software program are presented in this section of the report. The software program takes into account a number of different variables that affect particle transport through a sampling line. These include the flow rate; tube diameter, length, and physical orientation; presence of bends in the tube; orientation of the inlet nozzle to the gas flow; and particle size distribution characteristics such as distribution type, size, density, and geometric standard deviation. Values of a number of different variables must be entered into the program to describe the physical dimensions and geometry of the sampling line, gas flow characteristics, and characteristics of the aerosol and the associated size distribution. The end result of the calculations is the percent penetration through the transport line (i.e., the percent of particles that are transported through the entire line). 


\subsubsection{Comparisons and Assessments}

Comparison of the cascade impactor data to the laser spectrometer measurements and the theoretical numbers generated with the "DEPOSITION" software program creates some very interesting observations and assessments of the particle sampling situation that may very well be present in a number of stacks at Hanford.

Table 2-7 lists the results for a five-component sampling line that stimulates the actual sampling line. The line described included an inlet (sampling aligned with the flow stream), a $90^{\circ}$-elbow, and three other elements - each five meters in length - one length horizontal, one length at a $45^{\circ}$ angle compared to horizontal, and one length vertical. The sampling tube had an inside diameter of $9.4 \mathrm{~mm}$ (i.e., 1/2" OD - (2)(0.065" wall thickness)). The sampling rate used was $60 \mathrm{l} / \mathrm{m}$. The free-stream velocity used was $6.62 \mathrm{~m} / \mathrm{s}$ (i.e., $(1 \mathrm{cfm}) /$ $\left((\pi)\left(3 / 8^{\prime \prime} / 2 / 12^{\prime \prime} / \mathrm{ft}\right)^{2}\right)$ converted to the required units; $1 \mathrm{cfm}$ was the sample flow rate, $3 / 8^{\prime \prime}$ was the inside diameter of the sampling line $\left(3 / 8^{\prime \prime} / 2\right.$ was the radius in inches). A lognormal distribution and a geometric standard deviation of 1.4 were assumed for the particle population. Listed in Table 2-7 are the percent penetrations for particles of different sizes (i.e., 10.0, 5.0, 3.0, 2.0, 1.0, 0.5, 0.2, 0.1 micron) and different densities (i.e., 1.0, 1.5, 2.0 , and $5.0 \mathrm{gm} / \mathrm{cm}^{3}$ ).

A six-component sampling line was also used to "estimate" the sampling system. The system included the inlet and four straight sections that were each 3.75 meters in length. The sections were at $0^{\circ}, 30^{\circ}, 60^{\circ}$, and $90^{\circ}$ to horizontal. Essentially the equivalent percent penetrations were calculated when compared to the five-component system.

Table 2-7 summarizes the results of calculations performed changing the variables of particle size and density. The results show the importance of particle size and its effect on the percent penetration through different sections of the sampling line. Of course, larger particles deposit faster than smaller particles due to gravitational settling and a larger effect is seen in a horizontal orientation. If the particles are smaller than 1 micron in diameter, the effects of the variables discussed are minimal; however, with larger particles, the deposition is affected greatly by density and tube orientation. Comparison of cascade impactor and laser spectrometer data to these theoretical numbers is difficult. In the model used by Anand and McFarland (1991), there was no "generation" of material during sampling - only loss of material due to deposition. Some of the empirical data shows an estimated 20-30\% particle loss in certain size ranges. The data in Table 2-7 would suggest that in order to see a fractional loss of this level, the aerosol would need to be in the size range of 1 to 2 microns in diameter with a density of approximately $4 \mathrm{gm} / \mathrm{cc}$ for the 1 -micron particles and $1 \mathrm{gm} / \mathrm{cc}$ for the 2-micron particles.

The results of the laser spectrometer measurements support the hypothesis developed from the cascade impactor data. In all cascade impactor samples analyzed, radioactivity was collected in the pre-separator; this means that particles larger than 10 microns in aerodynamic diameter were present. These were present in the stack and downstream from 
Table 2-7. Theoretical Percent Penetration of Particles for the PR Stack Sampling Line

\begin{tabular}{|c|c|c|c|c|c|c|c|}
\hline \multirow{2}{*}{$\begin{array}{l}\text { Mens } \\
\text { Pertide } \\
\text { She (nos) }\end{array}$} & \multirow{2}{*}{$\stackrel{p}{(m / e c)}$} & \multicolumn{6}{|c|}{ \% Penctration } \\
\hline & & Inlet & $90^{\circ}$ Elbow & Element 3 & Element 4 & Element 5 & Total \\
\hline 10 & $\begin{array}{l}1.0 \\
1.5 \\
2.0 \\
5.0\end{array}$ & $\begin{array}{l}82.53 \\
77.91 \\
74.43 \\
63.57 \\
\end{array}$ & $\begin{array}{r}18.47 \\
10.37 \\
6.28 \\
0.68 \\
\end{array}$ & $\begin{array}{l}3.84 \\
1.11 \\
0.28 \\
0.00\end{array}$ & $\begin{array}{r}31.64 \\
17.08 \\
5.10 \\
0.09 \\
\end{array}$ & $\begin{array}{r}42.36 \\
24.43 \\
8.28 \\
100.00 \\
\end{array}$ & $\begin{array}{l}0.08 \\
0.00 \\
0.00 \\
0.00\end{array}$ \\
\hline 5 & $\begin{array}{l}1.0 \\
1.5 \\
2.0 \\
5.0\end{array}$ & $\begin{array}{l}93.75 \\
91.30 \\
89.14 \\
80.04 \\
\end{array}$ & $\begin{array}{l}57.29 \\
45.48 \\
36.82 \\
13.27 \\
\end{array}$ & $\begin{array}{r}39.13 \\
24.21 \\
15.75 \\
1.97 \\
\end{array}$ & $\begin{array}{l}63.33 \\
54.70 \\
48.36 \\
23.40 \\
\end{array}$ & $\begin{array}{l}71.06 \\
64.29 \\
59.04 \\
32.54 \\
\end{array}$ & $\begin{array}{l}9.46 \\
3.54 \\
1.48 \\
0.02 \\
\end{array}$ \\
\hline 3 & $\begin{array}{l}1.0 \\
1.5 \\
2.0 \\
5.0 \\
\end{array}$ & $\begin{array}{l}97.49 \\
96.36 \\
95.30 \\
89.97 \\
\end{array}$ & $\begin{array}{l}79.93 \\
72.14 \\
65.44 \\
39.30 \\
\end{array}$ & $\begin{array}{l}77.08 \\
63.70 \\
52.42 \\
18.08 \\
\end{array}$ & $\begin{array}{l}83.65 \\
76.28 \\
70.35 \\
50.10 \\
\end{array}$ & $\begin{array}{l}86.39 \\
80.79 \\
76.30 \\
60.42 \\
\end{array}$ & $\begin{array}{r}43.41 \\
27.29 \\
17.55 \\
1.94 \\
\end{array}$ \\
\hline 2 & $\begin{array}{l}1.0 \\
1.5 \\
2.0 \\
5.0 \\
\end{array}$ & $\begin{array}{l}98.84 \\
98.29 \\
97.76 \\
94.84 \\
\end{array}$ & $\begin{array}{l}89.99 \\
85.87 \\
81.47 \\
62.10 \\
\end{array}$ & $\begin{array}{l}92.82 \\
86.74 \\
80.25 \\
47.35 \\
\end{array}$ & $\begin{array}{l}93.84 \\
89.58 \\
85.50 \\
67.52 \\
\end{array}$ & $\begin{array}{l}94.47 \\
91.01 \\
87.81 \\
74.12 \\
\end{array}$ & $\begin{array}{l}73.19 \\
59.48 \\
47.98 \\
13.96 \\
\end{array}$ \\
\hline 1 & $\begin{array}{l}1.0 \\
1.5 \\
2.0 \\
5.0 \\
\end{array}$ & $\begin{array}{l}99.70 \\
99.56 \\
99.41 \\
98.56 \\
\end{array}$ & $\begin{array}{l}97.17 \\
95.80 \\
94.46 \\
86.99 \\
\end{array}$ & $\begin{array}{l}99.23 \\
98.55 \\
97.66 \\
89.39 \\
\end{array}$ & $\begin{array}{l}99.24 \\
98.59 \\
97.78 \\
91.30 \\
\end{array}$ & $\begin{array}{l}99.25 \\
98.63 \\
97.88 \\
92.37 \\
\end{array}$ & $\begin{array}{l}94.68 \\
91.40 \\
87.77 \\
64.64 \\
\end{array}$ \\
\hline 0.5 & $\begin{array}{l}1.0 \\
1.5 \\
2.0 \\
5.0 \\
\end{array}$ & $\begin{array}{l}99.93 \\
99.89 \\
99.85 \\
99.64\end{array}$ & $\begin{array}{l}99.19 \\
98.79 \\
98.39 \\
96.06 \\
\end{array}$ & $\begin{array}{l}99.72 \\
99.66 \\
99.58 \\
98.74 \\
\end{array}$ & $\begin{array}{l}99.72 \\
99.66 \\
99.59 \\
98.77 \\
\end{array}$ & $\begin{array}{l}99.72 \\
99.66 \\
99.59 \\
98.79 \\
\end{array}$ & $\begin{array}{l}98.28 \\
97.68 \\
97.03 \\
92.20\end{array}$ \\
\hline 0.2 & $\begin{array}{l}1.0 \\
1.5 \\
2.0 \\
5.0\end{array}$ & $\begin{array}{l}99.99 \\
99.98 \\
99.98 \\
99.94 \\
\end{array}$ & $\begin{array}{l}99.82 \\
99.79 \\
99.65 \\
99.13 \\
\end{array}$ & $\begin{array}{l}99.50 \\
99.49 \\
99.49 \\
99.43 \\
\end{array}$ & $\begin{array}{l}99.50 \\
99.50 \\
99.49 \\
99.43 \\
\end{array}$ & $\begin{array}{l}99.50 \\
99.50 \\
99.49 \\
99.43 \\
\end{array}$ & $\begin{array}{l}98.33 \\
98.22 \\
98.10 \\
97.39 \\
\end{array}$ \\
\hline 0.1 & $\begin{array}{l}1.0 \\
1.5 \\
2.0 \\
5.0\end{array}$ & $\begin{array}{r}100.00 \\
100.00 \\
99.99 \\
99.99\end{array}$ & $\begin{array}{l}99.94 \\
99.90 \\
99.87 \\
99.68\end{array}$ & $\begin{array}{l}98.97 \\
98.96 \\
98.96 \\
98.94 \\
\end{array}$ & $\begin{array}{l}98.97 \\
98.97 \\
98.96 \\
98.94 \\
\end{array}$ & $\begin{array}{l}98.97 \\
98.97 \\
98.96 \\
98.94 \\
\end{array}$ & $\begin{array}{l}96.87 \\
96.83 \\
96.79 \\
96.54 \\
\end{array}$ \\
\hline
\end{tabular}

Notes: Element $3=5 \mathrm{~m}$ in length, horizontal

Element $4=5 \mathrm{~m}$ in length, $45^{\circ}$ to horizontal

Element $5=5 \mathrm{~m}$ in length, vertical. 
the CAM sampling line; however; they were in greater presence downstream of the sampling line than in the stack. This "generation" of material was substantiated by the laser spectrometer measurements especially when the sampling line was vibrated. The hypothesis that material is present inside the sampling line (and perhaps inside the PR Stack) and is available to break free or flake off the transport surface is supported by both sets of data. Radioactive material is apparently attached to these larger particles.

\subsection{Development of General Test Methods and Procedures for Line-Loss Determinations}

The purpose of this section is to discuss steps that can be followed to obtain particle line-loss determinations for aerosol transport lines. These steps were developed from work plans that were written and used during the year to obtain cascade impactor samples and realtime laser spectrometer measurements and "lessons leamed" during the year. Other samplers and monitors (e.g., filters, condensation nuclei counters, mass concentration monitors) could also be used to obtain data. Preliminary actions required, sample acquisition needs, sample analyses, measurements, assessment needs, and methods to develop conclusions are discussed.

\subsubsection{Preliminary Actions}

Prior to the acquisition of any empirical data that can be used to determine loss of particles during transport through sampling lines, there are some basic decisions that need to be made and actions that need to be performed. These are related to the determination of the design of the stack and the effluent path, the design of the current effluent sampling system, any modifications in the sampling system that will be required, and locations of the line-loss evaluation equipment.

The design and characteristics of the effluent system (e.g., stack) need to be evaluated in terms of location, accessibility, physical dimensions, and documented flow rate (by WHC Vent and Balance personnel). The average linear velocity through the stack is calculated by dividing the average flow rate (cfm) by the cross-sectional area $\left(\mathrm{ft}^{2}\right)$ of the inside of the stack. This linear velocity $(\mathrm{f} / \mathrm{min})$ is used to design the sampling probe to be used with the cascade impactor or laser spectrometer. Two access points are required to determine the line losses in a sampling line. One sampling point should be at a location that samples directly from the stack or somewhere else upstream of the sampling line and the second needs to be downstream of the sampling line. Data from both locations are compared to evaluate the line losses in terms of total material transported, particle size distribution effects, or both. If the system used to obtain a sample directly from the stack needs to be moved periodically, it needs to be accessible by personnel - to move it and to check on air flow rates and vacuum gauge readings. The unit operating downstream from the sampling line must also be accessible for periodic performance checking. 
The design of the current eifluent monitoring system needs to be evaluated to determine the modifications that need to be nade. if any, before sampling with a cascade impactor or laser spectrometer can be performed. These "modifications" may be as simple as replacement of a CAM or record sampler with the other sampling equipment. Physical constraints, accessibility, and flow rates of the corresponding equipment need to be considered. Support stands, air flow splitters, and special fittings are examples of items that may need to be constructed, modified, or procured before the "new" sampling system can be completed. It may be necessary for a "major" modification such as the need for an air flow splitter, sampling line, vacuum pump, flow meter, vacuum gauge, and flow regulator to be installed with the sampling equipment. Scaffolding may need to be erected before sampling can be initiated.

Work plans need to be developed that describe the work to be performed and to identify the personnel who are responsible for each step in the work plans. Safety precautions and equipment needs are to be identified in the plans. Copies of the actual work plans used this year are included in this report as Appendix B. The plans should be developed by the Cognizant Engineer for the facility and the person responsible for the sampling and monitoring systems to be used. Input from nuclear safety, operations, health physics, environmental protection, industrial hygiene, and quality assurance personnel is necessary. Signatures showing concurrence from representatives from each of these organizations is required on the work plan before it can be activated. Corresponding work packages must also be prepared and given a priority to start the work. The work needs to be put on the work schedule and interfaced into the overall scheme of work being performed at the facility.

Once the work is scheduled to be performed, it is necessary to make sure all equipment that is needed is available and working properly. Table 2-8 is a checklist that was used on one of the cascade impactor installations; it helped insure that everything was ready prior to initiation of the work plan. Within one or two days prior to initiation of the work plan, all of the equipment should be located and, if possible, the sampling system should be completely put together and the performance checked. All fittings and tubing that will be needed should be accounted for prior to the initiation of the work plan. It is a good idea to have extra parts for the parts of the system that may easily break or be lost during transport. Each cascade impactor requires approximately 15-20 minutes to "load" with filters and to be prepared for operation. If the unit can be stored and transported in a vertical position prior to installation, it can be loaded one or two days before the work plan is started. If an appropriate area (e.g., controlled if required) is available, the impactor can be loaded just prior to installation. If the impactor is tilted or placed in a horizontal position, the support trays for the filters inside the impactor can slip and be off-center. The unit would have to be reopened to correct the situation.

As part of the preliminary actions, immediately before the work is started, a pre-job safety meeting is required to be held. Attendees to this meeting will be all of the people involved with the work including engineers, consultants, crafts personnel (e.g., pipe fitters, 
Table 28. Checklist of Items Needed for PR-Stack Cascade Impactor Samples PR STACK

1 Cascado Impactor (Losded)

Platiorm (wooden)

Strinicas Stod Sampling line - 2 parts (1 curved, 1 with inlet nozzlo)

Compreasion fittinge (2 Sets)

Extriaion cond (100 Ft)

Power bar

Plastic cover

$41 / 4^{\circ}$ bolts to bold down plastic cover

6-1/4" bolts and nuts to hold plastic cover togecher

Green tape

Cord

Vecuum gauge with fittings (cross with nipples)

flowmoter with fittings

Sherpie

Hoeses

- Cascado Inpactor to flowmeter

- Flowereter to vacuum gauge

- Vacurim gauge to pumps (2)

Rope to trasport equipment to roof

Temperiture controller \& heating tape

Buckets

\section{CAM BUILDING}

1 Cascade Impector (Losded)

Jeck with cronik

Vecurum gauge with compression fitting

Flowmeter

Hoses

- Cascado Impactor to flowmeter

- Flowmeter to vacuum gauge

Green tape

\section{MISCELLANEOUS}

Data sheets

Calculator

Work Plans (Official)

Peas

Notebook

Hat

Sunglasses

Watch 
insulators, millwrights), health physics technicians, operators, etc. Details of the work will be discussed and will include areas where sajery issues are important to consider. Areas of responsibility for different groups will be identified. Signatures of attendees will be documented.

\subsubsection{Sample Acquisition}

Several aspects of sample acquisition need to be evaluated and decisions made on specific procedures and equipment to use in order to obtain meaningful and useful data. The sample obtained directly from the stack (or upstream of the sampling line) and the sample obtained downstream of the sampling line need to be evaluated separately and together. It is suggested that the sampling lines used for the tests and routine sampling, if possible, be washed before and after each test to determine the presence of radioactivity.

If a sample is to be obtained directly from the stack, there should to be a hole in the stack or some other access point identified (e.g., it is possible to have the sampling line enter the top of the stack). The flow rate of the cascade impactor is 1 acfm; other flow rates can be used but other calibration data from the manufacturer is needed. The flow rate of the laser spectrometer is stated to be $1 \mathrm{scfm}$. In order to establish isokinetic sampling conditions, the linear flow rate at the inlet nozzle must equal the average linear flow rate of the stack. Using a flow rate of $1 \mathrm{acfm}$ or $1 \mathrm{scfm}$ will determine the diameter required for the inlet nozzle of the sampling probe. The sampling probe and line should be made of stainless steel. Measurement of the physical layout to be used prior to construction of the sampling system is imperative. Values for the diameter of the stack, stack wall thickness, distance of the stack from the roof, presence and location of safety rails on the roof, height of the access hole above the roof need to be known. The length of the sampling line should be minimized and "rounded" bends should be used. The best "representative" sample should be obtained. In the case of the PR-Stack sample obtained directly from the stack, a traverse of the stack was performed over the length of the sampling period. Locations from which the inlet nozzle sampled corresponded as well as possible to the locations where WHC Vent \& Balance personnel obtained velocity data. Another type of probe that could be used would be a shrouded probe as discussed by McFarland, et.al (1988). The system should be checked periodically to insure that it is working properly (i.e., within specific tolerances). These checks can correspond to the times when the system is to be moved if that is the case. The length of time between performance checks should not exceed one week. If the system is located in the outside environment, it must be protected from the weather. If cold temperature is expected, a temperature controller with heating tape can be used to eliminate the production of condensation inside the sampling line.

If a sample cannot easily be obtained directly from the stack, another possibility is to insert a flow splitter into the sampling line at a location just outside the stack. This is the procedure planned for the PUREX Main Stack. Scaffolding is required to support the systems near this flow splitter. 
Some of the same constraints that are put on the "upstream" sampling system need to be put on the "downstream" sampling system. The length of the sampling line needs to be minimized with as few bends as possible and if bends are needed, they need to be rounded. Periodic checks on the downstream system are required; the easiest method is to check the instrument readings near the same time as for the upstream system. The system should be protected from tampering if at all possible (e.g., access to the room where the equipment can be controlled).

The time required to sample with the cascade impactor systems is determined by the amount of radioactivity being released through the stack, the chemical extraction efficiency and the minimum detectable activity of the analysis laboratory. The collection efficiency of the cascade impactor is assumed to be $100 \%$. All of the particles not collected on the size fractionating stages are collected on the final filter. Sampling for a period of six weeks provided some useful data; however, one or two stages still had "less than detectable" levels. The last set of samples for FY 1992 were obtained over a 10-week period. Two major assumptions have to be made when operating the sampling systems for a period as long as this: 1) the stability in the air flow patterns remains constant over the period, and 2) operating conditions are stable. It should be remembered that both the "upstream" and "downstream" sampling systems are being operated concurrently.

The laser spectrometer makes real-time measurements. Long sampling periods are not involved; for the PR Stack, 3-minute measurements were obtained. A one-minute period was established between measurements to assist in the acquisition of "independent" measurements. It is important to consider coincidence counting errors with these units if the particle concentration is too high. Variability within sample sets as measured during the traverse across the stack can be determined. It is considered important to obtain measurements upstream and downstream of the sampling line on the same day if at all possible; this minimizes the effects of several different variables during comparison of the data sets.

\subsubsection{Sample Analyses and Measurements}

Methods by which the samples and data are to be analyzed should be known before the samples or measurements are collected. Decisions have to be made with respect to the period of sampling, the type of collection media to use, the radionuclides for which aralyses are to be performed, etc., because a number of variables affect the sensitivity and accuracy of the analyses and measurements. This is correct for the cascade impactor samples and the laser spectrometer measurements.

\subsubsection{Cascade Impactor}

The cascade impactor samples are taken to the 222-S Laboratory for analysis. The first set of samples taken in FY 1992 were fiberglass filters. This type of filter is very difficult to dissolve and/or ash. For the second and third sets of data, all collection filters 
were Whatman Type 41 paper filters except for the final filter in the impactor which was kept as fiberglass because of its higher collection efficiency. The Whatman filters dissolve more easily than the fiberglass. Laboratory personnel have stated that a better filter would be Millipore type AW03, AW06, or AW19 which are reinforced membrane filters that readily dissolve. These are being considered for future use.

The first two sets of cascade impactor filters were analyzed for ${ }^{239,240} \mathrm{Pu}$ and ${ }^{241} \mathrm{Am}$. The third set of filters were analyzed for ${ }^{239,240} \mathrm{Pu},{ }^{241} \mathrm{Am}$, and ${ }^{238} \mathrm{Pu}$; gross alpha counts were also obtained. Using the standard procedures for the analyses of the counting data from the 222-S Laboratory, a minimum detectable level for the radionuclides is approximately 0.5 $\mathrm{pCi}$ /sample; however, by looking at the raw counting data, it appears to be possible to estimate an activity as low as about $0.1 \mathrm{pCi} /$ sample. These values are important to consider when the length of the sampling interval is established. One can use the released levels published in the annual environmental report (i.e., Westinghouse Hanford Company Effluent Discharge and Solid Waste Management Repon for Calendar Year 1989: 200/600 Areas, WHC-EP-0141-2, May 1990) and estimate the amount of material to be released during a specific time interval and the amount of material that can be collected by the sampler. It must be remembered, however, that the total activity collected will be spread over 10 samples per impactor: the pre-separator, 8 collection stages, and the final filter.

\subsubsection{Laser Spectrometer}

As measurements are obtained with the laser spectrometer, the total number of counts to be obtained in the counting interval needs to be estimated. The maximum number that can be displayed is 999,999; if this number is exceeded, the readout will "roll-over" and it may be difficult to keep track of the actual numbers. Variability will be seen in the data, especially as one traverses a stack with the sampling probe, and it may be difficult to estimate the total number of counts that will be seen in the "highest" sample. The laser spectrometer can be operated in two modes: cumulative and differential. In the cumulative mode, the numbers collected by the unit are "greater than" numbers; for each size range, the numbers observed are number of particles greater than that specific size. In the differential mode, the numbers within a specific size range are displayed.

When data is being obtained in a remote location and the computer interface is not being used, it is important to make sure that the printer is activated before the measurements are initiated. The printout is the best documentation of the data as it is being accumulated; all of the important variables are recorded directly onto the printout. The staff obtaining the data can focus on operation of the equipment, and notes can be written directly onto the printout to identify specific changes in the data acquisition without having to worry about recording the counting data separately. 


\subsubsection{Data Assessment}

After the samples have been analyzed or the measurements taken, several different assessments can be made to determine the particle line losses in transport lines in terms of particle count differentials, total material changes, size distribution changes, etc. Complete data sets can be compared and single data points (e.g., specific size ranges) within data sets can be compared between two or more data sets.

\subsubsection{Cascade Impactor}

Once the counting data is obtained for each sample, the data for each cascade impactor can be analyzed. The total amount collected by the samplers upstream and downstream of the sampling line during the same collection period should be evaluated and compared. Within the data set for each impactor, the activities of the 10 samples can be looked at cumulatively with respect to the stages and a size-distribution can be determined with the use of logarithmic-probit graph paper. Activity median aerodynamic diameters and geometric standard deviations can be calculated. If the two cascade impactors have been operated at the same flow rate, corresponding stages of the two impactors can be compared.

\subsubsection{Laser Spectrometer}

Assessment of the data obtained with the laser spectrometer is similar to the methods used with the data from the cascade impactor. The total number of counts (i.e., number of particles larger than 0.1 micron) can be compared upstream and downstream of the sampling line. The average number of particles in a specific counting interval from the stack is actually an average of many different data sets obtained at pre-determined locations across the stack. If nine positions are used, then a total of 27 three-minute counts are obtained; this is with a one-minute "hold" between each three-minute count. The data set obtained downstream of the sampling line should be adequate to show that the readings are stable. Logarithmic-probit graph paper can be used to determine the count median diameter and geometric standard deviation of the particle size distribution. Information can also be derived from the frequency distribution of the data.

\subsubsection{Comparison of Cascade Impactor and Laser Spectrometer Data}

It is not easy to compare the data obtained with a cascade impactor to data obtained with a laser spectrometer. A cascade impactor measures aerodynamic properties of the aerosol and the laser spectrometer measures a physical property (i.e., projected-area diameter). Some assumptions can be made to estimate the relationship of the two measured size distributions of the aerosol with the two different instruments, though. When the data from the laser spectrometer is graphed using logarithmic-probit paper, the count median diameter and the geometric standard deviation of the distribution can be estimated. The mass median diameter of the aerosol can be calculated from these values using the equation $\mathrm{MMD}=(\mathrm{CMD}) \exp \left[3 \mathrm{ln}^{2} \mathrm{GSD}\right]$ where $\mathrm{MMD}$ equals the mass median diameter, $\mathrm{CMD}$ 
equals the count median diameter, and GSD equais the geometric standard deviation. The activity median aerodynamic diameter can be estimated from the equation $A M A D=M M D x$ (p) ${ }^{1 / 2}$ where AMAD equals the activity median aerodynamic diameter, $\rho$ equals the density of the material, and MMD equals the mass median diameter. This assumes that the radioactivity is homogeneous throughout the material. Of course, size distributions for cascade impactor samples based on activity are always AMAD. For the activity in process building exhausts where the probability is high that the activities are present are to some extent associated with inert particies, the activity must attach in some exact function of activity vs. mass for the correlation to be accurate.

One simple but very important difference between the data obtained with the cascade impactor and its analyses and the measurements obtained with the laser spectrometer is that the analyses of the cascade impactor data provides an estimate of the size and amount of radioactive aerosol. The laser spectrometer data describes the properties of the combination of all radioactive and non-radioactive aerosols; it can not differentiate between the two types of materiais.

\subsubsection{Development of Conclusions}

The development of conclusions is based on the results of the data obtained with the cascade impactors and laser spectrometers. Conclusions can be based on data from a single set of data (e.g., from the comparison of two cascade impactors operated simultaneously; one obtained upstream of the sampling line and the other downstream of the line) or from multiple sets of data obtained from the same locations. Multiple sets of data can be used to substantiate a conclusion and to develop trends.

Cascade impactor results can lead to conclusions on the presence of radioactive material in the effluent. Results from the laser spectrometer can lead to conclusions on the combination of radioactive and non-radioactive materials in the effluent.

The cascade impactor samples have been obtained over a relatively long period of time (i.e., 6 to 10 weeks); therefore, the data from these runs can be used to develop conclusions on average concentrations and particle size distributions of the aerosol over time. Any day-to-day variability will le "absorbed" by the averaged data.

The laser spectrometer measurements provide real-time descriptions of the particle concentrations and distributions in the airborne effluent. The measurements are taken in relatively short intervals; 1 - to 3-minute measurements should be adequate. Multiple measurements strengthen the data. Conclusions on the variability over a time interval of minutes to hours can be made with this instrumentation. Averaging data from multiple sampling locations during a traverse of a stack should provide a representative sample of the effluent being released through the stack. Any sudden change in the particle concentration can be measured with this real-time instrument. 
Comparison of cascade impactor data to laser spectrometer data is difficult; however, it is possible for the data from each to identify trends and to substantiate each other. An example is the large particles observed in the cascade impactor samples and the increase in the large particle count observed with the laser spectrometer when the CAM sampling line was vibrated. 
WHC-EP-0680

This page intentionally left blank. 


\subsection{CONCLLSIONS}

The following general conclusions can be made based on the work performed during FY 1992 and the first quarter of FY 1993 under this task:

- Empirical measurements were obtained during the year on the PR Stack CAM sampling line with the use of cascade impactors and a laser spectrometer.

- The methods developed under this task can be used to obtain samples and make measurements to determine particle line losses in aerosol transport lines from other stacks also.

- Cascade impactor samples and laser spectrometer measurements show that material may very well be deposited on the inside of the walls of the sampling line and perhaps the stack that is available to break loose or flake off and be transported out of the stack or down the sampling line.

- Further acquisition of data from the PR Stack could be justified to determine the chemical nature of the material deposited on the inside of the sampling line.

- The quality of the analyses of the samples is a key factor to the ability to interpret the data.

- It may be worthwhile to consider using a "shrouded" probe as developed by McFarland, et al., to obtain stack samples. The need for periodic movement of the sampling system would be eliminated.

- Work plans have been developed for the acquisition of line-loss data for the PUREX Main Stack and the AP Tank Farm Stack; these were not implemented in FY 1992.

- Percent penetration numbers generated with the DEPOSITION software program appear to be very reasonable; however, it assumes that particles are only deposited in the transport line and that there is no material available to be "resuspended".

- Estimates of particle line loss in the $25-35 \%$ range in specific size intervals can be made-even with the "generation" of additional material occurring at the same time. 
WHC-EP-0680

This page intentionally left blank.

3-2 


\subsection{REFERENCES}

Anand, N. K. and A. R. McFarland. 1991. "DEPOSITION: Software to Calculate Particle Penetration Through Aerosol Transport Lines." NUREG/GR-0006, U. S. Nuclear Regulatory Commission, Washington D.C.

Brodsky, A. 1992. "Exact Calculation of Probabilities of False Positives and False Negatives for Low Background Counting." Health Physics, 63(2):198-204.

Catlow, S. A. 1989. "Separation of Pu and Am by Ion Exchange." LA-943-123, Rev. E0, Westinghouse Hanford Company, Richland, Washington.

Catlow, S. A. 1991. "Electrodeposition of Actinides." LA-542-101MISC, Rev. C-0, Westinghouse Hanford Company, Richland, Washington.

Dowell, M.S. 1991. "Alpha Energy Analysis Using the Canberra Jupiter System." LA508-051MISC, Rev. A-3, Westinghouse Hanford Company, Richland, Washington.

Jones, R. A. 1991. "Total Alpha Counting by Alpha Proportional Counters." LA-508104MISC, Rev. A-3, Westinghouse Hanford Company, Richland, Washington.

McFarland, A. R., C. A. Ortiz, M. E. Moore, R. E. DeOtte, Jr., and S. Somasundaram. 1988. "A Shrouded Aerosol Sampling Probe." Aerosol Technology Laboratory Publication 5897/02/08/88/ARM, Department of Mechanical Engineering, Texas A\&M University, College Station, TX.

Ropp, R. C. 1985. "Display of Particle-Size Distributions." Analytical Laboratory, July:76-83.

U.S. EPA. 1990. 40 CFR 60, Appendix A, Method \#1, "Sample and Velocity Traverses for Stationary Sources." U. S. Environmental Protection Agency, Washington, D.C.

WHC. 1990. Westinghouse Hanford Company Effluent Discharge and Solid Waste Management Report for Calendar Year 1989: 200/600 Areas. WHC-EP-0141-2, Westinghouse Hanford Company, Richland, WA. 
WHC-EP-0680

This page intentionally left blank. 
WHC-EP-0680

\section{APPENDIX A}

\section{INSTRUMENT DESCRIPTIONS}

$$
\text { A-1 }
$$


WHC-EP-0680

This page intentionally left blank.

$A-i$ 
WHC-EP-0680

APPENDLX A-1

PROCUREMENT SPECIFICATIONS FOR A MULTI-STAGE CASCADE IMIPACTOR (1 CFM NOMINAL FLOW RATE)

\section{Requirements:}

Multi-stage cascade impactor to determine the particle size distribution of ambienttype and effluent aerosols from facility stacks. The unit will be operated at a nominal flow rate of $1 \mathrm{cfm}$.

\section{Specifications:}

1. A minimum of 8 particle size fractions 10 to 0.7 microns with a final filter with collection efficiency $>99.9 \%$ for most penetrating size is required.

2. A pre-separator is needed to collect particles $\geq 10$ microns.

3. A nominal flow rate of $1 \mathrm{cfm}$ is required.

4. Construction material (impactor): aluminum.

5. Stainless steel collection plates required.

6. The unit must have the flexibility to use different types of collection substrates with it (e.g., glass fiber filters, glass, stainless steel, aluminum and cellulose foils).

7. A backup filter holder that is an integral part of the impactor must be included.

8. A vacuum pump that operates on $115 \mathrm{VAC}$ with a flow rate (under load) of up to $1.5 \mathrm{cfm}$ is required.

9. A carrying case for the impactor, pre-separator, and stages is required.

10. A minimum of 200 filter paper collection substrates should be included in the bid. 
WHC-EP-0680

\section{ANDERSEN CASCADE MIPACTOR NISTRLMIENTATION DESCRIPTION}

\section{INTRODUCTION}

The Andersen 1 ACFM Non-Viable Ambient Particle Sizing Sampler is a multi-stage, multi-orifice cascade impactor which normally is used in the environmental working areas to measure the size distribution and total concentration levels of all liquid and solid particulate matter.

The Andersen Non-Viable Ambient Sampler was calibrated at the factory with unit density $\left(1 \mathrm{~g} / \mathrm{cm}^{3}\right)$ spherical particles so that all particles collected, regardless of their physical size, shape, or density, are sized aerodynamically equivalent to the reference particles.

A brief description of the operation of the sampling equipment follows:

1. Ambient gases enter the inlet cone and cascade through the succeeding orifice stages with successively higher orifice velocities from Stage 0 to Stage 7. Successively smaller particles are inertially impacted onto the collection plates. The submicrometer particles that are not collected by the last collection plate are caught in the backup filter, which is an integral part of the impactor immediately downstream from Stage 7. Stage 0 is an orificer stage only. Stage 8 is a collection stage only.

2. The clean gases are carried through the vacuum tube and through the pump and exhausted.

3. A constant air sample flow of 1 ACFM is provided by a continuous duty, carbon-vane vacuum pump. Flow rate through the impactor is controlled by an adjustable bleed valve on the pump which requires periodic calibration.

4. After sampling is completed, the sample time is recorded and collection substrates and backup filter are removed for analyses.

5. Radioactivity levels are determined and the size distribution is plotted.

\section{MMPACTOR}

\section{Deseription}

The Andersen 1 ACFM Ambient Sampler is comprised of 8 aluminum stages that are held together by three spring clamps and gasketed with O-ring seals (Figure A1-1). 


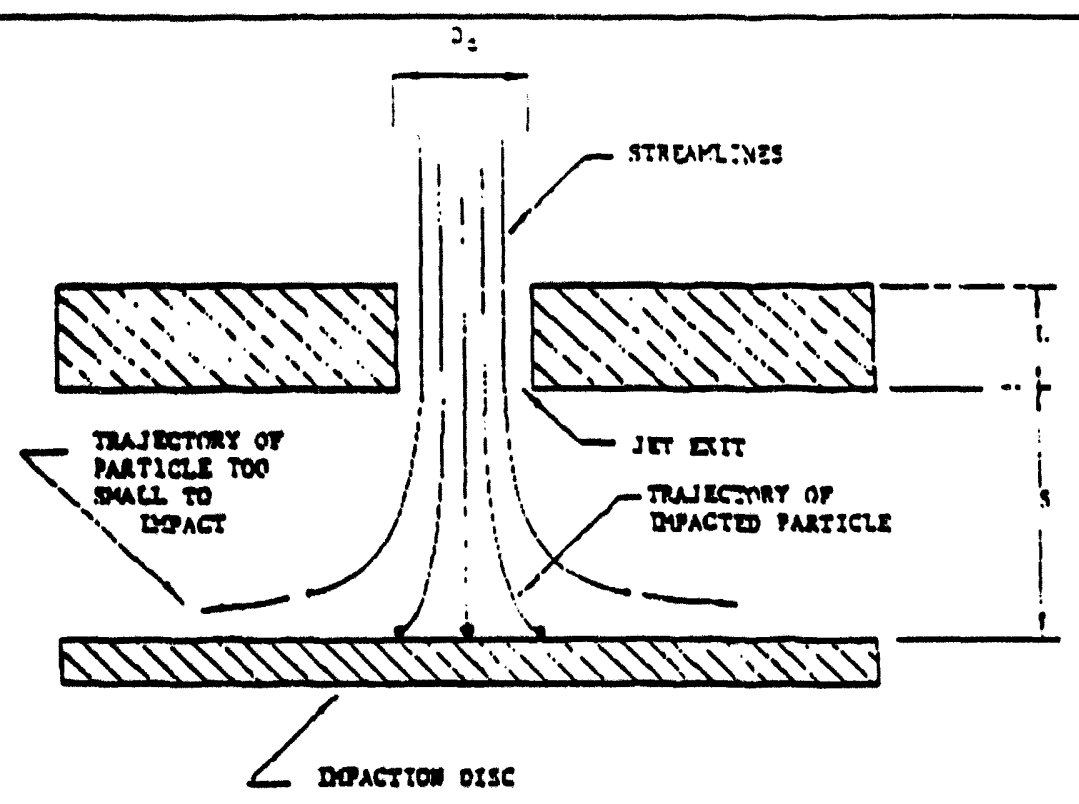

Figure Al-3. Schematic of Impactor Stage

Following are jet dimensions for each stage:

\begin{tabular}{|c|c|c|}
\hline \multicolumn{3}{|c|}{ MARK II } \\
\hline STAGE & $\begin{array}{c}\text { ORIFICE DIAMETER } \\
\text { (INCHES) }\end{array}$ & $\begin{array}{c}\text { NUMBER OF } \\
\text { ORIFICES }\end{array}$ \\
\hline 0 & 0.1004 & 96 \\
1 & 0.0743 & 96 \\
2 & 0.0360 & 400 \\
3 & 0.0280 & 400 \\
4 & 0.0210 & 400 \\
5 & 0.0135 & 400 \\
6 & 0.0100 & 400 \\
7 & 0.0100 & 201 \\
F & 0.1100 & Filter Holder \\
\hline
\end{tabular}

\section{Ascembly}

The orifice stages, preseparator, and collection plates must be clean before Sampler assembly. A mild detergent and warm water are sufficient for cleaning. The soap can be removed by holding the stages and plates under hot running water. Complete soap removal 
for the stages is more quickly done by immersing them in an ultrasonic cleaner containing clean water. After the soap is removed, the stages and plates may be rinsed with acetone which removes the water and which quickly evaporates, or they can be spread out on paper towels and blotted dry. Either operation may leave slight traces of film which are easily removed with a lint-free wiping paper. The stages and plates should be handled by the edges to prevent getting skin oil on the orifice and collection surfaces. Each stage should be examined for any material in the holes. If holes are plugged, or partially plugged, a jet blast of dry air is effective in cleaning the holes.

The complete impactor assembly consists of an inlet cone, 9 stages, 8 collection plates, and a backup filter. An impactor preseparator is optional. The stages are numbered $0,1,2,3,4,5,6,7$, and F. Stage 0 is an orifice stage only. Stage F contains the collection plate for Stage 7 and the backup filter. Each stage contains an O-ring (neoprenestandard, Teflon-optional) for sealing. In addition, there is a large-diameter 0 -ring inside Stage $\mathrm{F}$ which holds the backup filter in place. The optional preseparator simply replaces the inlet cone and requires no modification.

The impactor assembly begins by placing Stage $F$ on the base plate stage. A glass fiber backu, filter is inserted into Stage F and the large-diameter O-ring placed into position around the periphery of the filter. Next, place collection plate 7 onto Stage F so that the plate rests on the three raised, notched metal seats to prevent plate movement. There is no differentiation between top and bottom for the glass plates. The stainless steel plates should be placed with the curved lip down so that a raised, smooth surface is exposed for particle impingement. This is followed by Stage 7, collection plate 6, Stage 6, and so on until the inlet cone or preseparator is positioned last. The stainless steel collection plates that fit onto the raised notched seats on top of Stages 2 and 1 should have a 7/8" hole in the center of the plates.

It should be noted that there are three metal pins extending from the base of each orifice stage. These pins hold the collection plates in place so that the sampler can be used in any sampling orientation.

In addition, most people use special collection substrates other than the glass and stainless steel plates because of lighter tare weight and/or specific analytical requirements. These collection materials consist of glass fiber, cellulose, aluminum foil, vinyl metrical, and other materials which must be placed into the inverted stainless steel collection plate. The collection substrate for plates 1 and 2 have open centers (7/8" hole) while the remaining 6 collection discs and backup filter are solid.

The substrate surface must be level with the top of the curved stainless steel lip to maintain jet-to-collection-surface spacing. When using collection substrates, the Sampler should be used in an upright position at all times. 
After the Sampler has been assembled, connect the outlet nipple on the base stage to the pump intake port with the rubber tubing supplied with the sampler. If a longer piece of tubing is required in order to position the Sampler remotely from the vacuum source, refer to Pages A1-11 and Al-13 for re-calibration procedures.

\section{Sampling}

When ready to sample, the vacuum pump is turned on and a sample stream of 1 ACFM will flow through the sampler. Figure A1-3 shows how impaction occurs at the orifice collector interfaces.

Normally, there is no variation in flow rate throughout the sampling period since a constant pressure drop is maintained (no filtration occurs except at the backup filter, resulting in minimal pressure changes).

The particle size range collected at each of the 8 stages depends on the orifice velocity of the specific stage, the distance between the orifices and the collection surface, and the collection characteristics of the preceding stage. The combination of a constant flow rate and successively smaller diameter orifices increases the velocity of sample air as it cascades through the Sampler, resulting in the impaction of progressively smaller particles in succeeding stages. At 1 ACFM the particle fractionation ranges from 10.0 to 0.4 micrometers in diameter (Table Al-1).

Particles too small to be impacted on the last collection plate are collected in the backup filter which is an optional, integral part of the sampler. Sampling periods vary, depending upon the contamination levels and the sensitivity of the analytical procedure. Ten milligrams of particulate matter on any one stage represents an approximate upper limit because of re-entrainment problems. Overloading the Sampler can be detected easily by visual inspection and is rarely encountered in industrial hygiene applications. Whenever over-sampling occurs, rather than having well-defined, discrete piles of particulates, trails of particles can be seen leading from the sample deposits toward the periphery of the plate. This type of sample should be discarded.

After the sampling has been completed, the Sampler is disassembled. The collection plates and backup filter are removed and replaced with fresh, preconditioned, preweighed collection media if gravimetric or chemical analyses are to be performed. After conditioning, the collection media can be weighed for net particulate accumulations, or the particulate matter can be analyzed chemically for the various components of interest.

Since airborne particulates may have hygroscopic characteristics, all collection media used in the impactor should be preconditioned prior to weighing - both before and after a sampling cycle - in a desiccator. Filter weighing should be made to an accuracy of \pm 0.02 $\mathrm{mg}$ and a precision of $\pm 0.01 \mathrm{mg}$. 
It should be kept in mind that whenever a sample has been collected, the particle sizing has already been completed. To determine the nature of the size distribution, simply perform the required gravimetric and/or other analyses.

\section{Analysis}

The analytical requirements determine the type of collection surface used. Normally, the stainless steel and glass plates are not used as the collection surfaces for gravimetric determinations because of the high tare-weight-to-sample-weight ratio. Glass fiber discs are normally used for these analyses because of their light weight and non-hygroscopic properties. However, other types of collection media are required for most chemical determinations because of the high and variable trace metal background levels in the giass fiber. The type of filter media is also important when radioactive materials are being analyzed. Glass fiber filters should not normally be used for alpha particle counting unless the filter is going to be dissolved before analysis. Stainless steel plates are used in many applications where the collected sample is washed off for subsequent chemical analyses. Glass plates are used rarely and only when there is need to look at the collected particles optically. It is impossible to correlate aerodynamic dimensions with physical size because of the unknown particle density and shape characteristics. In addition, the particles might have shattered on impaction, which will not affect the aerodynamic sizing but would affect any optical sizing significantly.

\section{Data Interpretation Example (Gravimetric)}

(a) Determine the change in weight for each stage in the impactor including the backup filter.

(b) Add up the weight changes to obtain the total particulate weight collected.

(c) Divide the amount collected on each stage by the total amount collected to determine the percentage of the total collected in each fraction (Table A1-1).*

(d) The particle density should be considered as $1.0 \mathrm{~g} / \mathrm{cm}^{3}$ so that the particle sizes can be reported as equivalent aerodynamic diameters.

* The preseparator does not give an additional size cut, but prevents particle bouncing and re-entrainment so that the impactor stages perform properly.

(e) Using Table A1-1, select the lower size (smallest number) for each size range. This number represents the effective cutoff diameter (ECD) for each stage. This ECD can also be obtained from Figure A1-4. 
Table A1-1. Data Presentation

\begin{tabular}{|c|c|c|c|c|c|c|c|}
\hline Stage & Tare (g)* & Final (g) & Net (mg) & $\begin{array}{c}\text { \% in Size } \\
\text { Range }\end{array}$ & $\begin{array}{c}\text { Cumulative } \% \\
\text { Less than Size } \\
\text { Range }\end{array}$ & $\begin{array}{c}\text { Size Range } \\
\text { Micrometers }\end{array}$ & $\begin{array}{c}\text { ECD } \\
\text { Micrometers }\end{array}$ \\
\hline $\begin{array}{c}\text { Pre- } \\
\text { separator }\end{array}$ & 0 & 0.00009 & 0.09 & 0.7 & 99.3 & 10.0 \& above & 10.0 \\
\hline 0 & 1.000 & 1.00009 & 0.09 & 0.6 & 98.7 & $9.0-10.0$ & 9.0 \\
\hline 1 & 1.000 & 1.00017 & 0.17 & 1.2 & 97.5 & $5.8-9.0$ & 5.8 \\
\hline 2 & 1.000 & 1.00082 & 0.82 & 5.7 & 91.8 & $4.7-5.8$ & 4.7 \\
\hline 3 & 1.000 & 1.00194 & 1.94 & 13.6 & 78.2 & $3.3-4.7$ & 3.3 \\
\hline 4 & 1.000 & 1.00472 & 4.72 & 33.1 & 45.1 & $2.1-3.3$ & 2.1 \\
\hline 5 & 1.000 & 1.00431 & 4.31 & 30.2 & 14.9 & $1.1-2.1$ & 1.1 \\
\hline 6 & 1.000 & 1.00100 & 1.00 & 7.0 & 7.9 & $0.7-1.1$ & 0.7 \\
\hline 7 & 1.000 & 1.00082 & 0.82 & 5.7 & 2.2 & $0.4-0.7$ & 0.4 \\
\hline Backup & 1.000 & 1.00031 & 0.31 & 2.2 & 0 & $0-0.4$ & 0 \\
\hline Filter & & & 14.27 & & & &
\end{tabular}

* Note: Collection substrates will seldom weigh exactly the same. 


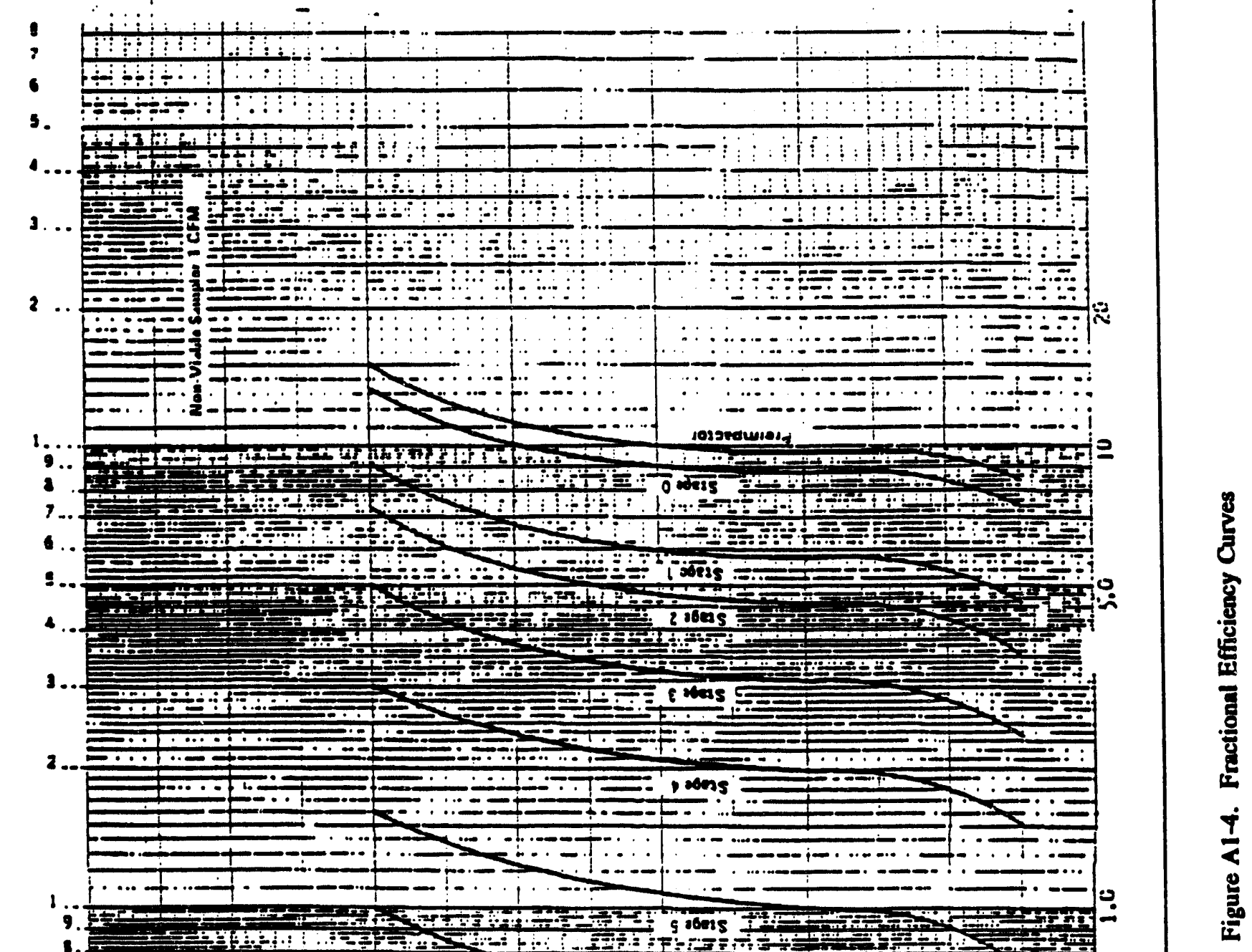


(f) Graph the results on log-probability paper with the ECD as the ordinate and the cumulative percent less than the size range by weight as the abscissa (Figure A1-5).

(g) Assuming a log-normal particle size distribution, the particle size geometric standard deviation $\sigma_{g}$ is given by:

$$
\sigma_{8}=\frac{84.13 \% \text { diameter }}{50 \% \text { diameter }}=\frac{50 \% \text { diameter }}{15.87 \% \text { diameter }}
$$

Whenever these two standard deviations are not equal (such as represented in a bimodal distribution), then the size distribution is not represented by a straight line (not really log-normal). A better method of presenting the standard deviation is:

$$
\sigma_{8}=\left(\frac{84.13 \% \text { diameter }}{15.87 \% \text { diameter }}\right)^{1 / 2}
$$

Generally, the particle size information should be presented in graphical form rather than merely reporting the mass mean diameter and the standard geometric deviation. By plotting the ECD and cumulative percent on logprobability paper, the particle concentration for any size range can be determined.

(h) From Table A1-1 and Figure A1-5, it can be seen that approximately $97 \%$ of this hypothetical sample is respirable (below $7 \mu \mathrm{m}$ ), that the mass mean diameter is $2.0 \mu \mathrm{m}$, and that the standard geometric deviation is $1.9 \mu \mathrm{m}$.

\section{Calibration}

Since the size fraction for each stage is determined by the orifice velocities, it is important that the sampler be operated at 1 ACFM. For this reason, the unit should be periodically recalibrated and whenever non-standard temperatures and pressures are encountered, calibration should be performed at the sampling conditions. Do not use rubber tubing of smaller diameter or length different than that supplied with the impactor unless the flow rate is readjusted.

Each Andersen pump is equipped with an adjustable valve. Always tighten the lock nut on the adjustment valve after the flow rate has been set. To adjust the flow, tum the screw in to increase flow and out to decrease flow. 
Comperr.

Aosication.

Penieno Size Diltribution Dald:

1. Sowe

2 Mocius ul Doterminsecan:

2 Sas:

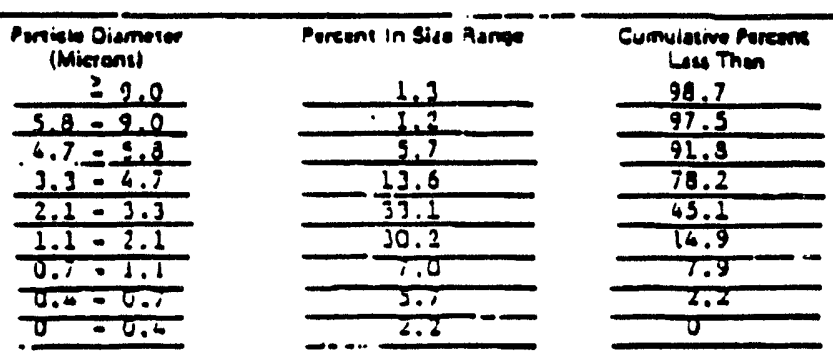

100

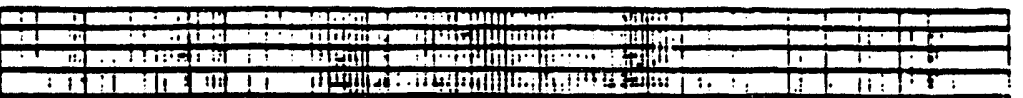

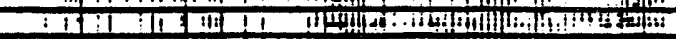
-

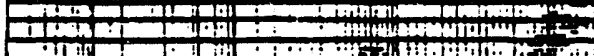

i $11, x^{2}$ !

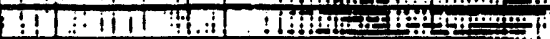

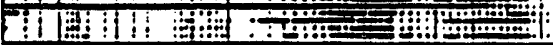

世ी! !:

It $1:$ : :

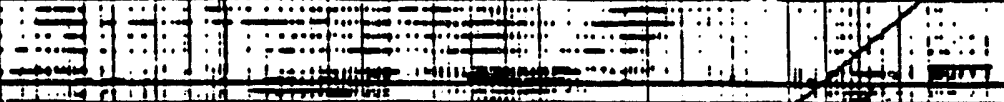

10

3

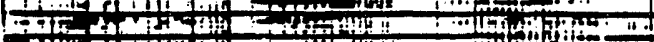

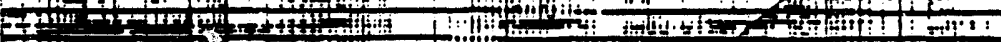

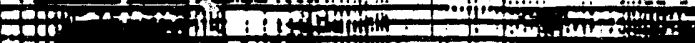

Q1.

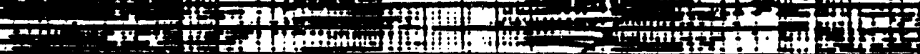

-H

T =

-

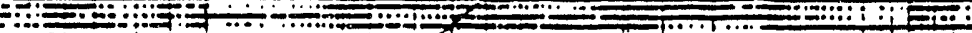

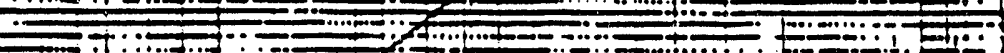

14

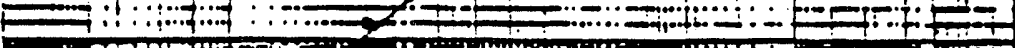

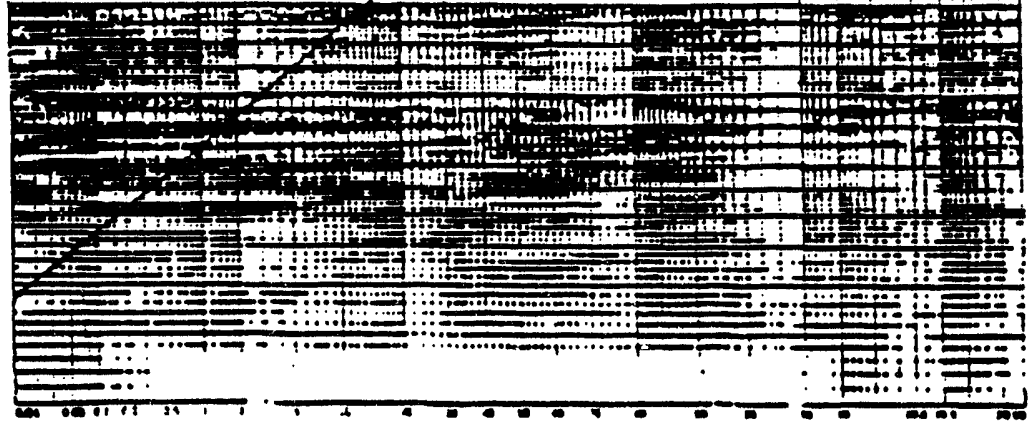

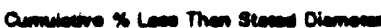

Figure A1-5. Particle Size Diameter Graph 
Each Andersen pump-impactor assembly is calibrated before shipment to deliver 1 ACFM at ambient temperature and pressure levels in Atlanta, GA. In order to recalibrate at your sampling environment, the following procedure is recommended:

Place a calibrated dry gas meter upstream from the Sampler. Attach a short 1" I.D. hose with approximately 1/4" wall to the inlet cone of the impactor and the other end to the outlet of the dry gas meter. Adjust the pump valve until you are drawing 1 ACFM over a three-minute test period as determined with an accurate stop watch. After maintaining 1 ACFM for three minutes, tighten the lock nut on the adjustment valve.

Because of the 1.4 ACFM free flow rating of the motor and pump, up to $50 \mathrm{ft}$ of tubing can be used between the Sampler and pump while still maintaining 1 ACFM through the Sampler. 
WHC-EP-0680

This page intentionally left blank.

A1-14 


\section{APPENDLX A-2}

\section{PROCUREMENT SPECIFICATIONS FOR THE LASER SPECTROMETER}

A laser spectrometer is required for use in the determination of particle loss in airborne effluent sampling and monitoring lines. This equipment will be used to measure the particle size distribution of particles entering and exiting sampling and monitoring lines. This equipment must be reasonably portable and in one unit. The following are specifications that the unit must meet.

Sample Flow Rate:

Particle Size Ranges:
Adjustable up to $1 \mathrm{cfm}$

Minimum of four size categories:

$$
\begin{aligned}
& \text { 0.3-0.5 micron, } \\
& \text { 0.5-1.0 micron, } \\
& \text { 1.0-5.0 microns, and } \\
& 5.0 \text { microns and greater }
\end{aligned}
$$

If possible, add 0.1-2.0 microns and 0.2-0.3 micron also.

Outputs:

Printer (with unit) and RS-232 port

Maximum Size:

$15^{\prime \prime}$ wide $\times 15^{n}$ deep $\times 8^{n}$ high

Maximum Weight:

40 pounds

Power:

$115 \mathrm{VAC}, 60 \mathrm{~Hz}$

Sample Time:

Adjustable from 1 second to 24 hours

Automatic and manual modes

Coincidence Errors:
Less than $5 \%$ at 100,000 particles $/ \mathrm{ft}^{2}$. 
WHC-EP-0680

This page intentionally left blank. 
WHC-EP-0680

APPENDEX A-2

MET ONE LASER PARTICLE SAIIPLER INSTRLIIENTATION DESCRIPTION

\section{INTRODUCTION}

The MET One Model A2200 Airbome Particle Counter and associated probes (A2200 System) is used to determine the size distributions of airborne particulates in the 0.1 to 5.0 micron range. The specific particle size ranges associated with this model are 0.1-0.2, $0.2-0.3,0.3-0.5,0.5-1,1-5$, and $>5$ microns.

The A2200 System is extremely sensitive at low particulate concentrations and is routinely used to verify the integrity of air filtration systems for clean rooms. It may, however, be used at concentrations of 830,000 particles $/ \mathrm{ft}^{3}$ with only a five percemt coincidence loss. Particulate concentrations downstream from HEPA filtration systems, e.g., the PUREX stack, are expected to be low and coincidence loss should be small.

Due to the extreme sensitivity of the instrument, it is able to measure particle size distributions with good counting statistics with sampling times of only several minutes. Other mass collecting samplers, such as the cascade impactor sizing systems, require weeks and months of collecting time to collect measurable amounts of airborne particles with no determination of dependency of particle concentration on environmental or process changes. Conversely, no information about material characteristics including radionuclide content may be gained during A2200 measurements. The A2200 System and mass-collecting systems, therefore, work together to provide a more comprehensive characterization of airbome particulates.

\section{COMPONENT DESCRIPTION}

The standard A2200 System consists of a laser particle counter and associated electronics, air sampling probes, humidity, temperature, and air velocity probes. The unit weighs approximately $40.4 \mathrm{lbs}$. Modifications of several of these components at the factory prior to shipment were performed to optimize the use of this instrument for stack sampling. Descriptions of A2200 components and modifications are given below:

1. A2200 Laser Particle Counter. This system contains the HeNe infrared laser, photodiode-sensor, light-scattering chamber, inlet and outiet ports for sample probes and vacuum source, flow meter, terminals and jacks for attachment of air flow, relative humidity and temperature sensors, printer, display panel and electronics associated with display, sensor, andlog functions. (See Figure A2-1). The life of the laser is estimated to be 35,000 hours.

The A2200 Laser Particle Counter's logic and display electronics allow for flexibility in the sampler's use. Any of the significant environmental or 


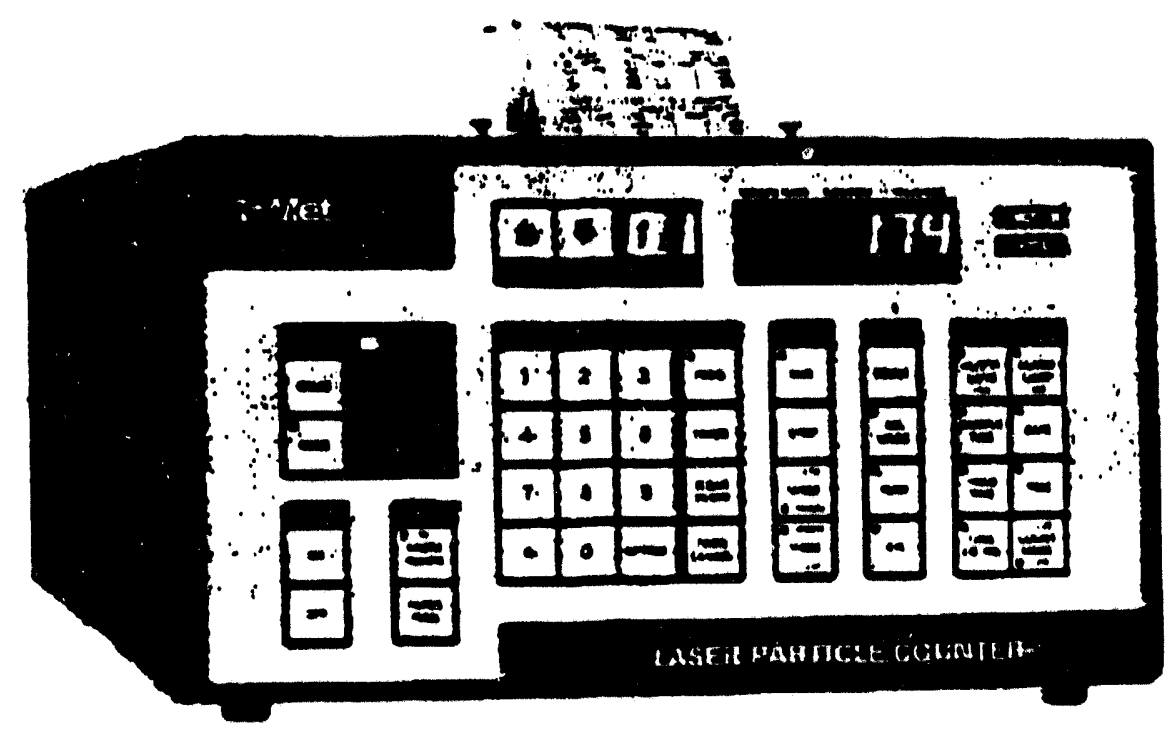

Figure A2-1. A2200 Laser Particle Counter

sampling parameters, including temperature, air velocity, humidity, sampling times and cycles, and alarm limits may be displayed by simple touch panel inputs. Particle size and corresponding counts may be displayed during sampling. Alarm conditions, indicating one or more sampling environmental parameters outside of the desired range, produce both an audible alarm and asterisks on the printed output by the specific parameter(s).

The standard A2200 Particle Counter contains a 1 CFM internal vacuum pump. The system used for PUREX stack sampling had its pump removed from the Particle counter chassis and mounted externally on a separate platform with pump relay wires and vacuum line attached to special connectors on the Particle Counter chassis. This factory modification allowed for alternate vacuum pump setups and flexibility during PUREX stack sampling.

2. Isokinetic Probe. This remote probe captures airbome particles for transport

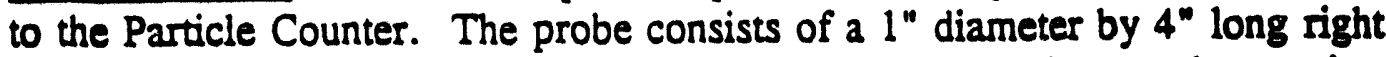
cylinder with a $1 / 8^{\prime \prime}$ concentric hole. The upstream end of the probe consists of a polished metallic nozzle which is tapered to permit isokinetic sampling at the nominal 1 CFM flow rate (see Figure A2-2). The downstream end attaches to the Laser Particle Counter with a plastic hose. The probe contains a retractable tripod stand and lockable universal joint. This probe was not used for sampling from the effluent stream, but could be used for ambient measurements. 


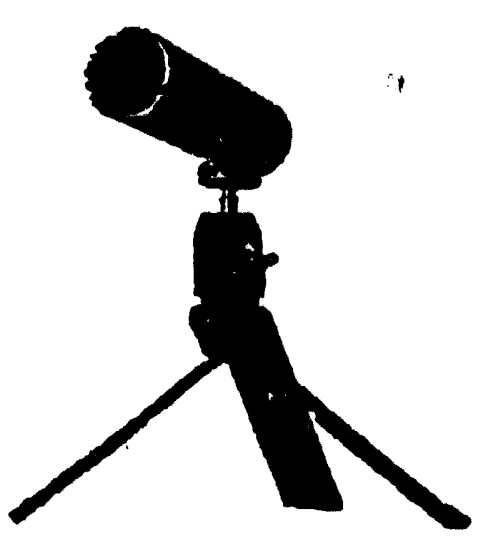

Figure A2-2. Isokinetic Probe

Jigure A2-3. Air Velocity Probe

3. Air Velocity Probes. The A2200 System normally comes with one velocity probe calibrated for a nominal 80 to $120 \mathrm{ft} / \mathrm{min}$ air flow rate designed for laminar flow hood environments. This A2200 System was factory modified to allow for attachment of a second velocity probe calibrated between 1000 and $1500 \mathrm{ft} / \mathrm{min}$ air velocity, typical of the PUREX PR Stack velocity. Both probes consist of an electrically heated wire and thermocouple on the end of a 1/4"-diameter, 2-ft-long cylindrical rod (see Figure A2-3). Cooling of the wire due to air flow is measured by the thermocouple and corresponding air velocity is calculated and displayed in the particle counter. The nominal accuracy of the standard probe is $\pm 2 \%$ at standard flow rates. The electrical cable of each probe attaches to the back of the particle counter with a multipin connector. The particle counter was modified to allow for display and printing of the additional probe.

4. Relative Humidity/Temperarure Sensor. The A2200 System allows for attachment of a relative humidity and temperature sensor. This sensor is a metal cylinder approximately $1 \mathrm{ft}$ long and 1/2" in diameter (see Figure A2-4). 


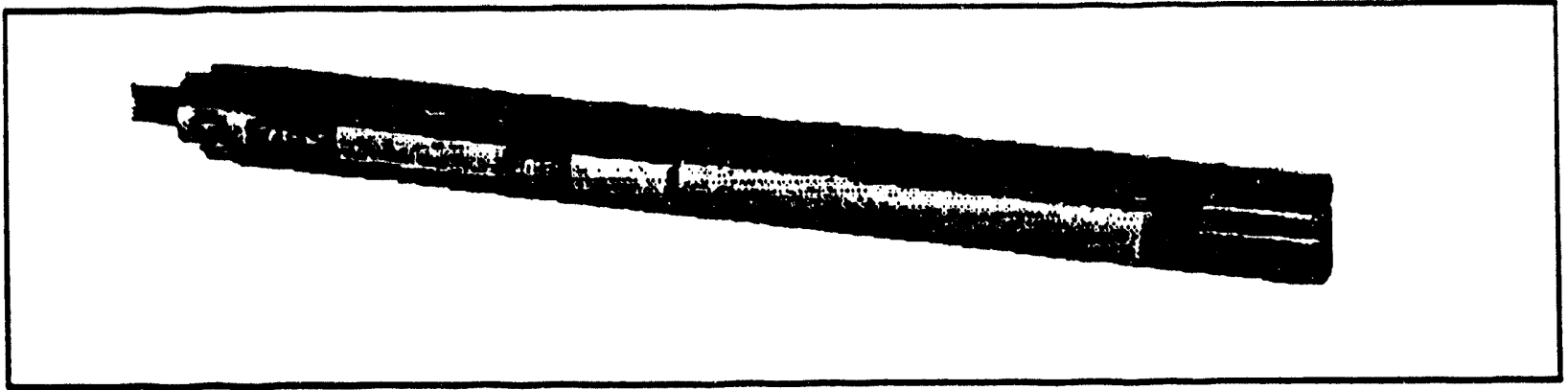

Figure A2-4. Relative Humidity/temperature sensor

The electrical cable for the probe attaches to the back of the particle counter with a multi-pin connector. The sensor has a $\pm 3 \%$ accuracy for temperature with 0 and $100^{\circ} \mathrm{F}$ and humidity within $10 \%$ and $100 \%$. 
WHC-EP-0680

APPENDIX B

W PLANS

B-1 


\section{WHC-EP-0680}

This page intentionally left blank.

\section{$B-i j$}


WHC-EP-0680

\section{APPENDIX B-1}

B1- $\mathbf{1}$ 
WHC-EP-0680

This page intentionally left blank.

$$
B 1-i j
$$


WHC-EP-0680

WORK PLAN

INSTALL AND REMOVE CASCADE IMPACTOR IN EP STACK

\section{GENERAL DESCRIPTION}

This work plan provides instructions for installing, operating, and removing a cascade impactor sampling system for the PR Stack on the roof of the PUREX Building. The impactor will be installed on the roof and will be located on a movable platform near the PR Stack. The cascade impactor system will be moved periodically to obtain a representative sample from the stack. Analys is of the impactor "filters" will provide information about the sizes of radioactive particles in the EP stream.

Both the installation and removal of this cascade impactor need to coincide as closely as possible (i.e., same day, near the same time) with the respective installation and removal of the cascade impactor discussed in Work P1 an WP-P-92-042 (Work Package 2A-92-00833).

II. PREPLANNING/COORDINATION

The organizational responsibilities are as follows:

Cognizant Effluent Engineer Function as the work plan manager, in association with SAIC personnel, with overall responsibility for coordinating the activities; technical point of contact for questions.

SAIC Personnel

PUREX Health and Safety

PUREX Maintenance
Provide cognizant effluent engineer with technical assistance and guidance for the duration of this plan. Also provide the cascade impactor system, fittirigs, sampling line, platform, and shelter.

Provide HPT coverage during the installation, moving, and removal of the impactor system. Provide mechanism to transfer cascade impactor to the Laboratory for analysis.

Support installation/removal of cascade impactor system per approved work package 2A-92-00831.

This work plan can be red-lined in the field with the appropriate approvals for the change per WHC-IP-0240, Section 4. 


\section{SAFETY.}

A. HP personnel must be present during performance of the installation and removal tasks.

B. Appropriate safety measures must be performed when relocating the equipment from the ground location to the roof and from the roof to the ground location. Personnel climbing up and down the ladder near the PR Stack must be aware of the proper methods to perform this safely per guidance from WHC Industrial Safety and WHC-CM-4-3, standards $C M-2$ and G-7. In particular:

1. Do not carry any equipment by hand up the ladders.

2. While on the canyon roof, remain within the area protected by the hand rails.

C. A pre-job safety meeting must be held.

D. All requirements of Radiation Protection Manua1, WHC-CM-4-10, and Radiation Work Requirements and Permits Manual, WHC-CM-4-15, Vol. 2 shall be followed. RWP A-045 applies to all work performed under this procedure.

\section{PLAN}

\section{A. PERFORM PRESTART CHECKS}

1. Hold a pre-job safety meeting.

Pre-job Safety Meeting Held

$$
\text { (signature) (date) }
$$

2. Ensure that the cascade impactor has been properly prepared and assembled as directed by SAIC.

3. Ensure that all supporting parts and connections are available as directed by SAIC.

4. Ensure that the vacuum pump is operational and that 1 acfm is obtainable. (SAIC/WHC)

PRESTART CHECXS COMPLETED: DATE: COGNIZANT ENGINEER:

\section{B. INSTALL CASCADE IMPACTOR SAMPLING SYSTEM}

NOTE: The installation of this cascade impactor needs to coincide as closely as possible (i.e., same day, near the same time) with the installation discussed. in Work PIan WP-P-92-042 (Work Package 2A-92-00833). Cognizant Engineer or SAIC personnel must be present before proceeding. 
NOTE: Follow the requirements of WHC-CM-4-3, Standard M-2. Do not handcarry anything on the ladders.

\section{WARNING}

DO NOT APPROACH THE EDGE OF THE ROOF AWAY FROM A HAND RAIL

1. Relocate equipment from ground level to canyon roof. (WHC)

a. Ensure that the following pieces of equipment/supplies are properly protected before relocating items to the roof:
(1) Impactor
(2) Flowmeter
(3) Vacuum Gauge
(4) Vacuum Pump
(5) Tubing
(6) Connectors
(7) Heating Tape/Sheath with Controller
(8) Platform
(9) Shelter
(10) Extension Cords
(11) Power Bar.

b. Transport equipment to the roof of $202 \mathrm{~A}$ near the PR stack.

2. Set up sampling system per SAIC guidance/ instructions.

a. Place appropriate equipment on the platform and make connections from the cascade impactor to the flowmeter, from the flowmeter to the vacuum gauge, and from the vacuum gauge to the vacuum pump per figure 1.

b. Field check equipment performance.

c. Locate equipment in proper location on the platform. Refer to Figure 1.

d. Prepare set-up for operation by securing all equipment to the platform and verify that all connections made to this point are secure.

3. Penetrate the PR stack with the sampling probe using the $1 / 2^{\prime \prime}$-hole located approximately $10^{\prime \prime}$ above the roof level. (WHC/SAIC)

4. Connect the sampling probe to the cascade impactor per Figure 1. (WHC) 
5. Initiate the cascade impactor sample. (SAIC)

a. Determine the appropriate correction factor for the in-line flowmeter using Table I.

b. Set the proper flow rate using Table II.

c. Record the day of the week under WEEK DAY STARTED on DATA SHEET.

d. Record the date and time the sample was initiated, and initial DATA SHEET.

6. Position and secure the shelter over the sampling system. (WHC)

INSTALLATION COMPLETED: DATE: COGNIZANT ENGINEER:

c. PERIODICALLY CHANGE LOCATION OF THE SAMPLE PROBE IN THE PR STACK ACCORDING TO THE SCHEDULE AND DESCRIPTION IN TABLE III. (SAIC/WHC)

NOTE: A continuous sample will be obtained using nine different locations in the PR Stack. The probe shall be moved to the specific locations inside the stack in the order listed in this procedure. This way, the probe will be inserted farther into the stack until the last position has been used. The probe will not be removed until all 9 samples have been obtained. Sample numbers corresponding to the sample locations have been pre-marked on the sample probe.

1. After the number of days specified on the DATA SHEET, move the probe to the next position listed on DATA SHEET.

2. Record on the DATA SHEET the date and time the probe was moved.

3. Initial the DATA SHEET.

SAMPLING COMPLETED: DATE/TIME:

COGNIZANT ENGINEER:

D. REMOVE CASCADE IMPACTOR SYSTEM

NOTE: The removal of this cascade impactor needs to coincide as closely as possible (i.e., same day, near the same time) with the removal discussed in Work P1 an WP-P-92-042 (Work Package 2A-92-00833).

NOTE: This operation will occur 10 weeks after the installation and will be directed by SAIC.

$$
\text { B1-4 }
$$




$$
\begin{array}{r}
\text { WHC-EP-0680 One Time Work Plan WP-P-92-041 } \\
\text { Page } 5 \text { of } 10
\end{array}
$$

1. Remove the shelter from the sampling system. (WHC)

2. Stop the cascade impactor sample. (SAIC)

3. Disconnect the sampling probe from the cascade impactor. (WHC)

* HP Hold Point **

4. Remove the sample probe from the PR stack. Wipe the probe as it is removed from the stack.

Sample probe wiped down an smearable contamination is < detectable (Initial/Date)

5. Bag or wrap the probe in plastic. (WHC/SAIC)

6. Remove the cascade impactor from the sampling system and bag it. (WHC)

7. Dismantle sampling system. (SAIC/WHC)

a. Survey equipment on the platform. (WHC)

b. Remove equipment from the platform. (WHC/SAIC)

c. Bag or package selected pieces of equipment as necessary per HPT direction. (WHC)

NOTE: Follow all Hoisting and Rigging requirements per WHC-CM-6-4 and WHC-CM-4-3, Standard $M-2$. Do not hand-carry anything on the ladders.

\section{$\overline{\text { WARNING }}$}

DO NOT APPROACH THE EDGE OF THE ROOF AWAY FROM A HAND RAIL.

8. Relocate equipment from roof to ground level. (WHC)

NOTE: The following two steps may be performed in any order

9. Store equipment as required. (WHC) 
** HP Hold Point **

10. Request HPT to survey impactor and sampling probe (as packaged), prepare them for transport, and transport them to the Laboratory. (WHC)

Impactor and Sample Probe surveyed and < detectable (initial/date)

SYSTEM REMOVAL COMPLETED: DATE: SAIC REPRESENTATIVE: 


WHC-EP-0680 Cne Time Work Plan WP-P-92-041
Page 7 of 10

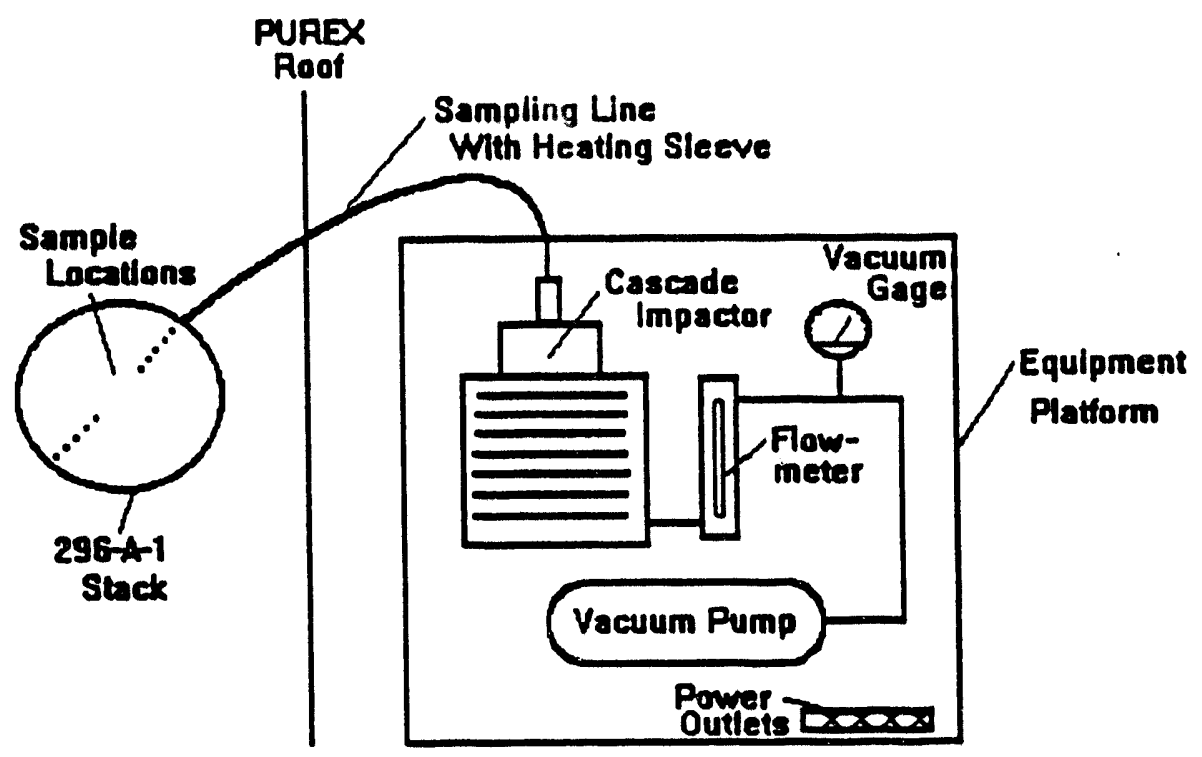

Figure 1. Cascade Impactor Set-Up for the PR Stack (Roof Sample) B1-7 
WHC-EP-0680 One Time Work Plan WP-P-92-041
Page 8 of 10

Table 1. Correction Factors Required for In-Line

Flowmeter Readings due to Vacuum

\begin{tabular}{||l|l|}
\hline Vacuun ("Hg) & $\begin{array}{c}\text { Flowmater } \\
\text { Correction } \\
\text { Factor }\end{array}$ \\
\hline 0.25 & 1.004 \\
0.50 & 1.008 \\
0.75 & 1.013 \\
1.00 & 1.017 \\
1.25 & 1.022 \\
1.50 & 1.026 \\
1.75 & 1.031 \\
2.00 & 1.035 \\
2.25 & 1.040 \\
2.50 & 1.045 \\
2.75 & 1.049 \\
3.00 & 1.054 \\
3.25 & 1.059 \\
3.50 & 1.064 \\
3.75 & 1.069 \\
4.00 & 1.074 \\
4.25 & 1.080 \\
4.50 & 1.085 \\
4.75 & 1.090 \\
5.00 & 1.096 \\
5.25 & 1.101 \\
5.50 & 1.107 \\
5.75 & 1.113 \\
6.00 & 1.118 \\
6.25 & 1.124 \\
6.50 & 1.130 \\
6.75 & 1.136 \\
7.00 & 1.143 \\
7.25 & 1.149 \\
7.50 & 1.155 \\
7.75 & 1.162 \\
8.00 & 1.168 \\
8.25 & 1.175 \\
8.50 & 1.182 \\
8.75 & 1.189 \\
9.00 & 1.196 \\
9.25 & 1.203 \\
9.50 & 1.210 \\
9.75 & 1.218 \\
10.00 & 1.226 \\
\hline & \\
\hline & \\
\hline
\end{tabular}

B1-8 
WHC-EP-0680 One Time Work PI an WP-P-92-041
Page 9 of 10

Table 11. Brooks Flowmeter (Model R-615-B, Carboloy, Spherical Ball) Calibration Data

\begin{tabular}{|c|c|c|c|c|c|c|c|}
\hline $\begin{array}{l}\text { Tube } \\
\text { Reading } \\
\text { (Im) }\end{array}$ & $\begin{array}{l}\text { Flow } \\
\text { Rate } \\
\text { (cfill) }\end{array}$ & $\begin{array}{l}\text { Tube } \\
\text { Reading }\end{array}$ & $\begin{array}{l}\text { Flow } \\
\text { Rate }\end{array}$ & $\begin{array}{c}\text { Tube } \\
\text { Reading }\end{array}$ & $\begin{array}{l}\text { Flow } \\
\text { Rate }\end{array}$ & $\begin{array}{l}\text { Tube } \\
\text { Reading } \\
\text { (mil) }\end{array}$ & $\begin{array}{l}\text { Flow } \\
\text { Rate }\end{array}$ \\
\hline $\begin{array}{l}150.0 \\
149.0 \\
148.0 \\
147.0 \\
146.0 \\
145.0 \\
144.0 \\
143.0 \\
142.0 \\
141.0 \\
140.0 \\
139.0 \\
138.0 \\
137.0 \\
136.0 \\
135.0 \\
134.0 \\
133.0 \\
132.0 \\
131.0 \\
130.0 \\
129.0 \\
128.0 \\
127.0 \\
126.0 \\
125.0 \\
124.0 \\
123.0 \\
122.0 \\
121.0 \\
120.0 \\
119.0 \\
118.0 \\
117.0 \\
116.0 \\
115.0 \\
114.0 \\
113.0 \\
112.0 \\
111.0\end{array}$ & $\begin{array}{l}2.160 \\
1.142 \\
2.123 \\
2.105 \\
2.086 \\
2.068 \\
2.049 \\
2.031 \\
2.013 \\
1.995 \\
1.977 \\
1.960 \\
1.942 \\
1.925 \\
1.908 \\
1.891 \\
1.875 \\
1.860 \\
1.844 \\
1.829 \\
1.813 \\
1.798 \\
1.783 \\
1.767 \\
1.752 \\
1.736 \\
1.721 \\
1.705 \\
1.689 \\
1.673 \\
1.656 \\
1.640 \\
1.624 \\
1.607 \\
1.591 \\
1.574 \\
1.558 \\
1.541 \\
1.525 \\
1.509\end{array}$ & $\begin{array}{l}110.0 \\
109.0 \\
108.0 \\
107.0 \\
106.0 \\
105.0 \\
104.0 \\
103.0 \\
102.0 \\
101.0 \\
100.0 \\
99.0 \\
98.0 \\
97.0 \\
96.0 \\
95.0 \\
94.0 \\
93.0 \\
92.0 \\
91.0 \\
90.0 \\
89.0 \\
88.0 \\
87.0 \\
86.0 \\
85.0 \\
84.0 \\
83.0 \\
82.0 \\
81.0 \\
80.0 \\
79.0 \\
78.0 \\
77.0 \\
76.0 \\
75.0 \\
74.0 \\
73.0 \\
72.0 \\
71.0\end{array}$ & $\begin{array}{l}1.493 \\
1.477 \\
1.461 \\
1.446 \\
1.430 \\
1.416 \\
1.401 \\
1.387 \\
1.373 \\
1.359 \\
1.345 \\
1.331 \\
1.317 \\
1.303 \\
1.289 \\
1.274 \\
1.260 \\
1.245 \\
1.230 \\
1.215 \\
1.199 \\
1.183 \\
1.167 \\
1.151 \\
1.134 \\
1.118 \\
1.102 \\
1.085 \\
1.069 \\
1.053 \\
1.036 \\
1.020 \\
1.005 \\
0.989 \\
0.974 \\
0.959 \\
0.944 \\
0.929 \\
0.915 \\
0.900\end{array}$ & $\begin{array}{l}70.0 \\
69.0 \\
68.0 \\
67.0 \\
66.0 \\
65.0 \\
64.0 \\
63.0 \\
62.0 \\
61.0 \\
60.0 \\
59.0 \\
58.0 \\
57.0 \\
56.0 \\
55.0 \\
54.0 \\
53.0 \\
52.0 \\
51.0 \\
50.0 \\
49.0 \\
48.0 \\
47.0 \\
46.0 \\
45.0 \\
44.0 \\
43.0 \\
42.0 \\
41.0 \\
40.0 \\
39.0 \\
38.0 \\
37.0 \\
36.0 \\
35.0 \\
34.0 \\
33.0 \\
32.0 \\
31.0\end{array}$ & $\begin{array}{l}0.886 \\
0.872 \\
0.857 \\
0.843 \\
0.829 \\
0.815 \\
0.801 \\
0.787 \\
0.772 \\
0.758 \\
0.744 \\
0.730 \\
0.716 \\
0.702 \\
0.689 \\
0.675 \\
0.661 \\
0.647 \\
0.634 \\
0.620 \\
0.606 \\
0.593 \\
0.579 \\
0.566 \\
0.553 \\
0.539 \\
0.526 \\
0.513 \\
0.500 \\
0.487 \\
0.475 \\
0.462 \\
0.449 \\
0.436 \\
0.423 \\
0.411 \\
0.398 \\
0.385 \\
0.373 \\
0.360\end{array}$ & $\begin{array}{r}30.0 \\
29.0 \\
28.0 \\
27.0 \\
26.0 \\
25.0 \\
24.0 \\
23.0 \\
22.0 \\
21.0 \\
20.0 \\
19.0 \\
18.0 \\
17.0 \\
16.0 \\
15.0 \\
14.0 \\
13.0 \\
12.0 \\
11.0 \\
10.0 \\
9.0 \\
8.0 \\
7.0 \\
6.0 \\
5.0\end{array}$ & $\begin{array}{l}0.347 \\
0.335 \\
0.323 \\
0.310 \\
0.298 \\
0.286 \\
0.273 \\
0.261 \\
0.249 \\
0.237 \\
0.225 \\
0.213 \\
0.201 \\
0.189 \\
0.177 \\
0.166 \\
0.154 \\
0.143 \\
0.131 \\
0.120 \\
0.109 \\
0.097 \\
0.086 \\
0.075 \\
0.063 \\
0.052\end{array}$ \\
\hline
\end{tabular}


WHC-EP-0680 One Time Work P1 an WP-P-92-041
Page 10 of 10

DATA SHEET

\begin{tabular}{|c|c|c|c|c|}
\hline \multirow[b]{2}{*}{$\begin{array}{l}\text { Sample } \\
\text { Number }\end{array}$} & \multirow[b]{2}{*}{$\begin{array}{l}\text { Location } \\
\text { Inside Stack }\end{array}$} & \multirow{2}{*}{$\begin{array}{c}\text { Week Day Started: } \\
\begin{array}{c}\text { Sampling Period } \\
\text { (days) }\end{array}\end{array}$} & \multicolumn{2}{|c|}{$\begin{array}{c}\text { Initial and Record Date and } \\
\text { Time as Each Sample is } \\
\text { Started }\end{array}$} \\
\hline & & & Initials & Date/Time \\
\hline 1 & $21 / 4^{\prime \prime}$ & 14 & & \\
\hline 2 & $31 / 2^{n}$ & 7 & & \\
\hline 3 & $51 / 2^{n}$ & 7 & & \\
\hline 4 & $81 / 4^{n}$ & 7 & & \\
\hline 5 & $153 / 4^{n}$ & 7 & & \\
\hline 6 & $181 / 2^{\prime \prime}$ & 7 & & \\
\hline 7 & $201 / 2^{\circ}$ & 7 & & \\
\hline 8 & $22^{\prime \prime}$ & 7 & & \\
\hline 9 & $233 / 8^{n}$ & 7 & & \\
\hline
\end{tabular}


WHC-EP-0680

APPENDIX B-2

$B 2-i$ 
WHC-EP-0680

This page intentionally left blank. 
WHC-EP-0680

One Time Work Plan WP-P-92-042

Page 1 of 10

WORK PLAN

INSTALL AND REMOVE CASCADE IMPACTOR FOR EP CAM SAMPLER

\section{GENERAL DESCRIPTION}

This work plan provides instructions for installing and removing a cascade impactor sampling system in parallel to the PR Stack CAM sampler. The impactor will be installed in the 292-AA building on one leg of the CAM flow splitter and will use existing vacuum to provide flow through the unit. Operation of the CAM and record sampler will continue while the cascade impactor is in use. Analysis of the data will provide particle size distribution information on effluent particulates.

Both the installation and removal of this cascade impactor need to coincide as closely as possible (i.e., same day, near the same time) with Work P1 an WP-P-92-041 (Work Package 2A-92-0831)

II. PREPLANNING/COORDINATION

The organizational responsibilities are as follows:

Cognizant Effluent Engineer - Function as the work plan manager, in association with SAIC personnel, with overall responsibility for coordinating the activities; technical point of contact for questions.

SAIC Personnel

PUREX Health and Safety

PUREX Maintenance
Provide cognizant effluent engineer with technical assistance and guidance for the duration of this plan. Also provide the cascade impactor system and fittings.

Provide HPT coverage during the installation and removal of the cascade impactor system. Also provide mechanism to transfer impactor to the laboratory for analysis.

- Support installation/removal of cascade impactor per approved work package \#2A-92-00833.

This work plan can be red-lined in the field with the appropriate approvals for the change per WHC-IP-0240, Section 4 . 


\section{SAFETY}

A. Limiting condition for Operation (LCO) 12.6 .3 requires operability of the sampling and monitoring systems on the 296-A-1 stack.

Ensure the record sample loop operation is not interrupted and CAM monitor downtime is minimized. An HPT must be present during performance of the installation/removal tasks.

B. Al1 requirements of Radiation Protection Manua1, WHC-CM-4-10, and Radiation Work Requirements and Permits Manual, WHC-CM-4-15, Vol. 2 shall be followed. RWP A-045 applies to all work performed under this procedure.

IV. PLAN

A. PERFORM PRESTART CHECKS

1. Hold a Pre-Job Safety Meeting.

$$
\text { (signature) (date) }
$$

2. Ensure that the cascade impactor has been properly prepared and assembled. (SAIC)

3. Ensure that all supporting parts and connections are available.

4. Ensure that the stack alpha monitor RAN-V29A-1-1 is operating properly.

5. Notify PUREX Health and Safety Supervisor and the Operating Shift Supervisor that RAN-V29A-1-1 will be taken out of service during the cascade impactor installation, and that the flow rate will be reduced for the next ten weeks.

6. Ensure pump P-V28A-1 is running.

NOTE - Step 7 will be performed with the assistance of the cognizant engineer, based on the stack flow rate and the design of the sample probe.

7. Determine flow required to maintain isokinesis through sample probe.

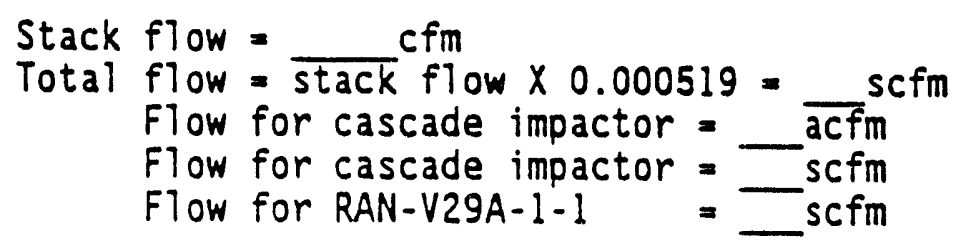

$B 2-2$ 
8. Calculate new monitor alarm set point using new monitor flow determined in step 7 above.

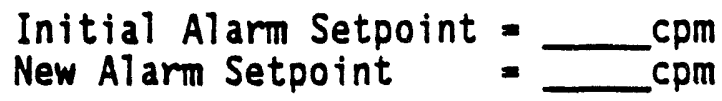

9. Install tag stating setpoint and monitor flow.

10. Notify the cognizant engineer, Operations Supervisor, and Health and Safety Supervisor that the monitor flow rate has been reduced and will remain at the new levels for approximately ten weeks.

PRESTART CHECKS COMPLETED: DATE COGNIZANT ENGINEER

B. INSTALL CASCADE IMPACTOR

NOTE - This plan involves the bothil the installation and removal of the cascade impactor. The time between the two operations

will be approximately ten weeks. Both the installation and the removal of this cascade impactor need to coincide as closely as possible (i.e., same day, near the same time) with the respective installation and removal in Work Plan WP-P-92-041 (Work Package 2A-92-0831). The cognizant engineer and SAIC personnel must be present before proceeding.

** HP Hold Point **

1. Notify PUREX dispatcher that there will be a low flow alarm on FA-V29A-3-1.

Dispatcher Notified (Initial/Date)

2. OPEN regulator FCV -V29A-1-1 and obtain flow rate determined in task A.7. Maintain flow for 10 minutes.

3. CLOSE VaTVe MV-V28A-5-3.

NOTE: As of July 1, MV-V28A-5-15 did not have an attached metal tag. It did have an adhesive plastic label, which stated MV/V29A/5/15.

4. Remove valve MV-V28A-5-15 and its associated tee per Figure 2. 
WHC-EP-0680

One Time Work Plan WP-P-92-042

Page 4 of 10

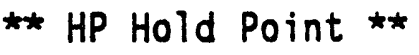

5. Survey MV-V28A-5-15 for smearable contamination.

Valve Surveyed (Initial/Date)

Survey Results

6. Place MV-V28A-5-15 plastic bag.

NOTE - Tubing supports may be loosened to provide free movement and space for connections.

7. Install impactor supports for impactor system.

8. Connect cascade impactor system in place of tee.

NOTE - Experience has shown that two pumps are needed to obtain sufficient vacuum.

9. Activate Pump P-V29A-1:

a. Energize Pump P-y29-A-1 using MS-V29A-4-4

b. Adjust valves in the following sequence:

MV-29A-5-1 OPEN

$M V-29 A-5-2$ OPEN

** HP Hold Point **

10. OPEN Valve MV-V28A-5-3 and adjust regulators FCV-V29A-2-1 and FCV-V29A-1-1 to obtain the flow values determined in Task $A$, step 6 .

Regulators Adjusted (Initial/Date)

Flow for cascade impactor:

Flow for RAN-V29A-1-1:

** HP Hold Point **

11. Adjust alpha monitor alarm to value determined in Task A, step 8.

INSTALLATION COMPLETED: DATE COGNIZANT ENGINEER 
WHC-EP-0680

One Time Work Plan WP-P-92-042

Page 5 of 10

C. REMOVE CASCADE IMPACTOR

NOTE - As noted in Task B above, this operation will occur approximately ten weeks after the installation.

** HP Hold Point **

1. Notify PUREX dispatcher that there will be a low flow alarm on FA-V29A-3-1.

Dispatcher Notified (Initial/Date):

2. If it is running, turn off pump $P-V 29 A-1$ :

a. Adjust valves in the following sequence:

MV-29A-5-2 CLOSE

MV-29A-5-1 CLOSE

b. De-energize Pump P-V29-A-1 using MS-V29A-4-4.

3. CLOSE valve MV-V28A-5-3.

4. Remove cascade impactor system.

IMPACTOR SYSTEM REMOVED: DATE TIME

INITIAL

5. Replace valve MV-V28A-5-15 and its associated tee removed in task $B$, step 4 .

NOTE - Tighten tubing supports loosened in task $B$.

6. CLOSE regulator FCV-V29A-1-1.

7. OPEN Valve MV-V28A-5-3.

** HP Hold Point **

8. Adjust regulator FCV-V29A-2-1 to maintain isokinetic flow through RAN-V29A-1-1.

Flow Rate: (Initial/Date)

** HP Hold Point **

9. Readjust monitor alarm set point to the original setpoint recorded in Task $A$, step 8 .

(Initial/Date)

B2-5 
** HP Hold Point **

10. Survey the work area and cascade impactor.

Survey Results:

(Initial/Date)

11. Prepare the cascade impactor for transport, and transport it to the laboratory for analysis.

12. Clean up work area.

IMPACTOR DELIVERED TO LABORATORY: DATE

SAIC Representative 
WHC-EP-CCSO

One Time Work Plan WP-P-92-042

Page 7 of 10

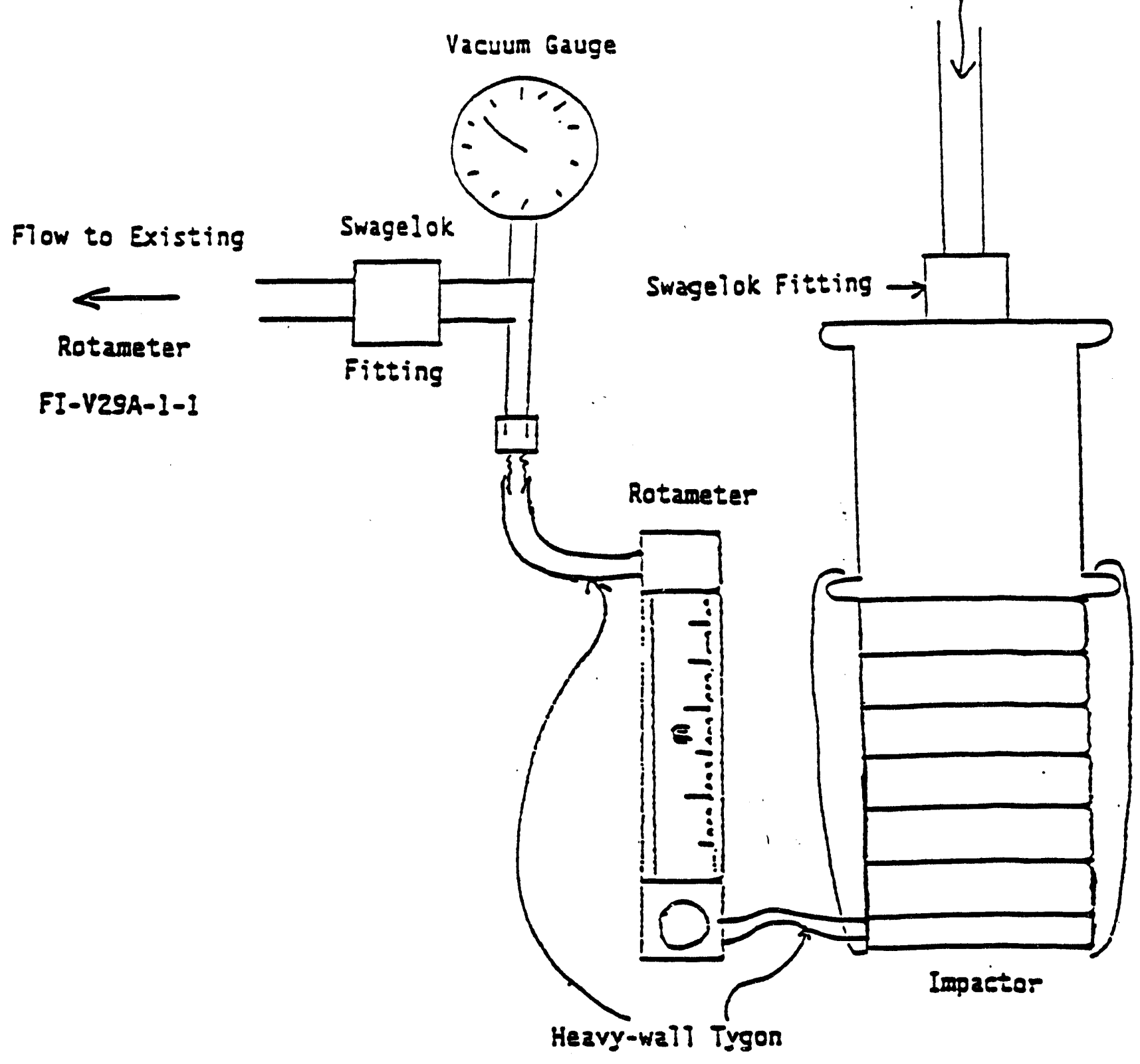

Figure 1. Cascade Impactor System Used to Sample from the CaM Sampling Line 
WHC-EP-0680

On= Time work Plan WP-P-92-042

Page 8 of 10

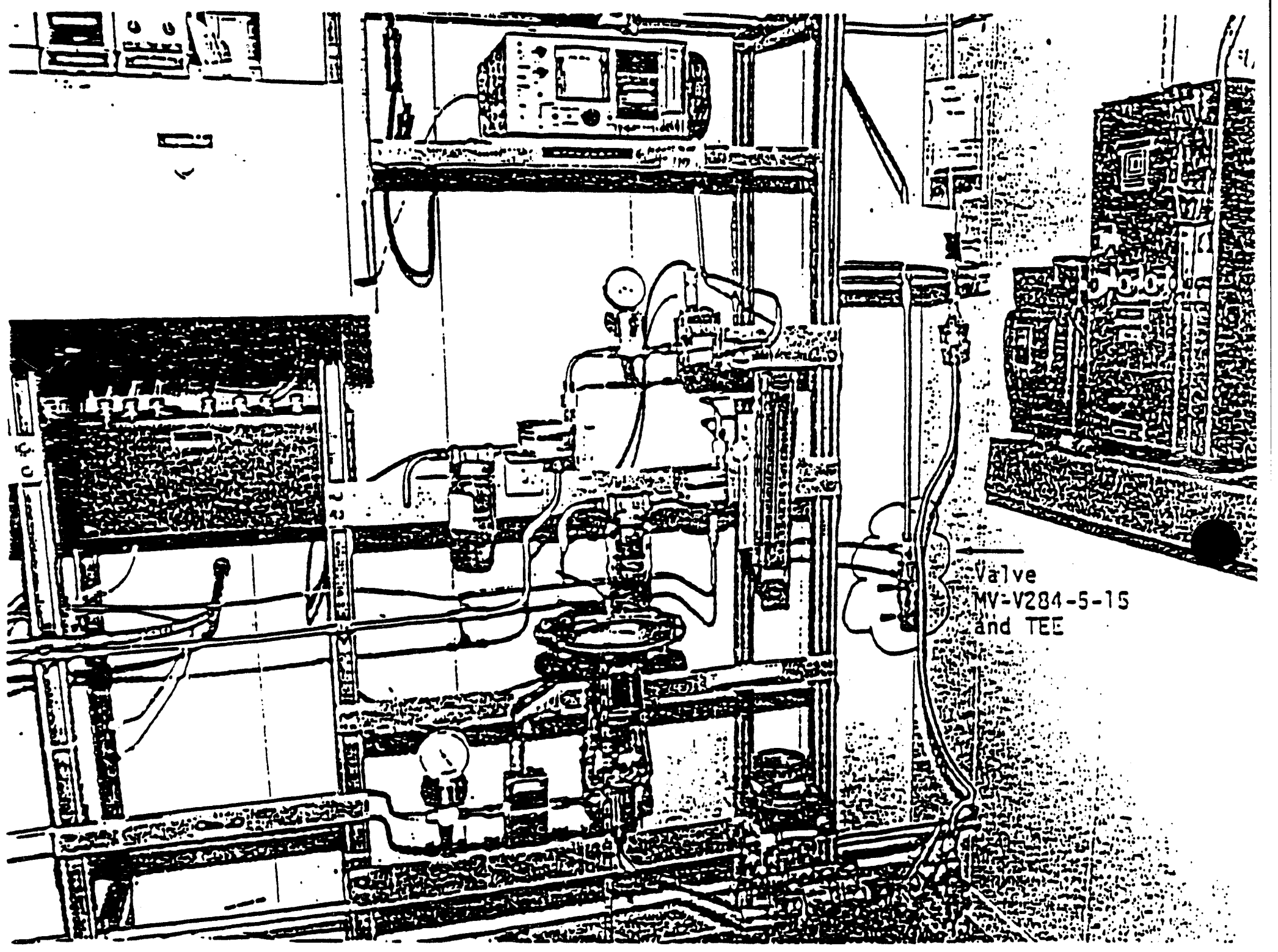

Figure 2. Current Effluent Sampling and Monitoring Systems for the PR Stack 
Table 1. Correction Factors Required for In-Line Flowmeter Readings due to Vacuum

\begin{tabular}{|c|c|c|c|c|c|}
\hline $\begin{array}{l}\text { Vacuu } \\
\left({ }^{\circ} \mathrm{Hg}\right)\end{array}$ & $\begin{array}{c}\text { Flowater Correction } \\
\text { Factor }\end{array}$ & $\begin{array}{l}\text { Vacuug } \\
\left({ }^{\circ} \mathrm{Hg}\right)\end{array}$ & $\begin{array}{c}\text { Flominter Correction } \\
\text { Factor }\end{array}$ & $\begin{array}{l}\text { Vacuum } \\
(\sim \mathrm{Hg})\end{array}$ & $\begin{array}{c}\text { Flometer Correction } \\
\text { Factor }\end{array}$ \\
\hline $\begin{array}{l}0.1 \\
0.2 \\
0.3 \\
0.4 \\
0.5 \\
0.6 \\
0.7 \\
0.8 \\
0.9 \\
1.0 \\
1.1 \\
1.2 \\
1.3 \\
1.4 \\
1.5 \\
1.6 \\
1.7 \\
1.8 \\
1.9 \\
2.0 \\
2.1 \\
2.2 \\
2.3 \\
2.4 \\
2.5 \\
2.6 \\
2.7 \\
2.8 \\
2.9 \\
3.0 \\
3.1 \\
3.2 \\
3.3 \\
3.4 \\
3.5 \\
3.6 \\
3.7 \\
3.8 \\
3.9 \\
4.0 \\
4.1 \\
4.2 \\
4.3 \\
4.4 \\
4.5 \\
4.6 \\
4.7 \\
4.8 \\
4.9 \\
5.0 \\
5.1 \\
5.2 \\
5.3 \\
5.4 \\
5.5 \\
5.6 \\
5.7 \\
5.8 \\
5.9\end{array}$ & $\begin{array}{l}1.002 \\
1.003 \\
1.005 \\
1.007 \\
1.008 \\
1.010 \\
1.012 \\
1.014 \\
1.015 \\
1.017 \\
1.019 \\
1.021 \\
1.022 \\
1.024 \\
1.026 \\
1.028 \\
1.030 \\
1.032 \\
1.033 \\
1.035 \\
1.037 \\
1.039 \\
1.041 \\
1.043 \\
1.045 \\
1.047 \\
1.048 \\
1.050 \\
1.052 \\
1.054 \\
1.056 \\
1.058 \\
1.060 \\
1.062 \\
1.064 \\
1.066 \\
1.068 \\
1.070 \\
1.072 \\
1.074 \\
1.076 \\
1.079 \\
1.081 \\
1.083 \\
1.085 \\
1.087 \\
1.089 \\
1.091 \\
1.094 \\
1.096 \\
1.098 \\
1.100 \\
1.102 \\
1.105 \\
1.107 \\
1.109 \\
1.111 \\
1.114 \\
1.116 \\
\end{array}$ & $\begin{array}{r}6.0 \\
6.1 \\
6.2 \\
6.3 \\
6.4 \\
6.5 \\
6.6 \\
6.7 \\
6.8 \\
6.9 \\
7.0 \\
7.1 \\
7.2 \\
7.3 \\
7.4 \\
7.5 \\
7.6 \\
7.7 \\
7.8 \\
7.9 \\
8.0 \\
8.1 \\
8.2 \\
8.3 \\
8.4 \\
8.5 \\
8.6 \\
8.7 \\
8.8 \\
8.9 \\
9.0 \\
9.1 \\
11.4 \\
11.4 \\
11.8 \\
11.9 \\
\end{array}$ & $\begin{array}{l}1.118 \\
1.121 \\
1.123 \\
1.125 \\
1.128 \\
1.130 \\
1.133 \\
1.135 \\
1.138 \\
1.140 \\
1.143 \\
1.145 \\
1.148 \\
1.150 \\
1.153 \\
1.155 \\
1.158 \\
1.160 \\
1.163 \\
1.166 \\
1.168 \\
1.171 \\
1.174 \\
1.176 \\
1.179 \\
1.182 \\
1.185 \\
1.187 \\
1.190 \\
1.193 \\
1.196 \\
1.199 \\
1.202 \\
1.205 \\
1.208 \\
1.210 \\
1.213 \\
1.216 \\
1.219 \\
1.222 \\
1.226 \\
1.229 \\
1.232 \\
1.235 \\
1.238 \\
1.241 \\
1.244 \\
1.248 \\
1.251 \\
1.254 \\
1.258 \\
1.261 \\
1.264 \\
1.268 \\
1.271 \\
1.274 \\
1.278 \\
1.281 \\
1.285 \\
1.289 \\
\end{array}$ & $\begin{array}{l}12.0 \\
12.1 \\
12.2 \\
12.3 \\
12.4 \\
12.5 \\
12.6 \\
12.7 \\
12.8 \\
12.9 \\
13.0 \\
13.1 \\
13.2 \\
13.3 \\
13.4 \\
13.5 \\
13.6 \\
13.7 \\
13.8 \\
13.9 \\
14.0 \\
14.1 \\
14.2 \\
14.3 \\
14.4 \\
14.5 \\
14.6 \\
14.7 \\
14.8 \\
14.9 \\
15.0 \\
15.1 \\
15.2 \\
15.3 \\
15.4 \\
15.5 \\
15.6 \\
15.7 \\
15.8 \\
15.9 \\
16.0 \\
16.1 \\
16.2 \\
16.3 \\
16.4 \\
16.5 \\
16.6 \\
16.7 \\
16.8 \\
16.9 \\
17.0 \\
17.1 \\
17.2 \\
17.3 \\
17.4 \\
17.5 \\
17.6 \\
17.7 \\
17.8 \\
17.9\end{array}$ & $\begin{array}{l}1.292 \\
1.296 \\
1.299 \\
1.303 \\
1.307 \\
1.311 \\
1.314 \\
1.318 \\
1.322 \\
1.326 \\
1.330 \\
1.334 \\
1.338 \\
1.342 \\
1.346 \\
1.350 \\
1.354 \\
1.358 \\
1.362 \\
1.367 \\
1.371 \\
1.375 \\
1.380 \\
1.384 \\
1.388 \\
1.393 \\
1.397 \\
1.402 \\
1.407 \\
1.411 \\
1.416 \\
1.421 \\
1.426 \\
1.431 \\
1.435 \\
1.440 \\
1.445 \\
1.451 \\
1.456 \\
1.461 \\
1.466 \\
1.471 \\
1.477 \\
1.482 \\
1.488 \\
1.493 \\
1.499 \\
1.504 \\
1.510 \\
1.516 \\
1.522 \\
1.528 \\
1.534 \\
1.540 \\
1.546 \\
1.552 \\
1.558 \\
1.565 \\
1.571 \\
1.578\end{array}$ \\
\hline
\end{tabular}


Table II. Brooks Flowmeter (Model R-615-B, Carboloy, Spherical Ball) Calibration Data

\begin{tabular}{|c|c|c|c|c|c|c|c|}
\hline $\begin{array}{c}\text { Tube Randing } \\
\text { (n) }\end{array}$ & $\begin{array}{c}\text { Fow Rate } \\
\text { (cfin) }\end{array}$ & Tube Reading & Flow Rate & Tube Reading & Fow Rate & $\begin{array}{c}\text { Tube Reading } \\
\text { (nim) }\end{array}$ & Flow Rate \\
\hline $\begin{array}{l}150.0 \\
149.0 \\
148.0 \\
147.0 \\
146.0 \\
145.0 \\
144.0 \\
143.0 \\
142.0 \\
141.0 \\
140.0 \\
139.0 \\
138.0 \\
137.0 \\
136.0 \\
135.0 \\
134.0 \\
133.0 \\
132.0 \\
131.0 \\
130.0 \\
129.0 \\
128.0 \\
127.0 \\
126.0 \\
125.0 \\
124.0 \\
123.0 \\
122.0 \\
121.0 \\
120.0 \\
119.0 \\
118.0 \\
117.0 \\
116.0 \\
115.0 \\
114.0 \\
113.0 \\
112.0 \\
111.0\end{array}$ & $\begin{array}{l}2.160 \\
1.142 \\
2.123 \\
2.105 \\
2.086 \\
2.068 \\
1.049 \\
2.031 \\
2.013 \\
1.995 \\
1.977 \\
1.960 \\
1.942 \\
1.925 \\
1.908 \\
1.891 \\
1.875 \\
1.860 \\
1.844 \\
1.829 \\
1.813 \\
1.798 \\
1.783 \\
1.767 \\
1.752 \\
1.736 \\
1.721 \\
1.705 \\
1.689 \\
1.673 \\
1.656 \\
1.640 \\
1.624 \\
1.607 \\
1.591 \\
1.574 \\
1.558 \\
1.541 \\
1.525 \\
1.509\end{array}$ & $\begin{array}{l}110.0 \\
109.0 \\
108.0 \\
107.0 \\
106.0 \\
105.0 \\
104.0 \\
103.0 \\
102.0 \\
101.0 \\
100.0 \\
99.0 \\
98.0 \\
97.0 \\
96.0 \\
95.0 \\
94.0 \\
93.0 \\
92.0 \\
91.0 \\
90.0 \\
89.0 \\
88.0 \\
87.0 \\
86.0 \\
85.0 \\
84.0 \\
83.0 \\
82.0 \\
81.0 \\
80.0 \\
79.0 \\
78.0 \\
77.0 \\
76.0 \\
75.0 \\
74.0 \\
73.0 \\
72.0 \\
71.0\end{array}$ & $\begin{array}{l}1.493 \\
1.477 \\
1.461 \\
1.446 \\
1.430 \\
1.416 \\
1.401 \\
1.387 \\
1.373 \\
1.359 \\
1.345 \\
1.331 \\
1.317 \\
1.303 \\
1.289 \\
1.274 \\
1.260 \\
1.245 \\
1.230 \\
1.215 \\
1.199 \\
1.183 \\
1.167 \\
1.151 \\
1.134 \\
1.118 \\
1.102 \\
1.085 \\
1.069 \\
1.053 \\
1.036 \\
1.020 \\
1.005 \\
0.989 \\
0.974 \\
0.959 \\
0.944 \\
0.929 \\
0.915 \\
0.900\end{array}$ & $\begin{array}{l}70.0 \\
69.0 \\
68.0 \\
67.0 \\
66.0 \\
65.0 \\
64.0 \\
63.0 \\
62.0 \\
61.0 \\
60.0 \\
59.0 \\
58.0 \\
57.0 \\
56.0 \\
55.0 \\
54.0 \\
53.0 \\
52.0 \\
51.0 \\
50.0 \\
49.0 \\
48.0 \\
47.0 \\
46.0 \\
45.0 \\
44.0 \\
43.0 \\
42.0 \\
41.0 \\
40.0 \\
39.0 \\
38.0 \\
37.0 \\
36.0 \\
35.0 \\
34.0 \\
33.0 \\
32.0 \\
31.0\end{array}$ & $\begin{array}{l}0.886 \\
0.872 \\
0.857 \\
0.843 \\
0.829 \\
0.815 \\
0.801 \\
0.787 \\
0.772 \\
0.758 \\
0.744 \\
0.730 \\
0.716 \\
0.702 \\
0.689 \\
0.675 \\
0.661 \\
0.647 \\
0.634 \\
0.620 \\
0.606 \\
0.593 \\
0.579 \\
0.566 \\
0.553 \\
0.539 \\
0.526 \\
0.513 \\
0.500 \\
0.487 \\
0.475 \\
0.462 \\
0.449 \\
0.436 \\
0.423 \\
0.411 \\
0.398 \\
0.385 \\
0.373 \\
0.360\end{array}$ & $\begin{array}{r}30.0 \\
29.0 \\
28.0 \\
27.0 \\
26.0 \\
25.0 \\
24.0 \\
23.0 \\
22.0 \\
21.0 \\
20.0 \\
19.0 \\
18.0 \\
17.0 \\
16.0 \\
15.0 \\
14.0 \\
13.0 \\
12.0 \\
11.0 \\
10.0 \\
9.0 \\
8.0 \\
7.0 \\
6.0 \\
5.0\end{array}$ & $\begin{array}{l}0.347 \\
0.335 \\
0.323 \\
0.310 \\
0.298 \\
0.286 \\
0.273 \\
0.261 \\
0.249 \\
0.237 \\
0.225 \\
0.213 \\
0.201 \\
0.189 \\
0.177 \\
0.166 \\
0.154 \\
0.143 \\
0.131 \\
0.120 \\
0.109 \\
0.097 \\
0.086 \\
0.075 \\
0.063 \\
0.052\end{array}$ \\
\hline
\end{tabular}


WHC-EP-0680

\section{APPENDIX B-3}

\section{B3-i}


This page intentionally left blank.

$B 3-i i$ 
WHC-EP-0680

Work Plan WP-P-92-

Page 1

WORK PLAN

INSTALL CASCADE IMPACTORS ON THE PUREX MA'N STACK (291-A-1)

\section{GENERAL DESCRIPTION}

This work plan provides instructions for installing and removing two cascade impactor sampling systems on the PUREX main stack. One of the impactor systems will be installed in the 292-AB Building and will sample from the 60-foot level of the main stack using facility system vacuum to provide flow through the impactor. Operation of the record sampler will continue during the impactor test and will not be affected. This work plan also provides instructions for installing and removing a second cascade impactor sampling system for the acquisition of an effluent sample directly from the main stack upstream from the external sampling line from the stack to the 292-AB Building. This impactor system will be installed on scaffolding and will be located at the 60foot level on a platform near the main stack and will use its own vacuum pumps for flow control through the system. Analysis of the impactor "filters" for both of these systems will provide information on particle size association and distribution of emitted radionuciides and a measurement of any significant particle deposition in the sampling line.

The installation and removal of both cascade impactor systems discussed in this work plan need to coincide as closely as possible (i.e., each unit should be activated and/or deactivated near the same time on the same day).

\section{PREPLANNING/COORDINATION}

The organizational responsibilities are as follows:

Cognizant Effluent Engineer - Function as the work $p l a n$ manager, in association with SAIC personnel, with overall responsibility for coordinating the activities; technical point of contact for questions.

SAIC Personnel

- Provide cognizant effluent engineer with technical assistance and guidance for the duration of this plan. Also provide the cascade impactor systems and fittings.

PUREX Health and Safety

- Provide HPT coverage during the installation and removal of the impactors. Provide mechanism to transfer impactors to 222-S Laboratory for analysis.

B3-1 
PUREX Maintenance

\section{SAFETY}

Limiting Condition for Operation (LCO) 12.6.3 requires operability of the sampling and monitoring systems on the 291-A-1 stack. Ensure the record sample loop operation is not interrupted. An HPT must be present during performance of the installation and removal tasks.

Appropriate safety measures must be performed when relocating the equipment from the ground location to the scaffolding and from the scaffolding to the ground location. Personnel climbing up and down the ladder near/on the stack must be aware of the proper methods to perform this safely per guidance from WHC Industrial Safety.

A pre-job safety meeting must be held.

All requirements of Radiation Protection Manual, WHC-CM-4-10, and Radiation Work Requirements and Permits Manual, WHC-CM-4-15, Vol. 2 shall be followed. RWP KEH-A35 applies to all work performed under these procedures.

A11 work performed under this work plan shall conform to WHC-CM-4-3 and all requirements for Hoisting and Rigging in WHC-CM-6-4 shall be met. Personnel shall not hand-carry anything on the ladders.

IV. PLAN

NOTE: This work plan can be red-lined in the field with the appropriate approvals for the change per WHC-IP-0240, Section 4.

A. CASCADE IMPACTOR SYSTEM UPSTREAM OF THE 60-FT LEVEL SAMPLE LINE

\section{PERFORM PREMODIFICATION/PRESTART CHECKS}

a. Ensure that scaffolding has been installed in the proper location for access to the 60-Ft level sampling Iine per Work Package

b. Ensure that all supporting parts and connections are available.
(1) Flow splitter (3/4" Tubing)
(2) Reducer Union ( $3 / 4$ " to $1 / 2$ " Tubing)
(3) Flowmeter
(4) 1/2" Stainless Steel tubing (If needed)
(5) Portable Vacuum pumps
(6) Vacuum Gauge
(7) Tygon Tubing
(8) Cascade Impactor

B3-2 
Hork Plan WP-P-92-

c. Ensure that the cascade impactor has been properly prepared and assembled.

d. Ensure that the portable vacuum pumps are operating properly and that 1 acfm can be drawn through the impactor.

e. Ensure that no air flow is going through the NOx sampling line.

e. Notify PUREX Health and Safety that work is about to be initiated on the modification of the system and installation of the cascade impactor system.

PREMOD/PRESTART CHECKS COMPLETED: DATE COGNIZANT ENGINEER

\section{MODIFY SYSTEM}

a. Install splitter in the NOx sampling line at the 60-Ft level of the PUREX Main Stack per Figure 1.

b. Install a $3 / 4^{n}$ to $1 / 2^{n}$ reducer union in one line from the splitter.

c. Install 1/2" stainless steel tubing for the cascade impactor (if needed) from one leg of the splitter to the cascade impactor per Figure 1 .

\section{INSTALL CASCADE IMPACTOR SYSTEM}

a. Transport all needed equipment to the scaffolding from the ground level.

b. Connect the cascade impactor downstream from the splitter on the $1 / 2^{n}$-tubing leg and secure the system to the platform.

c. Connect one end of the Tygon tubing to the cascade inipactor.

d. Secure the protective cover over the cascade impactor system on the scaffolding. 
WHC-EP-0680

Work Plan WP-P-92-

Page 4

e. Install the other end of the Tygon tubing, flowmeter, vacuum gauge, and vacuum pump on the ground level per Figure 1 .

f. Activate the vacuum pumps for the sampling line and ensure that proper flows can be obtained.

(1) Determine the appropriate correction factor for the in-line flowmeter using Table I.

(2) Set the proper flowrate using Table II.

INSTALLATION COMPLETED: DATE COGNIZANT ENGINEER

4. PERIODIC CHECKING OF THE CASCADE IMPACTOR

a. A continuous sample will be obtained from the PUREX Main Stack over a length of 4-5 weeks.

b. Periodic checks (i.e., at least once per week, approximately the same day of the week) will be made on the readings of the vacuum gauge and the in-line flowmeter on the ground level.

c. Meter readings, initials of responsible personnel, dates, and times that the observations are made shall be recorded in Table III.

SAMPLING COMPLETED: DATE/TIME:

COGNIZANT ENGINEER:

\section{REMOVE CASCADE IMPACTOR SYSTEM}

NOTE: This operation will occur 4-5 weeks after the installation and will be directed by SAIC.

a. Check the vacuum gauge and flowmeter for the cascade impactor system and record the readings.

b. Deactivate the pumps for the cascade impactor.

c. Remove the protective cover from the cascade impactor system on the scaffoiding. 
d. Disconnect the Tygon tubing from the cascade impactor and tape the end of the tubing and the hose nipple on the impactor.

e. Disconnect the cascade impactor from the $1 / 2^{n}$-tubing leg from the splitter, put tape over the inlet, and bag the unit.

f. Close off (plug) the 1/2"-tubing end of the splitter.

g. Transfer the cascade impactor to the ground level.

h. Dismantle the rest of the sampling system.

(1) Survey any other equipment on the scaffolding and any area of the scaffolding that may have become contaminated.

(2) Remove this equipment from the scaffolding and transfer it to the ground level.

(3) Bag or package selected pieces of equipment as necessary.

NOTE: The following two steps may be performed in any order.

i. Store equipment as required. (WHC)

j. Request HPT to survey the cascade impactor and prepare it for transport, and transport them to the 222-S Laboratory (WHC)

REMOVAL COMPLETED: DATE COGNIZANT ENGINEER

B. CASCADE IMPACTOR SYSTEM DOWNSTREAM OF THE 60-FT LEVEL SAMPLING LINE

1. PERFORM PREMODIFICATION/PRESTART CHECKS

a. Notify PUREX Health and Safety Supervisor and the Operating Shift Supervisor that the NOx monitors will remain out of service during the system modification and operation of the cascade impactor system.

b. Ensure that the cascade impactor has been properly prepared and assembied as directed by SAIC.

c. Ensure that all supporting parts and connections are available.

(1) Cascade Impactor 
Work Plan WP-P-92-

Page $\overline{6}$
(2) Flowmeter
(3) Vacuum Gauge
(4) Tygon Tubing
(5) Connectors
(6) Platform

d. Ensure that the vacuum system is operational and that 1 acfm is obtainable.

NOTE - Step e will be performed with the assistance of the cognizant engineer, based on the stack flow rate and the design of the sample probe.

e. Determine flow required to maintain isokinesis through the sample probe.

Total flow $=\ldots$ scfm

Flow for impactor (Upstream of Sampling Line) = 1 acfm Flow for impactor (Downstream of Sampling Line) = 1 acfm Flow for System Bypass

PREMOD/PRESTART CHECKS COMPLETED: DATE:

COGNIZANT ENGINEER:

2. MOOIFY NOX MONITORING SYSTEM

a. Disconnect the NOx monitoring lines from the appropriate side of the splitter downstream of the sampling line at the 60-Ft level per figure 2 .

MODIFICATION COMPLETED: DATE:

COGNIZANT ENGINEER:

3. INSTALL CASCADE IMPACTOR

NOTE - This plan involves the both the installation and remcval of the cascade impactor. The time between the two operations will be approximately 4-5 weeks. Cognizant Engineer and SAIC personnel must be present before proceeding.

a. Install impactor supports beneath impactor system if needed. 
Work Plan WP-P-92-

b. Install the cascade impactor in place of the NOX monitoring lines for units NMV191 and NMV192 per Figure 3 .

c. Connect the Tygon tubing to the hose nipple of the cascade impactor and the other end to the flowmeter, vacuum gauge, and vacuum system to be used.

d. Secure the flowmeter and the vacuum gauge near the connection to the vacuum system.

e. OPEN the appropriate valves and adjust regulators for the NOx system bypass and the cascade impactor system to obtain the flow values determined in Task B.1.e.

(1) Determine the appropriate correction factor for the in-line flowmeter using Table I.

(2) Set the proper flowrate using Table II.

INSTALLATION COMPLETED: DATE COGNIZANT ENGINEER

4. PERIODIC CHECKING OF THE CASCADE IMPACTOR

a. A continuous sample will be obtained from the PUREX Main Stack over a length of 4-5 weeks.

b. Periodic checks (i.e., at least once per week, approximately the same day of the week) will be made on the readings of the vacuum gauge and the in-line flowmeter in the 292-AB Building.

c. Meter readings, initials of responsible personnel, dates, and times that the observations are made shall be recorded in Table IV.

SAMPLING COMPLETED: DATE/TIME:

COGNIZANT ENGINEER:

5. REMOVE CASCADE IMPACTOR SYSTEM

NOTE - This operation will occur approximately 4-5 weeks after the installation of the cascade impactor system. 
WHC-EP-0680

Work Plan WP-P-92-

Page 8

a. Check the vacuum gauge and flowmeter for the cascade impactor system and record the readings.

b. CLOSE the appropriate valves to reduce the flowrate through the system to zero and deactivate the vacuum system.

c. Disconnect the cascade impactor from downstream of the flow splitter and bag it.

d. Reconnect the NOx monitor lines that were disconnected in Step B.2 per Figure 2.

e. Dismantle the rest of the cascade impactor system.

(1) Survey equipment as required.

(2) Remove equipment from the area.

(3) Bag and package selected pieces of equipment as necessary.

NOTE: The following two steps may be performed in any order.

f. Store equipment as required. (WHC)

g. Request HPT to survey the cascade impactor and prepare it for transport, and transport them to the 222-S Laboratory. (WhiC) 


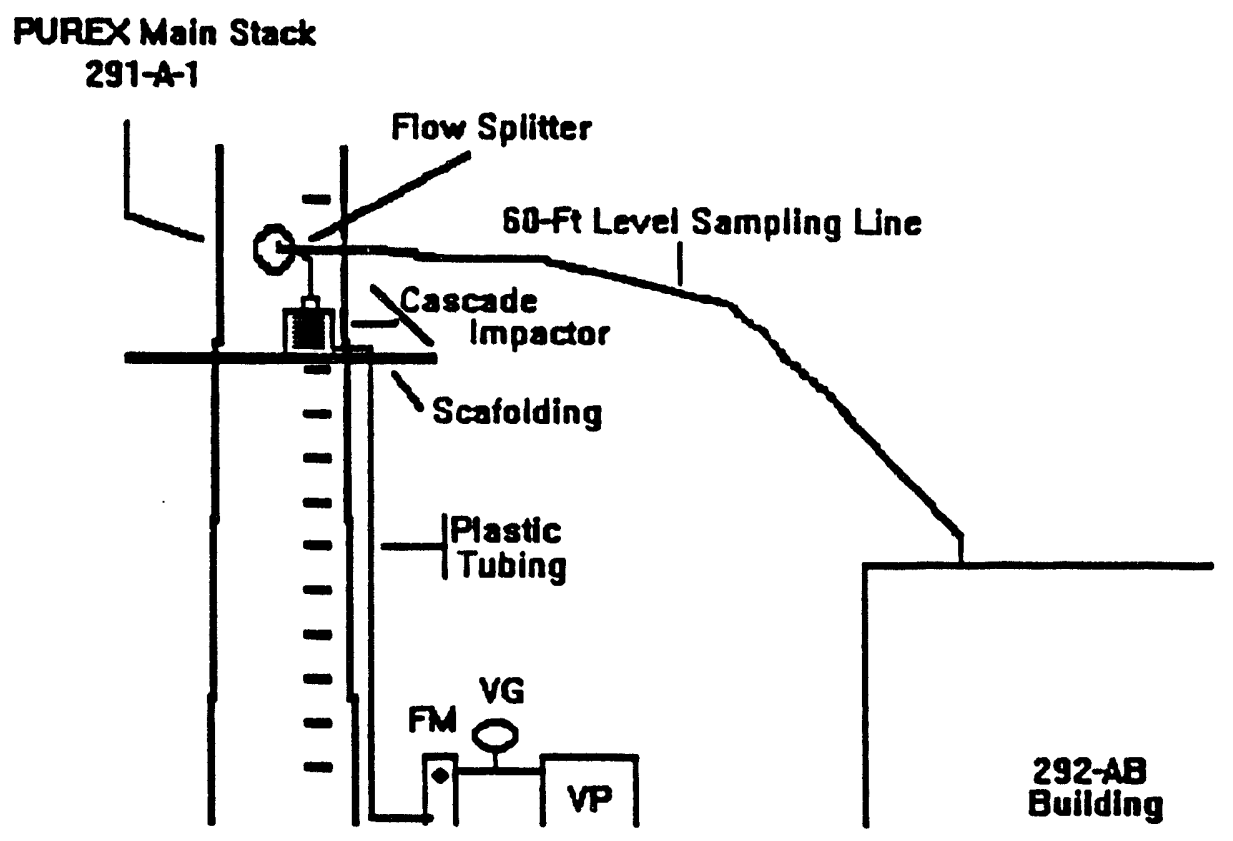

FM: Flowmeter

VG: Vacuum Gauge

VP: Vacuum Pump

Figure 1. Cascade Impactor System Sampling Directly from the PUREX Main Stack Upstream of the 60-Ft Level Sampling Line 
Work P1 an WP-P-92-

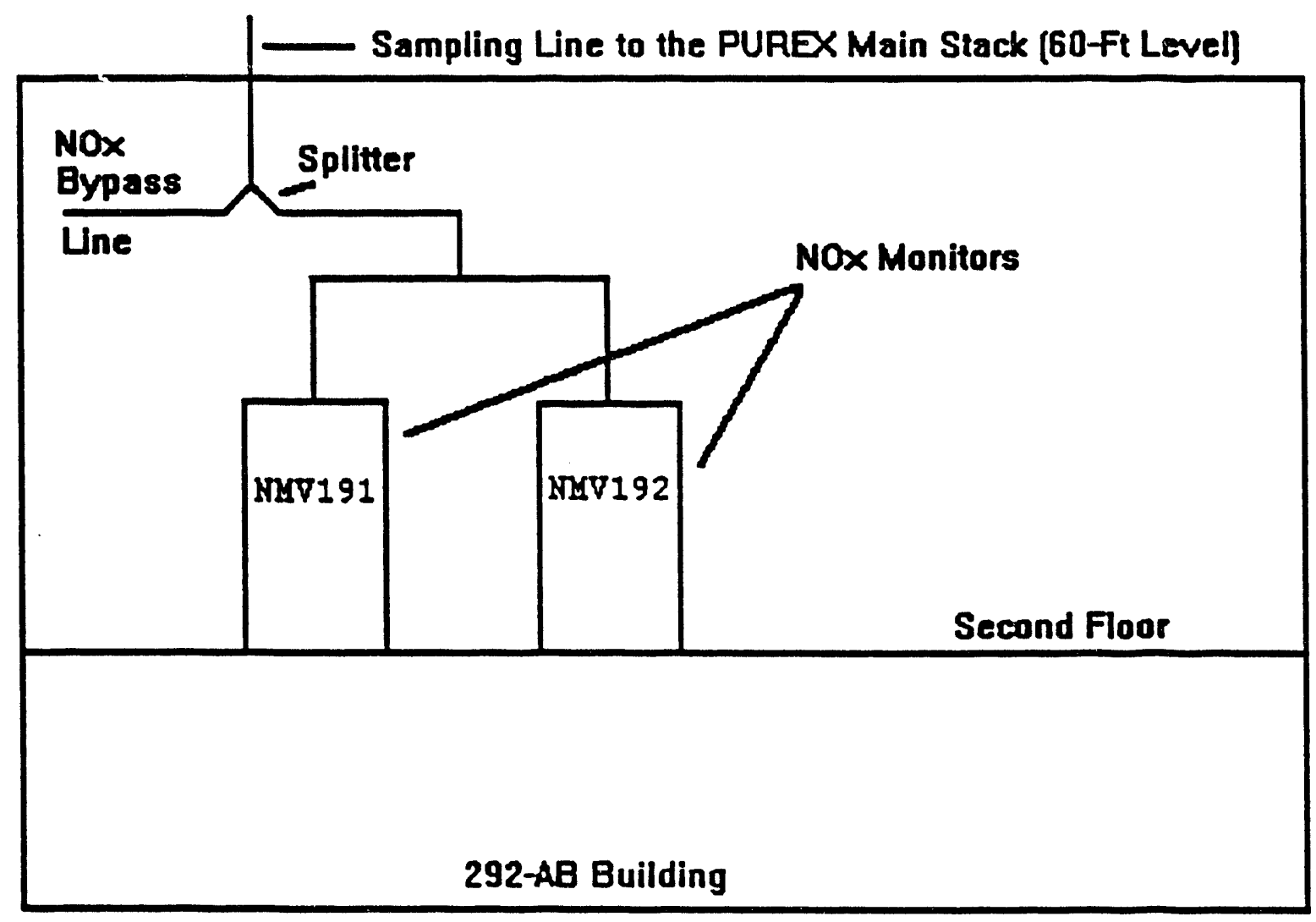

Figure 2. Existing Sampling Line Configuration for the NOx Monitors Inside the 292-AB Building 


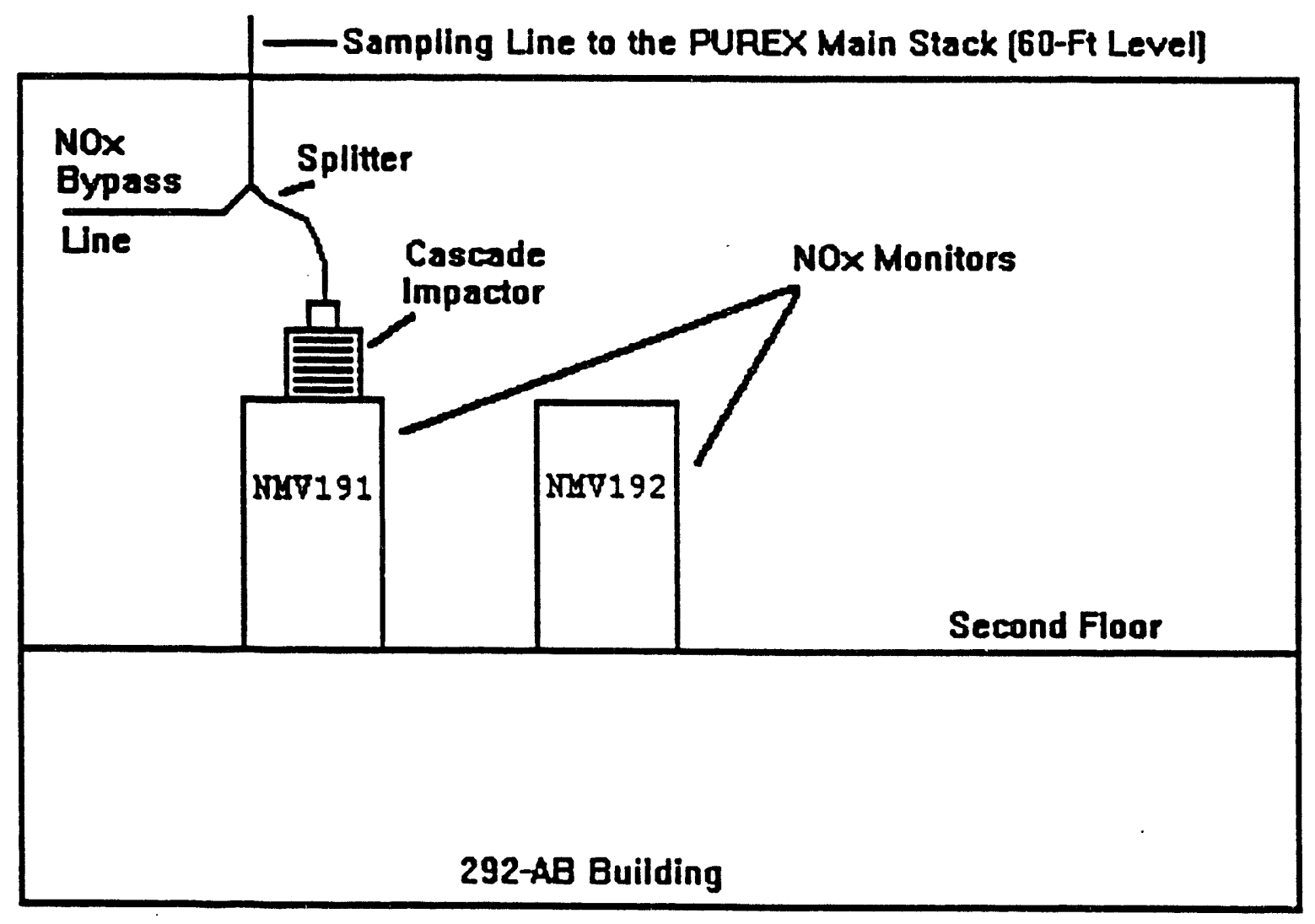

Figure 3. Cascade Impactor System Sampling Downstream of the 60-Ft Level Sampling Line 
Taole !. Correction Factors Requlred for in-ine

Flowmeter Readings Jue to Vacuum

\begin{tabular}{|c|c|c|c|c|c|}
\hline $\begin{array}{l}0.1 \\
0.2 \\
0.3 \\
0.4 \\
0.5 \\
0.6 \\
0.7 \\
0.8 \\
0.9 \\
1.0 \\
1.1 \\
1.2 \\
1.3 \\
1.4 \\
1.5 \\
1.6 \\
1.7 \\
1.8 \\
1.9 \\
2.0 \\
2.1 \\
2.2 \\
2.3 \\
2.4 \\
2.5 \\
2.6 \\
2.7 \\
2.8 \\
2.9 \\
3.0 \\
3.1 \\
3.2 \\
3.3 \\
3.4 \\
3.5 \\
3.6 \\
3.7 \\
3.8 \\
3.9 \\
4.0 \\
4.1 \\
4.2 \\
4.3 \\
4.4 \\
4.5 \\
4.6 \\
4.7 \\
4.8 \\
4.9 \\
5.0 \\
5.1 \\
5.2 \\
5.3 \\
5.4 \\
5.5 \\
5.6 \\
5.7 \\
5.8 \\
5.9\end{array}$ & $\begin{array}{l}1.002 \\
1.003 \\
1.005 \\
1.007 \\
1.008 \\
1.010 \\
1.012 \\
1.014 \\
1.015 \\
1.017 \\
1.019 \\
1.021 \\
1.022 \\
1.024 \\
1.026 \\
1.028 \\
1.030 \\
1.032 \\
1.033 \\
1.035 \\
1.037 \\
1.039 \\
1.041 \\
1.043 \\
1.045 \\
1.047 \\
1.048 \\
1.050 \\
1.052 \\
1.054 \\
1.056 \\
1.058 \\
1.060 \\
1.062 \\
1.064 \\
1.066 \\
1.068 \\
1.070 \\
1.072 \\
1.074 \\
1.076 \\
1.079 \\
1.081 \\
1.083 \\
1.085 \\
1.087 \\
1.089 \\
1.091 \\
1.094 \\
1.096 \\
1.098 \\
1.100 \\
1.102 \\
1.105 \\
1.107 \\
1.109 \\
1.111 \\
1.114 \\
1.116\end{array}$ & $\begin{array}{r}6.0 \\
6.1 \\
6.2 \\
6.3 \\
6.4 \\
6.5 \\
6.6 \\
6.7 \\
6.8 \\
6.9 \\
7.0 \\
7.1 \\
7.2 \\
7.3 \\
7.4 \\
7.5 \\
7.6 \\
7.7 \\
7.8 \\
7.9 \\
8.0 \\
8.1 \\
8.2 \\
8.3 \\
8.4 \\
8.5 \\
8.6 \\
8.7 \\
8.8 \\
8.9 \\
9.0 \\
9.1 \\
11.7 \\
11.8 \\
11.9 \\
11.4 \\
11.5 \\
9.3 \\
11.2 \\
9.4 \\
9.5 \\
9.6 \\
9.7 \\
9.8 \\
11.9 \\
10.9 \\
10.1 \\
10.2 \\
10.3 \\
10.4 \\
10.5 \\
10.6 \\
10.7 \\
10.8 \\
\end{array}$ & $\begin{array}{l}1.118 \\
1.121 \\
1.123 \\
1.125 \\
1.128 \\
1.130 \\
1.133 \\
1.135 \\
1.138 \\
1.140 \\
1.143 \\
1.145 \\
1.148 \\
1.150 \\
1.153 \\
1.155 \\
1.158 \\
1.160 \\
1.163 \\
1.166 \\
1.168 \\
1.171 \\
1.174 \\
1.176 \\
1.179 \\
1.182 \\
1.185 \\
1.187 \\
1.190 \\
1.193 \\
1.196 \\
1.199 \\
1.202 \\
1.205 \\
1.208 \\
1.210 \\
1.213 \\
1.216 \\
1.219 \\
1.222 \\
1.226 \\
1.229 \\
1.232 \\
1.235 \\
1.238 \\
1.241 \\
1.244 \\
1.248 \\
1.251 \\
1.254 \\
1.258 \\
1.261 \\
1.264 \\
1.268 \\
1.271 \\
1.274 \\
1.278 \\
1.281 \\
1.285 \\
1.289 \\
\end{array}$ & $\begin{array}{l}12.0 \\
12.1 \\
12.2 \\
12.3 \\
12.4 \\
12.5 \\
12.6 \\
12.7 \\
12.8 \\
12.9 \\
13.0 \\
13.1 \\
13.2 \\
13.3 \\
13.4 \\
13.5 \\
13.6 \\
13.7 \\
13.8 \\
13.9 \\
14.0 \\
14.1 \\
14.2 \\
14.3 \\
14.4 \\
14.5 \\
14.6 \\
14.7 \\
14.8 \\
14.9 \\
15.0 \\
15.1 \\
15.2 \\
15.3 \\
15.4 \\
15.5 \\
15.6 \\
15.7 \\
15.8 \\
15.9 \\
16.0 \\
16.1 \\
17.4 \\
17.5 \\
17.7 \\
17.8 \\
17.9 \\
16.3 \\
16.4 \\
16.5 \\
16.6 \\
16.7 \\
16.8 \\
16.9 \\
17.0 \\
17.1 \\
17.2 \\
\end{array}$ & $\begin{array}{l}1.292 \\
1.296 \\
1.299 \\
1.303 \\
1.307 \\
1.311 \\
1.314 \\
1.318 \\
1.322 \\
1.326 \\
1.330 \\
1.334 \\
1.338 \\
1.342 \\
1.346 \\
1.350 \\
1.354 \\
1.358 \\
1.362 \\
1.367 \\
1.371 \\
1.375 \\
1.380 \\
1.384 \\
1.388 \\
1.393 \\
1.397 \\
1.402 \\
1.407 \\
1.411 \\
1.416 \\
1.421 \\
1.426 \\
1.431 \\
1.435 \\
1.440 \\
1.445 \\
1.451 \\
1.456 \\
1.461 \\
1.466 \\
1.471 \\
1.477 \\
1.482 \\
1.488 \\
1.493 \\
1.499 \\
1.504 \\
1.510 \\
1.516 \\
1.522 \\
1.528 \\
1.534 \\
1.540 \\
1.546 \\
1.552 \\
1.558 \\
1.565 \\
1.571 \\
1.578 \\
\end{array}$ \\
\hline
\end{tabular}


Table II. Brooks Flowmeter (Model R-615-B, Carboloy, Spherical Ball) Calibration Data

\begin{tabular}{|c|c|c|c|c|c|c|c|}
\hline $\begin{array}{c}\text { Tube Racting } \\
\text { (D) }\end{array}$ & $\begin{array}{l}\text { Four Rste } \\
\text { (cfin) }\end{array}$ & Tube Randing & Flow Rate & Tube Reading & Flow Rate & $\begin{array}{c}\text { Tube Rearting } \\
\text { (min) }\end{array}$ & Fou Rate \\
\hline $\begin{array}{l}150.0 \\
149.0 \\
148.0 \\
147.0 \\
146.0 \\
145.0 \\
144.0 \\
143.0 \\
142.0 \\
141.0 \\
140.0 \\
139.0 \\
138.0 \\
137.0 \\
136.0 \\
135.0 \\
134.0 \\
133.0 \\
132.0 \\
131.0 \\
130.0 \\
129.0 \\
128.0 \\
127.0 \\
126.0 \\
125.0 \\
124.0 \\
123.0 \\
122.0 \\
121.0 \\
120.0 \\
119.0 \\
118.0 \\
117.0 \\
116.0 \\
115.0 \\
114.0 \\
113.0 \\
112.0 \\
111.0\end{array}$ & $\begin{array}{l}2.160 \\
1.142 \\
2.123 \\
2.105 \\
2.086 \\
2.068 \\
2.049 \\
2.031 \\
2.013 \\
1.995 \\
1.977 \\
1.960 \\
1.942 \\
1.925 \\
1.908 \\
1.891 \\
1.875 \\
1.860 \\
1.844 \\
1.829 \\
1.813 \\
1.798 \\
1.783 \\
1.767 \\
1.752 \\
1.736 \\
1.721 \\
1.705 \\
1.689 \\
1.673 \\
1.656 \\
1.640 \\
1.624 \\
1.607 \\
1.591 \\
1.574 \\
1.558 \\
1.541 \\
1.525 \\
1.509\end{array}$ & $\begin{array}{l}110.0 \\
109.0 \\
108.0 \\
107.0 \\
106.0 \\
105.0 \\
104.0 \\
103.0 \\
102.0 \\
101.0 \\
100.0 \\
99.0 \\
98.0 \\
97.0 \\
96.0 \\
95.0 \\
94.0 \\
93.0 \\
92.0 \\
91.0 \\
90.0 \\
89.0 \\
88.0 \\
87.0 \\
86.0 \\
85.0 \\
84.0 \\
83.0 \\
82.0 \\
81.0 \\
80.0 \\
79.0 \\
78.0 \\
77.0 \\
76.0 \\
75.0 \\
74.0 \\
73.0 \\
72.0 \\
71.0\end{array}$ & $\begin{array}{l}1.493 \\
1.477 \\
1.461 \\
1.446 \\
1.430 \\
1.416 \\
1.401 \\
1.387 \\
1.373 \\
1.359 \\
1.345 \\
1.331 \\
1.317 \\
1.303 \\
1.289 \\
1.274 \\
1.260 \\
1.245 \\
1.230 \\
1.215 \\
1.199 \\
1.183 \\
1.167 \\
1.151 \\
1.134 \\
1.118 \\
1.102 \\
1.085 \\
1.069 \\
1.053 \\
1.036 \\
1.020 \\
1.005 \\
0.989 \\
0.974 \\
0.959 \\
0.944 \\
0.929 \\
0.915 \\
0.900\end{array}$ & $\begin{array}{l}70.0 \\
69.0 \\
68.0 \\
67.0 \\
65.0 \\
65.0 \\
64.0 \\
63.0 \\
62.0 \\
61.0 \\
60.0 \\
59.0 \\
58.0 \\
57.0 \\
56.0 \\
55.0 \\
54.0 \\
53.0 \\
52.0 \\
51.0 \\
50.0 \\
49.0 \\
48.0 \\
47.0 \\
46.0 \\
45.0 \\
44.0 \\
43.0 \\
42.0 \\
41.0 \\
40.0 \\
39.0 \\
38.0 \\
37.0 \\
36.0 \\
35.0 \\
34.0 \\
33.0 \\
32.0 \\
31.0\end{array}$ & $\begin{array}{l}0.886 \\
0.872 \\
0.857 \\
0.843 \\
0.829 \\
0.815 \\
0.801 \\
0.787 \\
0.772 \\
0.758 \\
0.744 \\
0.730 \\
0.716 \\
0.702 \\
0.689 \\
0.675 \\
0.661 \\
0.647 \\
0.634 \\
0.620 \\
0.606 \\
0.593 \\
0.579 \\
0.566 \\
0.553 \\
0.539 \\
0.526 \\
0.513 \\
0.500 \\
0.487 \\
0.475 \\
0.462 \\
0.449 \\
0.436 \\
0.423 \\
0.411 \\
0.398 \\
0.385 \\
0.373 \\
0.360\end{array}$ & $\begin{array}{r}30.0 \\
29.0 \\
28.0 \\
27.0 \\
26.0 \\
25.0 \\
24.0 \\
23.0 \\
22.0 \\
21.0 \\
20.0 \\
19.0 \\
18.0 \\
17.0 \\
16.0 \\
15.0 \\
14.0 \\
13.0 \\
12.0 \\
11.0 \\
10.0 \\
9.0 \\
8.0 \\
7.0 \\
6.0 \\
5.0\end{array}$ & $\begin{array}{l}0.347 \\
0.335 \\
0.323 \\
0.310 \\
0.298 \\
0.286 \\
0.273 \\
0.261 \\
0.249 \\
0.237 \\
0.225 \\
0.213 \\
0.201 \\
0.189 \\
0.177 \\
0.166 \\
0.154 \\
0.143 \\
0.131 \\
0.120 \\
0.109 \\
0.097 \\
0.086 \\
0.075 \\
0.063 \\
0.052\end{array}$ \\
\hline
\end{tabular}


WHC-EP-0680

Table III. Upstrean Cascade Sample Check Information

\begin{tabular}{|c|c|c|c|c|}
\hline \multirow[b]{2}{*}{ Systen Chack } & \multirow[b]{2}{*}{$\begin{array}{l}\text { Vacum } 6 \text { ange } \\
\text { Rending }\left(\mathrm{Hg}^{\circ}\right)\end{array}$} & \multirow[b]{2}{*}{$\begin{array}{l}\text { In-Lin Flomer } \\
\text { Reading (m) }\end{array}$} & \multicolumn{2}{|c|}{$\begin{array}{c}\text { Initial and Record Date and Tine as } \\
\text { Each Sample is Checked }\end{array}$} \\
\hline & & & Initials & Datartin \\
\hline \multicolumn{5}{|l|}{1} \\
\hline \multicolumn{5}{|l|}{2} \\
\hline \multicolumn{5}{|l|}{3.} \\
\hline \multicolumn{5}{|l|}{4} \\
\hline \multicolumn{5}{|l|}{5} \\
\hline \multicolumn{5}{|l|}{6} \\
\hline \multicolumn{5}{|l|}{7} \\
\hline 8 & & & & \\
\hline
\end{tabular}

(11) Once an option is chosen and initiated. that schedule must be completed.

(2) Cirele the option being used. 
Table IV. Building 292-AB Cascade Sample Check Information

\begin{tabular}{|c|c|c|c|c|}
\hline \multirow{2}{*}{$\begin{array}{l}\text { System Cheak } \\
\text { intar }\end{array}$} & \multirow{2}{*}{$\begin{array}{l}\text { Vecum Gauge } \\
\text { Rading }(F)\end{array}$} & \multirow{2}{*}{$\begin{array}{l}\text { In-Line Flowater } \\
\text { Rading (m) }\end{array}$} & \multicolumn{2}{|c|}{$\begin{array}{c}\text { Initial and Record Date and Tim as } \\
\text { Each Sample is Checked }\end{array}$} \\
\hline & & & Initials & Data/Tín \\
\hline \multicolumn{5}{|l|}{1} \\
\hline \multicolumn{5}{|l|}{2} \\
\hline \multicolumn{5}{|l|}{3} \\
\hline \multicolumn{5}{|l|}{4} \\
\hline \multicolumn{5}{|l|}{5} \\
\hline \multicolumn{5}{|l|}{6} \\
\hline \multicolumn{5}{|l|}{7} \\
\hline 8 & & & & \\
\hline
\end{tabular}

(11 Once an option is chosen and initiated, that schedule must be completed.

(2) Circle the option being used. 
WHC.-EP-0680

This page intentionally left blank.

B3-16 
WHC-EP-0680

APPENDIX B-4

B4- $i$ 


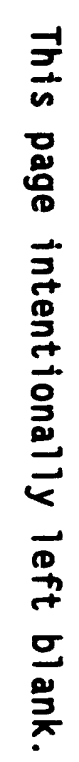

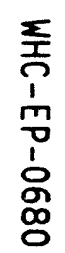


WHC-EP-0680

Work Plan WP-P-92-

Page 1

WORK PLAN

INSTALL CASCADE IMPACTORS ON THE AP TANK FARM STACK (296-A-40)

I. GENERAL DESCRIPTION

This work plan provides instructions for installing and removing two cascade impactor sampling systems on the AP Tank Farm stack. One of the impactors will be installed on one leg of the Beta CAM flow splitter and will use AP Tank Farm system vacuum to provide flow through the impactor. Appropriate adjustments will be made to the Beta CAM alarm setpoints to maintain Beta CAM function. Operation of the Beta CAM and record sampler will continue during the impactor test. This work plan also provides instructions for installing, operating, and removing a second cascade impactor sampling system for the acquisition of an effluent sample near the outlet of the AP Tank Farm stack. This impactor will be installed on the scafolding and will be located on a movable platform near the AP Tank Farm Stack. This cascade impactor system will be moved periodically to obtain a representative sample from the stack. Analysis of the impactor "filters" will provide particle size association and distribution of emitted radionuclides.

\section{PREPLANNING/COORDINATION}

The organizational responsibilities are as follows:

Cognizant Effluent Engineer - Function as the work plan manager, in association with SAIC personnel, with overall responsibility for coordinating the activities; technical point of contact for questions.

SAIC Personnel

Tank Farm Health and Safety

Tank Farm Maintenance
- Provide cognizant effluent engineer with technical assistance and guidance for the duration of this plan. Also provide the cascade impactor systems and fittings.

Provide HPT coverage during the installation and removal of the impactors. Provide mechanism to transfer impactors to 222-S Laboratory for analysis.

- Support installation/removal of cascade impactors per approved work package 


\section{SAFETY}

Limiting Condition for Operation (LCO) 12.6 .3 requires operability of the sampling and monitoring systems on the 296-A-40 stack. Ensure the record sample loop operation is not interrupted and the Beta CAM downtime is minimized. An HPT must be present during performance of the installation, periodic moving, and removal tasks.

A pre-job safety meeting must be held.

All requirements of Radiation Protection Manual, WHC-CM-4-10, and Radiation Work Requirements and Permits Manual, WHC-CM-4-15, Vol. 2 shall be followed. RWP under these procedures. applies to all work performed

All work performed under this work plan shall conform to WHC-CM-4-3.

IV. PLAN

NOTE: This work plan can be red-lined in the field with the appropriate approvals for the change per WHC-IP-0240, Section 4.

\section{A. MODIFICATION OF AP TANK FARM EFFLUENT SAMPLING SYSTEM}

1. PERFORM PREMODIFICATION CHECKS

a. Ensure that all supporting parts and connections are available.

(1) Flow splitter

(2) Valve

(3) Tee

(4) 1/2" Stainless Steel tubing

(5) Vacuum pump (2 CFM)

(6) Flowmeter

(7) Flow Regulator

b. Ensure that stack Beta CAM RE-KI-1 and the associated pump are operating properly per figure 1 .

c. Notify Tank Farm Health and Safety Supervisor and the Operating Shift Supervisor that Beta CAM RE-K1-1 wil1 be taken out of service during the system modification. 
WHC-EP-0680

Work Plan WP-P-92-

Page 3

2. MODIFY SYSTEM

a. Notify Tank Farm dispatcher that there will be a low flow alarm on FAS-KI-1.

b. Turn off the vacuum pump for Beta CAM RE-K1-1.

c. Install splitter upstream of the Beta CAM near the top of the instrument cabinet per Figure 2 .

d. Install 1/2" stainless steel tubing for the cascade impactor from one leg of the splitter per Figure 2.

e. Install vacuum pump in instrument cabinet per Figure 2.

f. Install 1/2" stainless steel tubing from the vacuum pump to the flow regulator to the vacuum gauge to the flowmeter to the new valve with associated tee per Figure 2.

g. Complete the sampling line by connecting the other end of the tee to the stainless steel tubing from the splitter per Figure 2.

h. Activate pumps for the Beta CAM and the new sampling line to ensure that proper flows can be obtained.

MODIFICATION COMPLETED: DATE COGNIZANT ENGINEER

B. CASCADE IMPACTOR SYSTEM TO SAMPLE FROM THE BETA CAM SAMPLING LINE

1. PERFORM PRESTART CHECKS

a. Ensure that the cascade impactor has been properly prepared and assembled per Figure 3.

b. Ensure that all supporting parts and connections are available.

c. Ensure that the stack Beta CAM RE-KI-1 is operating properly.

d. Notify Tank Farm Health and Safety Supervisor and the Operating Shift Supervisor that Beta CAM RE-K1-1 will be taken out of service during the impactor installation.

e. Ensure that the pump for the Beta CAM is running.

B4-3 
Work Plan WP-P-92-

NOTE - Step $f$ will be performed with the assistance of the cognizant engineer, based on the stack flow rate and the design of the sample probe.

f. Determine flow required to maintain isokinesis through the sample probe.

Total flow =

Flow for CAM RE-K1-1 = scfm (Approx. 1/2 of total)

Flow for cascade impactor = Tacfm (Approx. $1 / 2$ of total)

NOTE - $\quad$ HPT surveillance data sheet may need to be temporarily changed to reflect the new alarm setpoint. Step $g w+11$ be performed with the assistance of the cognizant engineer. It is expected that the setpoint will be conservatively set to $100 \mathrm{cpm}$, which is half the normal setpoint.

g. Calculate new monitor alarm set point using new monitor flow determined in step $f$ above.

Initial Alarm Setpoint $=\ldots$ cpm

New Alarm Setpoint = $\mathrm{cpm}$

h. Install tag stating setpoint and monitor flow.

i. Notify the cognizant engineer, Operations Supervisor, and Health and Safety Supervisor that the monitor flow rate and alarm setpoint have been reduced and will remain at the new levels for approximately six weeks.

PRESTART CHECKS COMPLETED: DATE COGNIZANT ENGINEER

\section{INSTALL CASCADE IMPACTOR}

NOTE - This plan involves the both the installation and removal of the cascade impactor. The time between the two operations will be approximately 6 weeks. Cognizant Engineer and SAIC personnel must be present before proceeding.

a. Notify Tank Farm dispatcher that there will be a low flow alarm on FAS-KI-1.

b. OPEN the appropriate regulator and obtain flow rate determined in Task B.1.f. Maintain flow for 10 minutes.

c. CLOSE the appropriate valve. 
WHC-EP-0680

Work Plan WP-P-92-

Page 5

d. Remove the newly installed valve and its associated tee per Figures 2 and 3 . -

NOTE - Tubing supports may be loosened to provide free movement and space for connections.

e. Install impactor supports beneath impactor system if needed.

f. Connect impactor system in place of tee.

g. OPEN the appropriate valve and adjust regulators for the Beta CAM and the cascade impactor system to obtain the flow values determined in Task B.1.f.

(1) Determin the appropriate correction factor for the in-line flowmeter using Table I.

(2) Set the proper flowrate using Table II.

h. Adjust Beta CAM alarm to value determined in Task B.1.g.

INSTALLATION COMPLETED: DATE COGNIZANT ENGINEER

3. REMOVE CASCADE IMPACTOR

NOTE - As noted in Task B.2 above, this operation will occur approximately 6 weeks after the installation.

a. Notify Tank Farm dispatcher that there will be a low flow alarm on FAS-K1-1.

b. CLOSE the appropriate valve.

c. Remove impactor system.

d. Replace the valve for the new sampling line and its associated tee removed from step B.2.d per Figure 2 .

NOTE - $\quad$ Tighten tubing supports loosened in Task B.2.

e. CLOSE the regulator for the new sampling line.

f. Turn off the pump for the new sampling line.

g. Adjust the appropriate regulator to maintain isokinetic flow through Beta CAM RE-KI-1.

h. Readjust monitor alarm set point to the original setpoint recorded in Task B.l.g.

\section{B4-5}


Work Plan WP-P-92-

i. Have HPT survey impactor, prepare it for transport, and transport it to the 222-S Laboratory.

IMPACTOR TEST COMPLETED: DATE COGNIZANT ENGINEER

C. CASCADE IMPACTOR SYSTEM TO SAMPLE FROM NEAR THE STACK OUTLET

1. PERFORM PRESTART CHECKS

a. Ensure that the cascade impactor has been properly prepared and assembled as directed by SAIC.

b. Ensure that all supporting parts and connections are available as directed by SAIC.

c. Ensure that the vacuum pump is operational and that 1 acfm is obtainable. (SAIC/WHC)

PRESTART CHECKS COMPLETED: DATE: COGNIZANT ENGINEER:

2. INSTALL CASCADE IMPACTOR SAMPLING SYSTEM

a. Ensure that the following pieces of equipment/supplies are properly protected before relocating the items:
(1) Impactor
(2) Flowmeter
(3) Vacuum Gauge
(4) Vacuum Pump(s)
(5) Tubing
(6) Connectors
(7) Heating Tape/Sheath with Controller
(8) Platform
(9) Shelter
(10) Extension Cord
(11) Power Bar.

b. Set up sampling system per SAIC guidance/ instructions.

(1) Place appropriate equipment on the platform and make connections from the cascade impactor to the flowmeter, from the flowmeter to the vacuum gauge, and from the vacuum gauge to the vacuum pump per Figure 4.

(2) Field check equipment performance. 
WHC-EP-0680

Work Plan WP-P-92-

Page $\overline{7}$

(3) Locate equipment in proper location on the platform. Refer to Figure 4.

(4) Prepare set-up for operation by securing all equipment to the platform and verify that all connections made to this point are secure.

c. Penetrate the AP Tank Farm stack with the sampling probe under guidance from the Cognizant Engineer (WHC or the SAIC representative).

d. Connect the sampling probe to the cascade impactor per Figure 4. (WHC)

e. Initiate the cascade impactor sample. (SAIC)

(1) Determine the appropriate correction factor for the in-line flowmeter using Table I.

(2) Set the proper flowrate using. Table II.

f. Position and secure the shelter over the sampling system. (WHC)

INSTALLATION COMPLETED: DATE: COGNIZANT ENGINEER:

3. PERIODICALLY CHANGE LOCATION OF THE SAMPLE PROBE IN THE AP STACK (296-A-40) ACCORDING TO THE SCHEDULE AND DESCRIPTION IN TABLE III. (SAIC/WHC)

a. A continuous sample will be obtained using ten different locations in the AP Stack.

b. Three options for the sampling schedule are offered. The option chosen will be based on the availability of WHC personnel to initiate the sampling.

c. The option chosen is to be circled in the procedure.

d. Initials of responsible personnel, dates, and times that the probe is moved shall be recorded in Table III.

e. The probe shall be moved to the specific locations inside the stack in the order 1 isted in this procedure. This way, the probe will be inserted farther into the stack until the last position has been used. The probe will not be removed until all 10 samples have been obtained. 
WHC-EP-0680

Work Plan WP-P-92-

f. Sample numbers corresponding to the sample locations have been pre-marked on the sample probe.

SAMPLING COMPLETED: DATE/TIME: COGNIZANT ENGINEER:

4. REMOVE CASCADE IMPACTOR SYSTEM

NOTE: This operation will occur 6-7 weeks after the installation and will be directed by SAIC.

a. Remove the shelter over the sampling system. (WHC)

b. Stop the cascade impactor sample. (SAIC)

c. Disconnect the sampling probe from the cascade impactor. (WHC)

d. Remove the sampling probe from the AP stack and bag or wrap it in plastic. (WHC/SAIC)

e. Remove the cascade impactor from the sampling system and bag it. (WHC)

f. Dismantle sampling system. (SAIC/WHC)

(1) Survey equipment- on the platform. (WHC)

(2) Remove equipment from the platform. (WHC/SAIC)

(3) Bag or package selected pieces of equipment as necessary. (WHC)

g. Relocate equipment from scafolding to ground level. (WHC)

NOTE: The following two steps may be performed in any order.

h. Store equipment as required. (WHC)

i. Request HPT to survey impactor and sampling probe, prepare them for transport, and transport them to the 222-S Laboratory (WHC)

SYSTEM REMOVAL COMPLETED: DATE: COGNIZANT ENGINEER: 
Work Plan WP-P-92-

Page 9

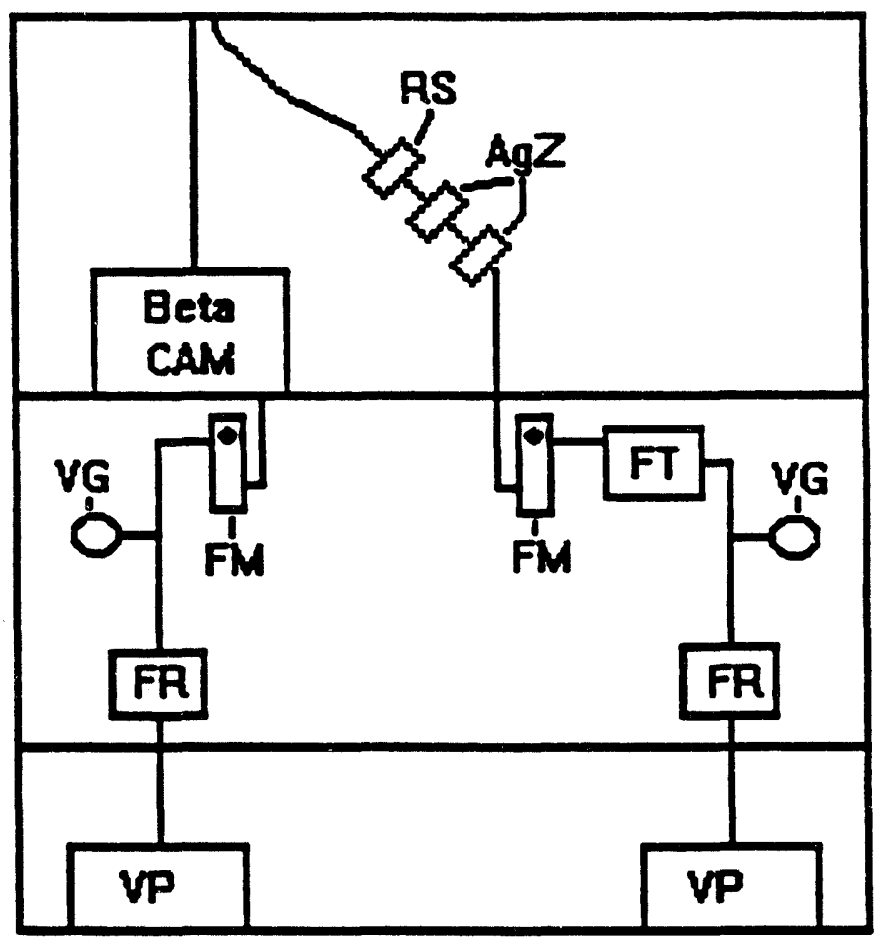

LEGEND: RS - Record Sampler; AgZ - Silver Zeolite Cartridges; VG - Vacuum Gauge; FM - Flowneter; FT - Flow Totalizer; FR - Flow Regulator; VP - Vacuum Pump

Figure 1. AP Tank Farm Stack (296-A-40) Instrument Cabinet (Prior to Modifications) 
Work Plan WP-P-92-

Page $\overline{10}$

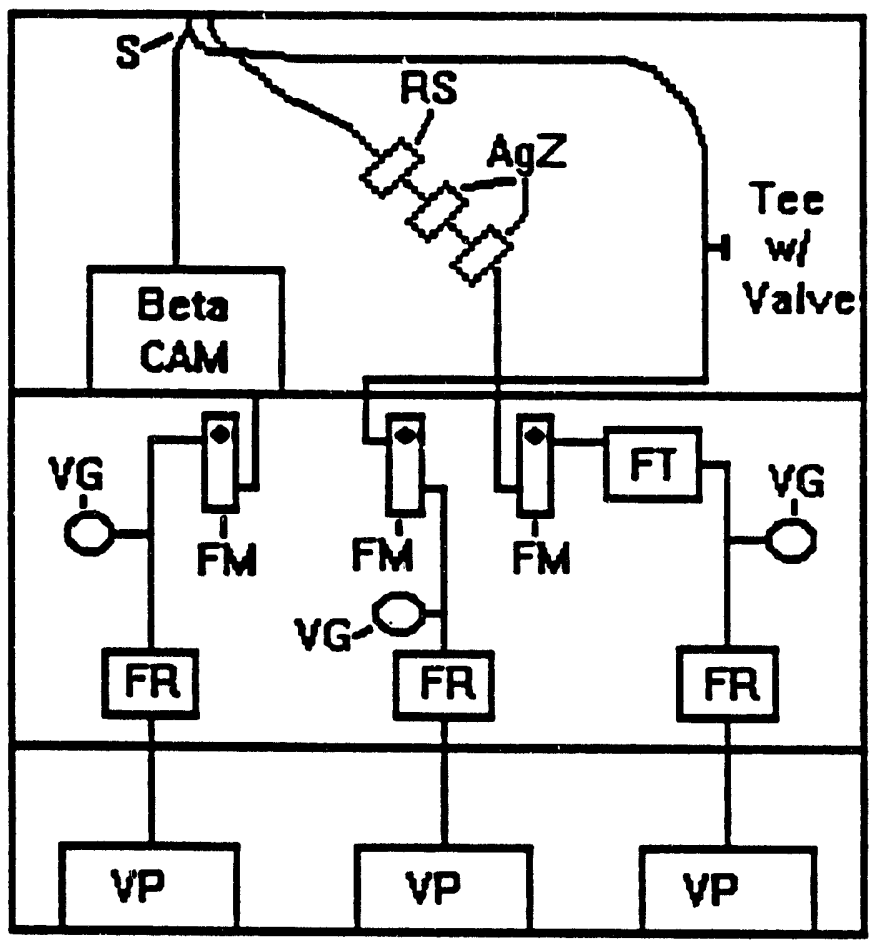

LEGEND: S- Splitter; RS - Record Sampler; AgZ - Silver Zeolite Cartridges; VG - Vacuum Gauge; FM - Flowmeter; FT - Flow Totalizer; FR - Flow Regulator; VP - Vacuum Pump

Figure 2. AP Tank Farm Stack (296-A-40) Instrument Cabinet with Tee and Associated Valve in New Sampling System 


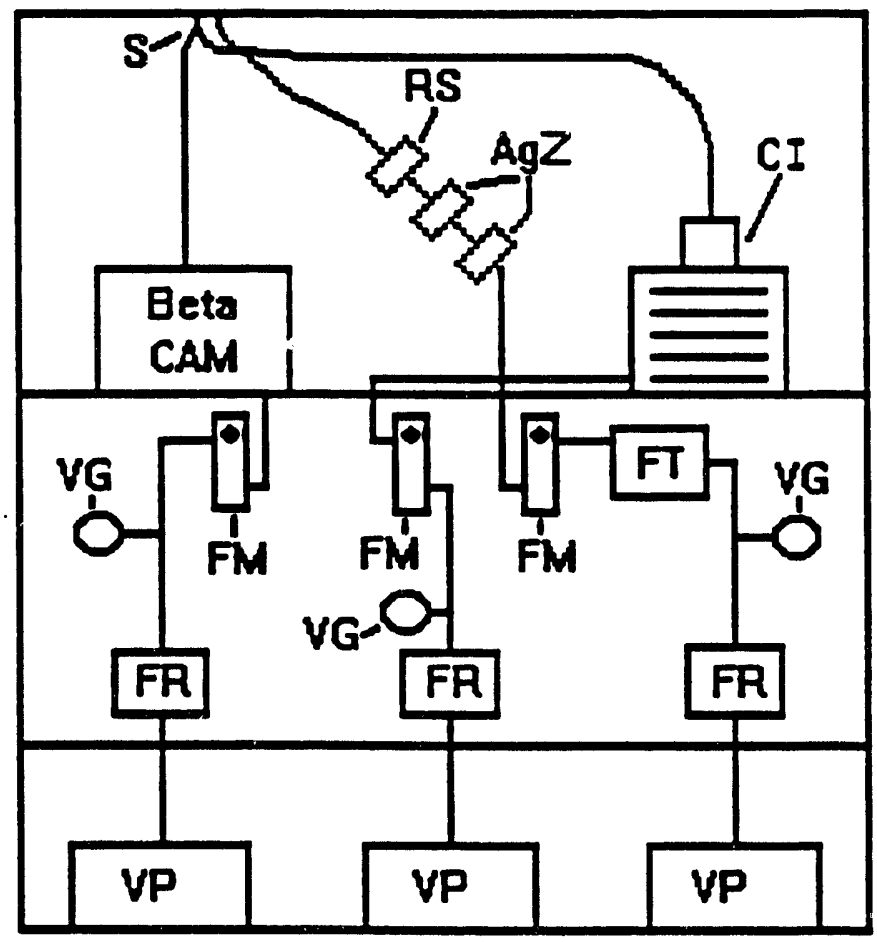

LEGEND: S- Splitter; RS - Record Sampler; AgZ - Silver Zeolite Cartridges; VG - Vacuum Gauge; FM - Flowmeter; FT - Flow Totalizer; FR - Flow Regulator; VP - Vacuum Pump; CI - Cascade Impactor

Figure 3. AP Tank Farm Stack (296-A-40) Instrument Cabinet with Cascade Impactor Sampling System 


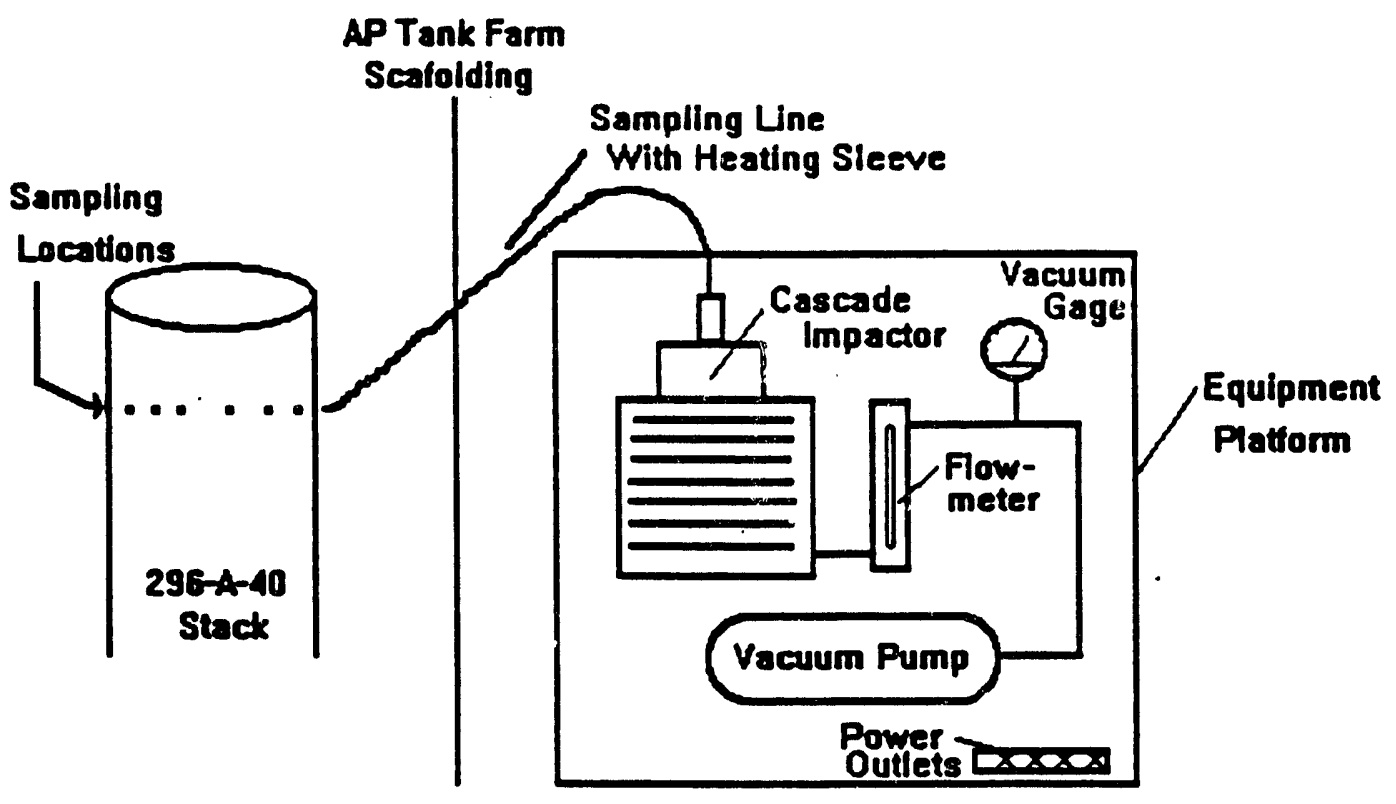

Figure 4. Cascade Impactor Sampling System to be Used to Sample Near the Outlet of Stack $296-A-40$ 
Table I. Correction Factors Required for In-Line Flowmeter Readings due to Vacuum

\begin{tabular}{|c|c|c|c|c|c|}
\hline Vacura & $\begin{array}{c}\text { Fownter Correction } \\
\text { Factor }\end{array}$ & $\begin{array}{l}\text { Vacum } \\
\left({ }^{\circ} \mathrm{Hg}\right)\end{array}$ & $\begin{array}{c}\text { Fowneter Correction } \\
\text { Factor }\end{array}$ & $\begin{array}{l}\text { Vacuug } \\
\left({ }^{\circ} \mathrm{Hg}\right)\end{array}$ & $\begin{array}{c}\text { Fownatar Correction } \\
\text { Factor }\end{array}$ \\
\hline $\begin{array}{l}0.1 \\
0.2 \\
0.3 \\
0.4 \\
0.5 \\
0.6 \\
0.7 \\
0.8 \\
0.9 \\
1.0 \\
1.1 \\
1.2 \\
1.3 \\
1.4 \\
1.5 \\
1.6 \\
1.7 \\
1.8 \\
1.9 \\
2.0 \\
2.1 \\
2.2 \\
2.3 \\
2.4 \\
2.5 \\
2.6 \\
2.7 \\
2.8 \\
2.9 \\
3.0\end{array}$ & $\begin{array}{l}1.002 \\
1.003 \\
1.005 \\
1.007 \\
1.008 \\
1.010 \\
1.012 \\
1.014 \\
1.015 \\
1.017 \\
1.019 \\
1.021 \\
1.022 \\
1.024 \\
1.026 \\
1.028 \\
1.030 \\
1.032 \\
1.033 \\
1.035 \\
1.037 \\
1.039 \\
1.041 \\
1.043 \\
1.045 \\
1.047 \\
1.048 \\
1.050 \\
1.052 \\
1.054 \\
1.056 \\
1.058 \\
1.060 \\
1.062 \\
1.064 \\
1.066 \\
1.068 \\
1.070 \\
1.072 \\
1.074 \\
1.076 \\
1.079 \\
1.081 \\
1.083 \\
1.085 \\
1.087 \\
1.089 \\
1.091 \\
1.094 \\
1.096 \\
1.098 \\
1.100 \\
1.102 \\
1.105 \\
1.107 \\
1.109 \\
1.111 \\
1.114 \\
1.116\end{array}$ & $\begin{array}{l}6.0 \\
6.1 \\
6.2 \\
6.3 \\
6.4 \\
6.5 \\
6.6 \\
6.7 \\
6.8 \\
6.9 \\
7.0 \\
7.1 \\
7.2 \\
7.3 \\
7.4 \\
7.5 \\
7.6 \\
7.7 \\
7.8 \\
7.9 \\
8.0 \\
8.1 \\
8.2 \\
8.3 \\
8.4 \\
8.5 \\
8.6 \\
8.7 \\
8.8 \\
8.9 \\
9.0 \\
9.1 \\
9.2 \\
9.3 \\
9.4 \\
9.5 \\
11.9 \\
11.3 \\
11.6 \\
11.4 \\
9.5 \\
11.3 \\
9.8 \\
9.9 \\
10.0 \\
10.1 \\
10.2 \\
10.3 \\
10.4 \\
10.5 \\
10.6 \\
10.7 \\
10.8 \\
10.9 \\
11.0 \\
11.1 \\
11.2 \\
\end{array}$ & $\begin{array}{l}1.118 \\
1.121 \\
1.123 \\
1.125 \\
1.128 \\
1.130 \\
1.133 \\
1.135 \\
1.138 \\
1.140 \\
1.143 \\
1.145 \\
1.148 \\
1.150 \\
1.153 \\
1.155 \\
1.158 \\
1.160 \\
1.163 \\
1.166 \\
1.168 \\
1.171 \\
1.174 \\
1.176 \\
1.179 \\
1.182 \\
1.185 \\
1.187 \\
1.190 \\
1.193 \\
1.196 \\
1.199 \\
1.202 \\
1.205 \\
1.208 \\
1.210 \\
1.213 \\
1.216 \\
1.219 \\
1.222 \\
1.226 \\
1.229 \\
1.232 \\
1.235 \\
1.238 \\
1.241 \\
1.244 \\
1.248 \\
1.251 \\
1.254 \\
1.258 \\
1.261 \\
1.264 \\
1.268 \\
1.271 \\
1.274 \\
1.278 \\
1.281 \\
1.285 \\
1.289\end{array}$ & $\begin{array}{l}12.0 \\
12.1 \\
12.2 \\
12.3 \\
12.4 \\
12.5 \\
12.6 \\
12.7 \\
12.8 \\
12.9 \\
13.0 \\
13.1 \\
13.2 \\
13.3 \\
13.4 \\
13.5 \\
13.6 \\
13.7 \\
13.8 \\
13.9 \\
14.0 \\
14.1 \\
14.2 \\
14.3 \\
14.4 \\
14.5 \\
14.6 \\
14.7 \\
14.8 \\
14.9 \\
15.0 \\
15.1 \\
15.2 \\
15.3 \\
15.4 \\
15.5 \\
15.6 \\
15.7 \\
15.8 \\
15.9 \\
16.0 \\
17.9 \\
17.1 \\
16.2 \\
16.3 \\
16.4 \\
17.6 \\
16.5 \\
16.6 \\
16.7 \\
16.8 \\
16.9 \\
17.0 \\
17.1 \\
17.2 \\
17.3 \\
\end{array}$ & $\begin{array}{l}1.292 \\
1.296 \\
1.299 \\
1.303 \\
1.307 \\
1.311 \\
1.314 \\
1.318 \\
1.322 \\
1.326 \\
1.330 \\
1.324 \\
1.338 \\
1.342 \\
1.346 \\
1.350 \\
1.354 \\
1.358 \\
1.362 \\
1.367 \\
1.371 \\
1.375 \\
1.380 \\
1.384 \\
1.388 \\
1.393 \\
1.397 \\
1.402 \\
1.407 \\
1.411 \\
1.416 \\
1.421 \\
1.426 \\
1.431 \\
1.435 \\
1.440 \\
1.445 \\
1.451 \\
1.456 \\
1.461 \\
1.466 \\
1.471 \\
1.477 \\
1.482 \\
1.488 \\
1.493 \\
1.499 \\
1.504 \\
1.510 \\
1.516 \\
1.522 \\
1.528 \\
1.534 \\
1.540 \\
1.546 \\
1.552 \\
1.558 \\
1.565 \\
1.571 \\
1.578\end{array}$ \\
\hline
\end{tabular}


Table II. Brooks Flowmeter (Model R-615-B, Carboloy, Spherical 8all) Calibration Data

\begin{tabular}{|c|c|c|c|c|c|c|c|}
\hline $\begin{array}{l}\text { Tube Reading } \\
\text { (mol) }\end{array}$ & $\begin{array}{c}\text { Fow Rate } \\
\text { (cfin) }\end{array}$ & Tube Reading & Fow Rate & Tube Reading & Flow Rate & $\begin{array}{c}\text { Tube Reading } \\
\text { (mim) }\end{array}$ & Fow Rate \\
\hline $\begin{array}{l}150.0 \\
149.0 \\
148.0 \\
147.0 \\
146.0 \\
145.0 \\
144.0 \\
143.0 \\
142.0 \\
141.0 \\
140.0 \\
139.0 \\
138.0 \\
137.0 \\
136.0 \\
135.0 \\
134.0 \\
133.0 \\
132.0 \\
131.0 \\
130.0 \\
129.0 \\
128.0 \\
127.0 \\
126.0 \\
125.0 \\
124.0 \\
123.0 \\
122.0 \\
121.0 \\
120.0 \\
119.0 \\
118.0 \\
117.0 \\
116.0 \\
115.0 \\
114.0 \\
113.0 \\
112.0 \\
111.0\end{array}$ & $\begin{array}{l}2.160 \\
1.142 \\
2.123 \\
2.105 \\
2.086 \\
2.068 \\
2.049 \\
2.031 \\
2.013 \\
1.995 \\
1.977 \\
1.960 \\
1.942 \\
1.925 \\
1.908 \\
1.891 \\
1.875 \\
1.860 \\
1.844 \\
1.829 \\
1.813 \\
1.798 \\
1.783 \\
1.767 \\
1.752 \\
1.736 \\
1.721 \\
1.705 \\
1.689 \\
1.673 \\
1.656 \\
1.640 \\
1.624 \\
1.607 \\
1.591 \\
1.574 \\
1.558 \\
1.541 \\
1.525 \\
1.509\end{array}$ & $\begin{array}{r}110.0 \\
109.0 \\
108.0 \\
107.0 \\
106.0 \\
105.0 \\
104.0 \\
103.0 \\
102.0 \\
101.0 \\
100.0 \\
99.0 \\
98.0 \\
97.0 \\
96.0 \\
95.0 \\
94.0 \\
93.0 \\
92.0 \\
91.0 \\
90.0 \\
89.0 \\
88.0 \\
87.0 \\
86.0 \\
85.0 \\
84.0 \\
83.0 \\
82.0 \\
81.0 \\
80.0 \\
79.0 \\
78.0 \\
77.0 \\
76.0 \\
75.0 \\
74.0 \\
73.0 \\
72.0 \\
71.0\end{array}$ & $\begin{array}{l}1.493 \\
1.477 \\
1.461 \\
1.446 \\
1.430 \\
1.416 \\
1.401 \\
1.387 \\
1.373 \\
1.359 \\
1.345 \\
1.331 \\
1.317 \\
1.303 \\
1.289 \\
1.274 \\
1.260 \\
1.245 \\
1.230 \\
1.215 \\
1.199 \\
1.183 \\
1.167 \\
1.151 \\
1.134 \\
1.118 \\
1.102 \\
1.085 \\
1.069 \\
1.053 \\
1.036 \\
1.020 \\
1.005 \\
0.989 \\
0.974 \\
0.959 \\
0.944 \\
0.929 \\
0.915 \\
0.900\end{array}$ & $\begin{array}{l}70.0 \\
69.0 \\
68.0 \\
67.0 \\
66.0 \\
65.0 \\
64.0 \\
63.0 \\
62.0 \\
61.0 \\
60.0 \\
59.0 \\
58.0 \\
57.0 \\
56.0 \\
55.0 \\
54.0 \\
53.0 \\
52.0 \\
51.0 \\
50.0 \\
49.0 \\
48.0 \\
47.0 \\
46.0 \\
45.0 \\
44.0 \\
43.0 \\
42.0 \\
41.0 \\
40.0 \\
39.0 \\
38.0 \\
37.0 \\
36.0 \\
35.0 \\
34.0 \\
33.0 \\
32.0 \\
31.0\end{array}$ & $\begin{array}{l}0.886 \\
0.872 \\
0.857 \\
0.843 \\
0.829 \\
0.815 \\
0.801 \\
0.787 \\
0.772 \\
0.758 \\
0.744 \\
0.730 \\
0.716 \\
0.702 \\
0.689 \\
0.675 \\
0.661 \\
0.647 \\
0.634 \\
0.620 \\
0.606 \\
0.593 \\
0.579 \\
0.566 \\
0.553 \\
0.539 \\
0.526 \\
0.513 \\
0.500 \\
0.487 \\
0.475 \\
0.462 \\
0.449 \\
0.436 \\
0.423 \\
0.411 \\
0.398 \\
0.385 \\
0.373 \\
0.360\end{array}$ & $\begin{array}{r}30.0 \\
29.0 \\
28.0 \\
27.0 \\
26.0 \\
25.0 \\
24.0 \\
23.0 \\
22.0 \\
21.0 \\
20.0 \\
19.0 \\
18.0 \\
17.0 \\
16.0 \\
15.0 \\
14.0 \\
13.0 \\
12.0 \\
11.0 \\
10.0 \\
9.0 \\
8.0 \\
7.0 \\
6.0 \\
5.0\end{array}$ & $\begin{array}{l}0.347 \\
0.335 \\
0.323 \\
0.310 \\
0.298 \\
0.286 \\
0.273 \\
0.261 \\
0.249 \\
0.237 \\
0.225 \\
0.213 \\
0.201 \\
0.189 \\
0.177 \\
0.166 \\
0.154 \\
0.143 \\
0.131 \\
0.120 \\
0.109 \\
0.097 \\
0.086 \\
0.075 \\
0.063 \\
0.052\end{array}$ \\
\hline
\end{tabular}


Table III. Cascade Sample Acquisition Information

\begin{tabular}{|c|c|c|c|c|c|c|}
\hline \multirow[b]{2}{*}{$\begin{array}{l}\text { Saple } \\
\text { number }\end{array}$} & \multirow[b]{2}{*}{$\begin{array}{l}\text { Location } \\
\text { Instde Stack }\end{array}$} & \multicolumn{3}{|c|}{$\begin{array}{c}\text { Day Started } \\
\text { (Sampling Period [days]) }^{(1)}(2)\end{array}$} & \multicolumn{2}{|c|}{$\begin{array}{l}\text { Initial and Record Date and } \\
\text { Time as Each Sample is Started }\end{array}$} \\
\hline & & Option 1 & Option 2 & Option 3 & Initials & Date/Tín \\
\hline 1 & $7 / 8^{\circ}$ & $\omega(9)$ & $F(10)$ & $M(9)$ & & \\
\hline 2 & $11 / 2^{\circ}$ & $f(5)$ & $M(4)$ & $H(5)$ & & \\
\hline 3 & $21 / 4^{\circ}$ & $W(5)$ & $F(5)$ & $M(4)$ & & \\
\hline 4 & $33 / 8^{\prime \prime}$ & $M(4)$ & $W(5)$ & $F(5)$ & & \\
\hline 5 & $65 / 8^{\circ}$ & $F(5)$ & $M(4)$ & $H(5)$ & & \\
\hline 6 & $73 / 4^{m}$ & $W(5)$ & $F(5)$ & $M(4)$ & & \\
\hline 7 & $81 / 2^{\circ}$ & $M(4)$ & $W(5)$ & $F(5)$ & & \\
\hline 8 & $91 / 8^{\circ}$ & $F(10)$ & $M(9)$ & $W(9)$ & & \\
\hline
\end{tabular}

(II) Once an option is chosen and initiated, that schedule must be completed.

(2) Circle the option being used. 
WHC-EP-0680

This page intentionally left blank.

B4-16 
WHC-EP-0680

\section{APPENDIX B-5}

B5- 1 
WHC-EP-0680

This page intentionally left blank.

$B 5-i i$ 
INSTALL LASER SPECTROMETER ON

PR (296-A-1) STACX (ROOF LOCATION)

I. GENERAL DESCRIPTION

This work plan provides instructions for installing, operating, and removing a laser spectrometer monitoring system for the PR Stack on the roof of the PUREX Butlding. The spectrometer will be installed on the roof and will be located on a movable platform near the PR Stack to measure the atr in the PR Stack. The sample probe and spectrometer will be moved periodically (1.e., after readings have stabilized) to obtain representative data from the stack. Analysis of the data obtained with the unit will provide particle size distribution information on particulates in the EP gaseous effluent stream.

The installation and removal of this laser spectrometer need to coincide as closely as possible (i.e., same day, near the same time) with Work Plan WP-P-92-029 (Work Package 2A-92-0665).

II. PREPLANNING/COORDINATION

The organizational responsibilities are as follows:

Cognizant Effluent Engineer Function as the work $p$ lan manager, in association with SAIC personnel, with overall responsibility for coordinating the activities; technical point of contact for questions.

SAIC Personnel

Provide cognizant effluent engineer with technical assistance and guidance for the duration of this plan. Also provide the fittings, sampling line with inlet probe, and platform.

Environmental Protection Personne 1

Provide the laser spectrometer.

PUREX Heal th and Safety

Provide HPT coverage during the installation, moving, and removal of the laser spectrometer system.

PUREX Maintenance

Support installation/removal of laser spectrometer system per approved work package 2A-92-0666.

This work plan can be red-lined in the field with the appropriate approvals for the change per WHC-IP-0240, Section 4. 


\section{SAFETY}

A. HP personnel must be present during performance of the installation, periodic moving, and removal tasks.

B. Appropriate safety measures must be performed when relocating the equipment from the ground location to the roof and from the roof to the ground location. Personnel climbing up and down the ladder near the PR Stack must be aware of the proper methods to perform this safely per guidance from WHC Industrial Safety and WHC-CM-4-3, standards $\mathrm{CM}-2$ and G-7. In particular:

1. Do not carry any equipment by hand up the ladders.

2. While on the canyon roof, remain within the area protected by the hand rails.

3. Lift the laser spectrometer to the roof by walking the rope from the edge of the roof, rather than lifting with the back or arms.

C. A pre-job safety meeting must be held.

D. All requirements of Radiation Protection Manual, WHC-CM-4-10, and Radiation Work Requirements and Permits Manual, WHC-CM-4-15, Vol. 2 shall be followed. RWP AKEH-011 applies to all work performed under these procedures.

E. All work performed under this work plan shall conform to WHC-CM-43 and all requirements for Hoisting and Rigging in WHC-CM-6-4 shall be met. Personnel shall not hand-carry anything on the ladders.

IV. PLAN

\section{A. PERFORM PRESTART CHECKS}

1. Hold a pre-job safety meeting.

Pre-job Safety Meeting Held (signature) (date)

2. Ensure that the laser spectrometer system has been properly prepared, is operational, and is assembled as directed by SAIC.

3. Ensure that all supporting parts and connections are available as directed by SAIC.

4. Ensure that the vacuum pump is operational and that 1 cfm is obtainable. (SAIC/WHC)

PRESTART CHECKS COMPLETED: DATE: COGNIZANT ENGINEER: 
B. INSTALL LASER SPECTROMETER MONITORING SYSTEM

NOTE: The installation of this laser spectrometer needs to coincide as closely as possible ( $1 . e .$, same day, near the same time) with Work Plan WP-P-92-029 (Work Package 2A-92-0665).

NOTE: Follow all Hoisting and Rigging Requirements per WHC-CM-6-4 and WHC-CM-4-3, Standard M-2. Do not hand-carry anything on the ladders.

1. Relocate the laser spectrometer to the canyon roof

a. Ensure that the laser spectrometer is properly protected (per SAIC guidance) before relocating to the canyon roof.

b. Use two ropes from the laser spectrometer to the canyon roof.

\section{WARNING}

DO NOT ATTEMPT TO LIFT THE LASER SPECTROMETER TO THE CANYON ROOF WITH YOUR BACK AND ARMS; USE YOUR LEGS. DO NOT WALK OVER HALF-WAY ACROSS THE ROOF WHILE LIFTING THE LASER SPECTROMETER; LET SOMEONE ELSE START AT THE EDGE OF THE ROOF BY THE HAND RAIL. DO NOT APPROACH THE EDGE OF THE ROOF AWAY FROM A HAND RAIL.

c. Use one person on each rope, walking away from the edge of the roof to lift the laser spectrometer.

d. When one person reaches the center line of the roof, have another start lifting from the hand rail.

e. When the laser spectrometer has reached the level of the canyon roof, it may be lifted through or over the hand rail. 
2. Relocate remaining equipment from ground level to roof. (WHC)

a. Ensure that the following pieces of equipment/supplies are properly protected before relocating items to the roof:

(1) Flowneter

(2) Vacuum Gauge

(3) Vacuum Pump

(4) Tubing

(5) Connectors

(6) Platform

(7) Extension Cords

(8) Power bar

(9) Extension Cords

b. Transport equipment to the roof of $202 \mathrm{~A}$ near the PR stack using ropes, buckets, etc.

3. Set up monitoring system per SAIC guidance/instructions.

a. Place appropriate equipment on the platform and make connections from the laser spectrometer to the flowmeter, from the flowmeter to the vacuum gauge, and from the vacuum gauge to the vacuum pump per figure 1.

b. Field check equipment performance.

c. Locate equipment in proper location on the platform. Refer to Figure 1.

d. Prepare set-up for operation by securing all equipment to the platform and verify that all connections made to this point are secure.

4. Penetrate the PR stack with the sampling probe using the $1 / 2^{\prime \prime}$-hole located approximately $10^{\prime \prime}$ above the roof level. (WHC/SAIC)

5. Connect the sampling probe to the laser spectrometer per Figure 1. (WHC)

6. Initiate the laser spectrometer sample. (SAIC)

a. Determine the appropriate correction factor for the in-line flowmeter using Table I.

b. Set the proper flowrate using Table II.

INSTALLATION COMPLETED: DATE: COGNIZANT ENGINEER: 
C. CHANGE LOCATION OF THE SAMPLE PROBE IN THE PR STACK ACCORDING TO THE DESCRIPTION IN TABLE III. (SAIC/WHC)

\section{Particulate measurements will be made at nine different locations in the PR Stack}

2. Record initials of responsible personnel and times that the probe is moved in Table III.

NOTE: The probe will be inserted farther into the stack until the last position has been used. The probe will not be removed until all 9 measurements have been obtained.

3. Move the probe to the specific locations inside the stack in the order listed in this procedure, per instructions from SAIC personnel.

4. Sample numbers corresponding to the sample locations have been pre-marked on the sample probe.

MONITORING COMPLETED: DATE/TIME: COGNIZANT ENGINEER:

D. REMOVE LASER SPECTROMETER SYSTEM

1. Stop the laser spectrometer sample. (SAIC)

2. Disconnect the sampling probe from the laser spectrometer. (WHC)

* HP Hold Point *t

3. Remove the sampling probe from the PR stack. Wtpe the probe as it is removed from the stack.

Sample probe wiped down and smearable contamination is < detectable (Initial/Date)

4. Bag or wrap the probe in plastic. (WHC/SAIC)

5. Remove the laser spectrometer from the sampling system, survey it, and re-position it in its transport box. (WHC)

6. Dismantle sampling system. (SAIC/WHC)

a. Survey equipment on the platform. (WHC)

b. Remove equipment from the platform. (WHC/SAIC) 
c. Bag or package selected pieces of equipment as necessary per HPT direction. (WHC)

NOTE: Follow all Hoisting and Rigging requirements per WHC-CM-6-4 and WHC-CM-4-3, standard M-2. Do not hand-carry anything on the ladders.

7. Relocate the laser spectrometer from the canyon roof to the shop roof.
a. Ensure that the laser spectrometer is properly protected (per SAIC guidance) before relocating to the shop roof.
b. Use two ropes from the laser spectrometer to the canyon roof.

\section{WARNING}

DO NOT ATTEMPT TO LIFT THE LASER SPECTROMETER FROM THE CANYON ROOF WITH YOUR BACK AND ARMS; USE YOUR LEGS. DO NOT WALK OVER HALF-WAY ACROSS THE ROOF WHILE RELOCATING THE LASER SPECTROMETER. DO NOT APPROACH THE EDGE OF THE ROOF AWAY FROM A HAND RAIL.

c. Use one person on each rope, walking toward the hand rail to lift the laser spectrometer down to the shop roof.

d. When one person reaches the hand rail, have anotlier start lifting from the center line of the roof.

8. Relocate equipment from roof to ground level. (WHC)

NOTE: The following two steps may be performed in any order

9. Store equipment as required. (WHC)

*t HP Hold Point t*

10. Request HPT to survey the sampling probe for release.

Sampling probe surveyed (Initial/Date):

11. Prepare the sampling probe for transport, and transport it to storage or to the next location of use. (WHC)

12. Clean up work area.

SYSTEM REMOVAL COMPLETED: DATE: COGNIZANT ENGINEER: 


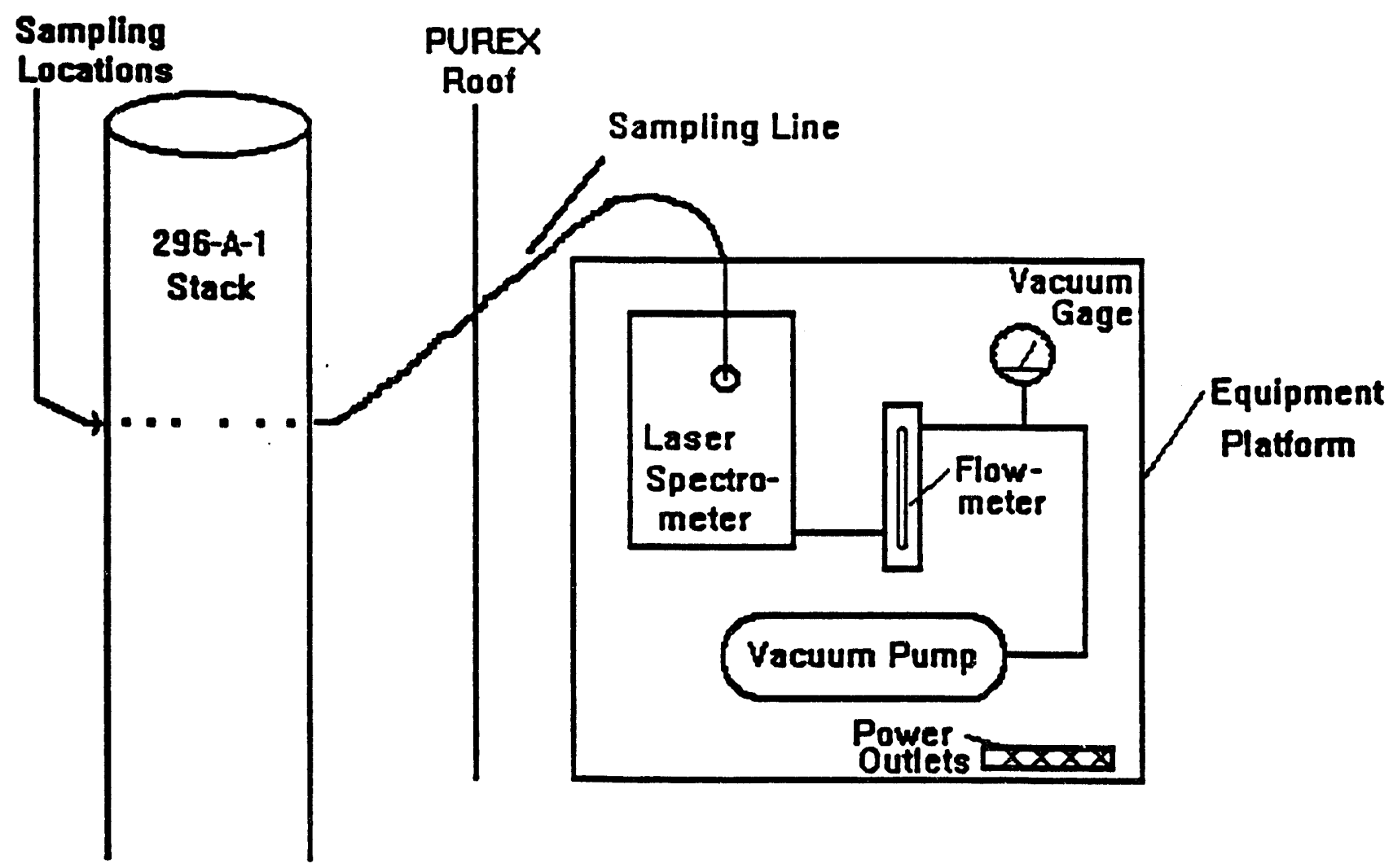

Figure 1. Laser Spectrometer Set-Up for the PR Stack (Roof Sample) B5-7 
Table 1. Correction Factors Required for In-Line Flowmeter Readings due to Vacuum

\begin{tabular}{|c|c|}
\hline Vacuum ("Hg) & $\begin{array}{c}\text { Flowmeter } \\
\text { Correction } \\
\text { Factor }\end{array}$ \\
\hline $\begin{array}{l}0.25 \\
0.50 \\
0.75 \\
1.00 \\
1.25 \\
1.50 \\
1.75 \\
2.00 \\
2.25 \\
2.50 \\
2.75 \\
3.00 \\
3.25 \\
3.50 \\
3.75 \\
4.00 \\
4.25 \\
4.50 \\
4.75 \\
5.00 \\
5.25 \\
5.50 \\
5.75 \\
6.00 \\
6.25 \\
6.50 \\
6.75 \\
7.00 \\
7.25 \\
7.50 \\
7.75 \\
8.00 \\
8.25 \\
8.50 \\
8.75 \\
9.00 \\
9.25 \\
9.50 \\
9.75 \\
10.00\end{array}$ & $\begin{array}{l}1.004 \\
1.008 \\
1.013 \\
1.017 \\
1.022 \\
1.026 \\
1.031 \\
1.035 \\
1.040 \\
1.045 \\
1.049 \\
1.054 \\
1.059 \\
1.064 \\
1.069 \\
1.074 \\
1.080 \\
1.085 \\
1.090 \\
1.096 \\
1.101 \\
1.107 \\
1.113 \\
1.118 \\
1.124 \\
1.130 \\
1.136 \\
1.143 \\
1.149 \\
1.155 \\
1.162 \\
1.168 \\
1.175 \\
1.182 \\
1.189 \\
1.196 \\
1.203 \\
1.210 \\
1.218 \\
1.226\end{array}$ \\
\hline
\end{tabular}


Table II. Brooks Flowmeter (Model R-615-8, Carjoloy, Spherical Ball) Calibration Data

\begin{tabular}{|c|c|c|c|c|c|c|c|}
\hline $\begin{array}{c}\text { Tube } \\
\text { Reading } \\
\text { (Ii) }\end{array}$ & $\begin{array}{l}\text { Flow } \\
\text { Rate } \\
\text { (cfm) }\end{array}$ & $\begin{array}{l}\text { Tube } \\
\text { Reading }\end{array}$ & $\begin{array}{l}\text { Flow } \\
\text { Rate }\end{array}$ & $\begin{array}{c}\text { Tube } \\
\text { Reading }\end{array}$ & $\begin{array}{l}\text { Flow } \\
\text { Rate }\end{array}$ & $\begin{array}{c}\text { Tube } \\
\text { Reading } \\
\text { (IIII) }\end{array}$ & $\begin{array}{l}\text { Flow } \\
\text { Rate }\end{array}$ \\
\hline $\begin{array}{l}150.0 \\
149.0 \\
148.0 \\
147.0 \\
146.0 \\
145.0 \\
144.0 \\
143.0 \\
142.0 \\
141.0 \\
140.0 \\
139.0 \\
138.0 \\
137.0 \\
136.0 \\
135.0 \\
134.0 \\
133.0 \\
132.0 \\
131.0 \\
130.0 \\
129.0 \\
128.0 \\
127.0 \\
126.0 \\
125.0 \\
124.0 \\
123.0 \\
122.0 \\
121.0 \\
120.0 \\
119.0 \\
118.0 \\
117.0 \\
116.0 \\
115.0 \\
114.0 \\
113.0 \\
112.0 \\
111.0\end{array}$ & $\begin{array}{l}2.160 \\
1.142 \\
2.123 \\
2.105 \\
2.086 \\
2.068 \\
2.049 \\
2.031 \\
2.013 \\
1.995 \\
1.977 \\
1.960 \\
1.942 \\
1.925 \\
1.908 \\
1.891 \\
1.875 \\
1.860 \\
1.844 \\
1.829 \\
1.813 \\
1.798 \\
1.783 \\
1.767 \\
1.752 \\
1.736 \\
1.721 \\
1.705 \\
1.689 \\
1.673 \\
1.656 \\
1.640 \\
1.624 \\
1.607 \\
1.591 \\
1.574 \\
1.558 \\
1.541 \\
1.525 \\
1.509\end{array}$ & $\begin{array}{l}110.0 \\
109.0 \\
108.0 \\
107.0 \\
106.0 \\
105.0 \\
104.0 \\
103.0 \\
102.0 \\
101.0 \\
100.0 \\
99.0 \\
98.0 \\
97.0 \\
96.0 \\
95.0 \\
94.0 \\
93.0 \\
92.0 \\
91.0 \\
90.0 \\
89.0 \\
88.0 \\
87.0 \\
86.0 \\
85.0 \\
84.0 \\
83.0 \\
82.0 \\
81.0 \\
80.0 \\
79.0 \\
78.0 \\
77.0 \\
76.0 \\
75.0 \\
74.0 \\
73.0 \\
72.0 \\
71.0\end{array}$ & $\begin{array}{l}1.493 \\
1.477 \\
1.461 \\
1.446 \\
1.430 \\
1.416 \\
1.401 \\
1.387 \\
1.373 \\
1.359 \\
1.345 \\
1.331 \\
1.317 \\
1.303 \\
1.289 \\
1.274 \\
1.260 \\
1.245 \\
1.230 \\
1.215 \\
1.199 \\
1.183 \\
1.167 \\
1.151 \\
1.134 \\
1.118 \\
1.102 \\
1.085 \\
1.069 \\
1.053 \\
1.036 \\
1.020 \\
1.005 \\
0.989 \\
0.974 \\
0.959 \\
0.944 \\
0.929 \\
0.915 \\
0.900\end{array}$ & $\begin{array}{l}70.0 \\
69.0 \\
68.0 \\
67.0 \\
66.0 \\
65.0 \\
64.0 \\
63.0 \\
62.0 \\
61.0 \\
60.0 \\
59.0 \\
58.0 \\
57.0 \\
56.0 \\
55.0 \\
54.0 \\
53.0 \\
52.0 \\
51.0 \\
50.0 \\
49.0 \\
48.0 \\
47.0 \\
46.0 \\
45.0 \\
44.0 \\
43.0 \\
42.0 \\
41.0 \\
40.0 \\
39.0 \\
38.0 \\
37.0 \\
36.0 \\
35.0 \\
34.0 \\
33.0 \\
32.0 \\
31.0\end{array}$ & $\begin{array}{l}0.886 \\
0.872 \\
0.857 \\
0.843 \\
0.829 \\
0.815 \\
0.801 \\
0.787 \\
0.772 \\
0.758 \\
0.744 \\
0.730 \\
0.716 \\
0.702 \\
0.689 \\
0.675 \\
0.661 \\
0.647 \\
0.634 \\
0.620 \\
0.606 \\
0.593 \\
0.579 \\
0.566 \\
0.553 \\
0.539 \\
0.526 \\
0.513 \\
0.500 \\
0.487 \\
0.475 \\
0.462 \\
0.449 \\
0.436 \\
0.423 \\
0.411 \\
0.398 \\
0.385 \\
0.373 \\
0.360\end{array}$ & $\begin{array}{r}30.0 \\
29.0 \\
28.0 \\
27.0 \\
26.0 \\
25.0 \\
24.0 \\
23.0 \\
22.0 \\
21.0 \\
20.0 \\
19.0 \\
18.0 \\
17.0 \\
16.0 \\
15.0 \\
14.0 \\
13.0 \\
12.0 \\
11.0 \\
10.0 \\
9.0 \\
8.0 \\
7.0 \\
6.0 \\
5.0\end{array}$ & $\begin{array}{l}0.347 \\
0.335 \\
0.323 \\
0.310 \\
0.298 \\
0.286 \\
0.273 \\
0.261 \\
0.249 \\
0.237 \\
0.225 \\
0.213 \\
0.201 \\
0.189 \\
0.177 \\
0.166 \\
0.154 \\
0.143 \\
0.131 \\
0.120 \\
0.109 \\
0.097 \\
0.086 \\
0.075 \\
0.063 \\
0.052\end{array}$ \\
\hline
\end{tabular}


Table III. Laser Spectrometer Sample Acquisition Information

\begin{tabular}{|c|c|c|c|c|}
\hline \multirow{2}{*}{$\begin{array}{l}\text { Sample } \\
\text { Number }\end{array}$} & \multirow{2}{*}{$\begin{array}{l}\text { Location } \\
\text { Inside Stack }\end{array}$} & \multicolumn{2}{|c|}{$\begin{array}{l}\text { Initial and Record Time } \\
\text { Each Sample is Started }\end{array}$} & \multirow[b]{2}{*}{ Comments } \\
\hline & & Initials & Time & \\
\hline 1 & $21 / 4^{n}$ & & & \\
\hline 2 & $31 / 2^{n}$ & & & \\
\hline 3 & $51 / 2^{n}$ & & & \\
\hline 4 & $81 / 4^{\prime \prime}$ & & & \\
\hline 5 & $153 / 4^{n}$ & & & \\
\hline 6 & $181 / 2^{n}$ & & & \\
\hline 7 & $201 / 2^{n}$ & & & \\
\hline 8 & $22^{\prime \prime}$ & & & \\
\hline 9 & $233 / 8^{n}$ & & & \\
\hline
\end{tabular}


WHC-EP-0680

\section{APPENDIX B-6}

B6-i 
WHC-EP-0680

This page intentionally left blank.

B6-ii 
WHC-EP-0680

One Time Work Plan WP-P-92-029

Page 1 of 9

WORK PLAN

IMSTALL LASER SPECTROMETER ON PR (296-A-1) STACK CAM SAMPLER SYSTEM

I. GENERAL DESCRIPTION

This work plan provides instructions for installing and removing a laser spectrometer monitoring system in the PR Stack CAM sampler. The spectrometer will be installed on one leg of the CAM flow splitter and will use existing vacuum to provide flow through the unit. Operation of the CAM and record sampler will continue during the laser spectrometer test. Analysis of the data will provide particle size distribution information on effluent particulates.

Data will be printed during the acquisition of the data with the realtime monitor. Each printout will be labled, and the label copied onto the blue copy of this work plan.

The installation and removal of this laser spectrometer needs to coincide as closely as possible (i.e., same day, near the same time) with Work Plan WP-P-92-030 (Work Package 2A-92-0666)

II. PREPLANNING/COORDINATION

The organizational responsibilities are as follows:

Cognizant Effluent Engineer - Function as the work $p l$ an manager, in association with SAIC personnel, with overall responsibility for coordinating the activities; technical point of contact for questions.

SAIC Personne1

Environmental Protection Personnel

PUREX Health and Safety
- Provide cognizant effluent engineer with technical assistance and guidance for the duration of this plan. Also provide the fittings, platform, tubing, and sampling line with the inlet probe.

- Provide the laser spectrometer.

- Provide HPT coverage during the installation and removal of the laser spectrometer system.

B6-1 
WHC-EP-0680

PUREX Maintenance

One Time Work Plan WP-P-92-029

Page 2 of 9

Support installation/removal of laser spectrometer per approved work package \#2A-92-0665.

This work plan can be red-lined in the field with the appropriate approvals for the change per WHC-IP-0240, Section 4.

\section{SAFETY}

Limiting Condition for Operation (LCO) 12.6.3 requires operability of the sampling and monitoring systems on the 296-A-1 stack. Ensure the i zcord sample loop operation is not interrupted and CAM monitor downtime is minimized. An HPT must be present during performance of the installation/removal tasks.

IV. PLAN

A. PERFORM PRESTART CHECKS

1. Hold a Pre-Job Safety Meeting.

(signiture) (date)

2. Ensure that the laser spectrometer has been properly prepared and assembled. (SAIC)

3. Ensure that all supporting parts and connections are available.

4. Ensure that the stack alpha monitor RAN-V29A-1-1 is operating properly.

5. Notify PUREX Heal th and Safety Supervisor and the Operating Shift Supervisor that RAN-V29A-1-1 will be taken out of service during the laser spectrometer installation and use.

6. Ensure pump P-V28A-1 is running. 
WHC-EP-0680

One Time Work PIan WP-P-92-029

Page 3 of 9

NOTE - Step 7 will be performed with the assistance of the cognizant engineer, based on the stack flow rate and the design of the sample probe.

7. Determine flow required to maintain isokinesis through sample probe.

Stack flow $=\overline{\text { stack }}^{\text {cfm }}$ flow $\times 0.000519=\ldots$ scfm
Total flow
Flow for laser spectrometer $=$ scfm $_{\text {scfm }}$

8. Install tag stating setpoint and monitor flow.

9. Notify the cognizant engineer, Operations Supervisor, and Health and Safety Supervisor that the monitor flow rate has been reduced and will remain at the new levels for approximately one to two hours.

PRESTART CHECKS COMPLETED: DATE COGNIZANT ENGINEER

\section{B. INSTALL LASER SPECTROMETER}

NOTE - This plan involves the both the installation and removal of the laser spectrometer. The time between the two operations will be approximately two hours. The installation of this laser spectrometer needs to coinctde as closely as possible (i.e., same day, near the same time) with Work Plan WP-P-92-030 (Work Package 2A-92-0666). Cognizant Engineer and SAIC personnel must be present before proceeding.

* HP Hold Point *

1. Notify PUREX dispatcher that there will be a low flow alarm on FA-V29A-3-1.

Dispatcher Notified (Initial/Date)

2. OPEN regulator FCV -V29A-1-1 and obtain flow rate determined in task A.6. Maintain flow for 10 minutes.

3. CLOSE valve MV-V28A-5-3.

4. Remove valve MV-V28A-5-15 and its associated tee per Figure 1. 
WHC-EP-0680

One Time Work Plan WP-P.92-029

Page 4 of 9

* HP Hold Point **

5. Survey MV-V28A-5-15 for smearable contamination.

Valve Surveyed (Initial/Date)

Survey Results

6. Place MV-V28A-5-15 plastic bag.

NOTE - Tubing supports may be loosened to provide free movement and space for connections.

7. Connect laser spectrometer system in place of tee.

NOTE - Experience has shown that two pumps may be needed to obtain suffictent vacuum.

8. If needed to supply sufficient vacuum, activate Pump P-V29A-1:

a. Energize Pump P-V29-A-1 using MS-V29A-4-4.

b. Adjust valves in the following sequence:

MV-29A-5-1 OPEN

MV-29A-5-2 OPEN

* HP Hold Point **

9. OPEN valve MV-V28A-5-3 and adjust regulators FCV-V29A-2-1 and FCV-V29A-1-1 to obtain the flow values determined in Task A, step 6.

Regulators Adjusted (Initial/Date)

Flow for laser spectrometer:

Flow for RAN-V29A-1-1:

INSTALLATION COMPLETED: DATE COGNIZANT ENGINEER 
C. OPERATE LASER SPECTROMETER

NOTE: SAIC personnel will operate the laser spectrometer to measure the particle loading in the sample line. The laser spectrometer will print out the resulting data.

1. Obtain at least one printout of data from the laser spectrometer.

2. Label all printouts and record the labels, with appropriate comments, below:

Printout Time/Initials Comments
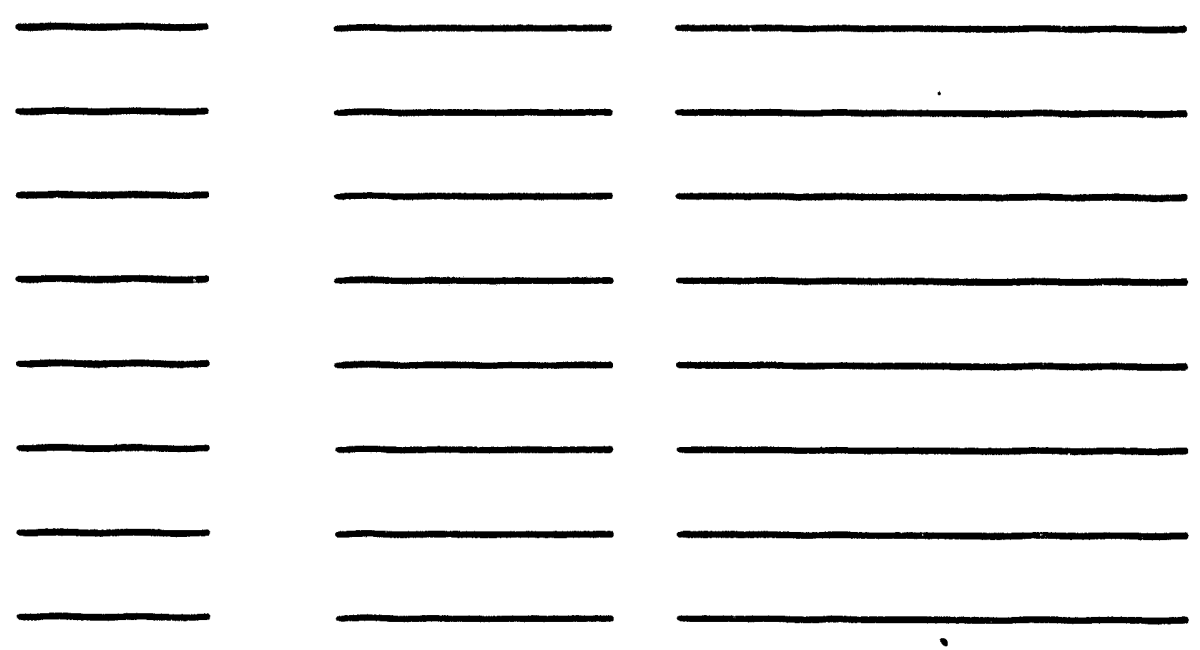

\section{REMOVE LASER SPECTROMETER}

NOTE - As noted in Task B above, this operation will occur approximately two hours after the installation.

* HP Hold Point *

1. Notify PUREX dispatcher that there will be a low flow alarm on FA-V29A-3-1.

Dispatched Notified (Initial/Date):

2. If it is running, turn off pump P-V29A-1:

a. Adjust valves in the following sequence:

MV-29A-5-2 CLOSE

MV-29A-5-1 CLOSE 
WHC-EP-0680

One Time Work Plan WP-P-92-029

Page 6 of 9

b. Energize Pump P-V29-A-1 using MS-V29A-4-4 .

3. CLOSE vaive MV-V28A-5-3.

4. Remove laser spectrometer system.

5. Replace valve MV-V28A-5-15 and its associated tee removed from step 4 in task $B$.

NOTE - Tighten tubing supports loosened in task $B$.

6. CLOSE regulator FCV-V29A-1-1.

7. OPEN Valve MV-V28A-5-3.

* HP Hold Point **

8. Adjust regulator FCV-V29A-2-1 to maintain isokinetic flow through RAN-V29A-1-1.

Flow Rate: (Initial/Date)

* HP Hold Point **

9. Survey the work area and laser spectrometer

Survey Results:

(Initial/Date)

10. Prepare the laser spectrometer for transport, and transport it to storage or to the next location for use.

11. Clean up work area.

LASER SPECTROMETER TEST COMPLETED: DATE COGNIZANT ENGINEER

B6-6 


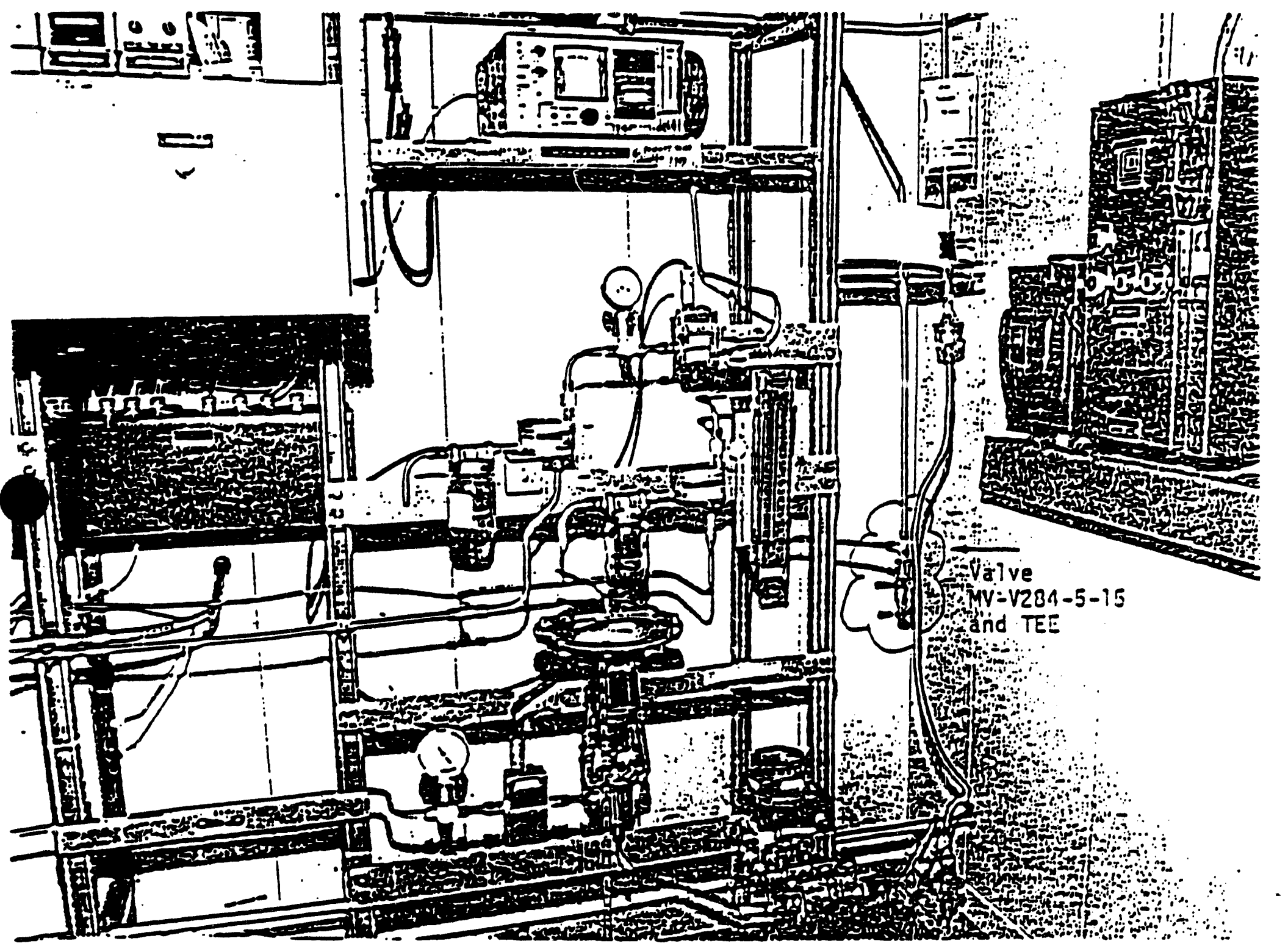

Figure 1. Current Effluent Sampling and Monitoring Systems for the PR Stack 
Table 1. Correction Factors Required for In-Line Flowmeter Readings due to Vacuum

\begin{tabular}{|c|c|c|c|c|c|}
\hline Veang & $\begin{array}{c}\text { Flomerer Correction } \\
\text { Fector }\end{array}$ & $\begin{array}{l}\text { Vecung } \\
\left({ }^{\circ} \mathrm{Hg}\right)\end{array}$ & $\begin{array}{l}\text { Floweter Correction } \\
\text { Factor }\end{array}$ & Vacue & $\begin{array}{l}\text { Fomitar Correction } \\
\text { Factor }\end{array}$ \\
\hline $\begin{array}{l}0.1 \\
0.2 \\
0.3 \\
0.4 \\
0.5 \\
0.6 \\
0.7 \\
0.8 \\
0.9 \\
1.0 \\
1.1 \\
1.2 \\
1.3 \\
1.4 \\
1.5 \\
1.6 \\
1.7 \\
1.8 \\
1.9 \\
2.0 \\
2.1 \\
2.2 \\
2.3 \\
2.4 \\
2.5 \\
2.6 \\
2.7 \\
2.8 \\
2.9 \\
3.0 \\
3.1 \\
3.2 \\
3.3 \\
3.4 \\
3.5 \\
3.6 \\
3.7 \\
3.8 \\
3.9 \\
4.0 \\
4.1 \\
4.2 \\
4.3 \\
4.4 \\
4.5 \\
4.6 \\
4.7 \\
4.8 \\
4.9 \\
5.0 \\
5.1 \\
5.2 \\
5.3 \\
5.4 \\
5.5 \\
5.6 \\
5.7 \\
5.8 \\
5.9\end{array}$ & $\begin{array}{l}1.002 \\
1.003 \\
1.005 \\
1.007 \\
1.008 \\
1.010 \\
1.012 \\
1.014 \\
1.015 \\
1.017 \\
1.019 \\
1.021 \\
1.022 \\
1.024 \\
1.026 \\
1.028 \\
1.030 \\
1.032 \\
1.033 \\
1.035 \\
1.037 \\
1.039 \\
1.041 \\
1.043 \\
1.045 \\
1.047 \\
1.048 \\
1.050 \\
1.052 \\
1.054 \\
1.056 \\
1.058 \\
1.060 \\
1.062 \\
1.064 \\
1.065 \\
1.068 \\
1.070 \\
1.072 \\
1.074 \\
1.076 \\
1.079 \\
1.081 \\
1.083 \\
1.085 \\
1.087 \\
1.089 \\
1.091 \\
1.094 \\
1.096 \\
1.098 \\
1.100 \\
1.102 \\
1.105 \\
1.107 \\
1.109 \\
1.111 \\
1.114 \\
1.116\end{array}$ & $\begin{array}{r}6.0 \\
6.1 \\
6.2 \\
6.3 \\
6.4 \\
6.5 \\
6.6 \\
6.7 \\
6.8 \\
6.9 \\
7.0 \\
7.1 \\
7.2 \\
7.3 \\
7.4 \\
7.5 \\
7.6 \\
7.7 \\
7.8 \\
7.9 \\
8.0 \\
8.1 \\
8.2 \\
8.3 \\
8.4 \\
8.5 \\
8.6 \\
8.7 \\
8.8 \\
8.9 \\
9.0 \\
9.1 \\
11.8 \\
11.9\end{array}$ & $\begin{array}{l}1.118 \\
1.121 \\
1.123 \\
1.125 \\
1.128 \\
1.130 \\
1.133 \\
1.135 \\
1.138 \\
1.140 \\
1.143 \\
1.145 \\
1.148 \\
1.150 \\
1.153 \\
1.155 \\
1.158 \\
1.160 \\
1.163 \\
1.166 \\
1.168 \\
1.171 \\
1.174 \\
1.176 \\
1.179 \\
1.182 \\
1.185 \\
1.187 \\
1.190 \\
1.193 \\
1.196 \\
1.199 \\
1.202 \\
1.205 \\
1.208 \\
1.210 \\
1.213 \\
1.216 \\
1.219 \\
1.222 \\
1.226 \\
1.229 \\
1.232 \\
1.235 \\
1.238 \\
1.241 \\
1.244 \\
1.248 \\
1.251 \\
1.254 \\
1.258 \\
1.261 \\
1.264 \\
1.268 \\
1.271 \\
1.274 \\
1.278 \\
1.281 \\
1.285 \\
1.289\end{array}$ & $\begin{array}{l}12.0 \\
12.1 \\
12.2 \\
12.3 \\
12.4 \\
12.5 \\
12.6 \\
12.7 \\
12.8 \\
12.9 \\
13.0 \\
13.1 \\
13.2 \\
13.3 \\
13.4 \\
13.5 \\
13.6 \\
13.7 \\
13.8 \\
13.9 \\
14.0 \\
14.1 \\
14.2 \\
14.3 \\
14.4 \\
14.5 \\
14.6 \\
14.7 \\
14.8 \\
14.9 \\
15.0 \\
15.1 \\
15.2 \\
15.3 \\
15.4 \\
15.5 \\
15.6 \\
15.7 \\
17.8 \\
17.6 \\
17.8 \\
17.9\end{array}$ & $\begin{array}{l}1.292 \\
1.296 \\
1.299 \\
1.303 \\
1.307 \\
1.311 \\
1.314 \\
1.318 \\
1.322 \\
1.326 \\
1.330 \\
1.334 \\
1.338 \\
1.342 \\
1.346 \\
1.350 \\
1.354 \\
1.358 \\
1.362 \\
1.367 \\
1.371 \\
1.375 \\
1.380 \\
1.384 \\
1.388 \\
1.393 \\
1.397 \\
1.402 \\
1.407 \\
1.411 \\
1.416 \\
1.421 \\
1.426 \\
1.431 \\
1.435 \\
1.440 \\
1.445 \\
1.451 \\
1.456 \\
1.461 \\
1.466 \\
1.471 \\
1.477 \\
1.482 \\
1.488 \\
1.493 \\
1.499 \\
1.504 \\
1.510 \\
1.516 \\
1.522 \\
1.528 \\
1.534 \\
1.540 \\
1.546 \\
1.552 \\
1.558 \\
1.565 \\
1.571 \\
1.578\end{array}$ \\
\hline
\end{tabular}


Table II. Brooks Flowmeter (Model R-615-B, Carboloy, Spherical Ball) Calibration Data

\begin{tabular}{|c|c|c|c|c|c|c|c|}
\hline $\begin{array}{c}\text { Tube Randing } \\
\text { (n) }\end{array}$ & $\begin{array}{l}\text { Fow Rate } \\
\text { (cfial) }\end{array}$ & Tube Reading & Fow Rate & Tube Reading & Flow Rate & $\begin{array}{l}\text { Tube Reading } \\
\text { (ma) }\end{array}$ & Flow Rate \\
\hline $\begin{array}{l}150.0 \\
149.0 \\
148.0 \\
147.0 \\
146.0 \\
145.0 \\
144.0 \\
143.0 \\
142.0 \\
141.0 \\
140.0 \\
139.0 \\
138.0 \\
137.0 \\
136.0 \\
135.0 \\
134.0 \\
133.0 \\
132.0 \\
131.0 \\
130.0 \\
129.0 \\
128.0 \\
127.0 \\
126.0 \\
125.0 \\
124.0 \\
123.0 \\
122.0 \\
121.0 \\
120.0 \\
119.0 \\
118.0 \\
117.0 \\
116.0 \\
115.0 \\
114.0 \\
113.0 \\
112.0 \\
111.0 \\
\end{array}$ & $\begin{array}{l}2.160 \\
1.142 \\
2.123 \\
2.105 \\
2.086 \\
2.068 \\
2.049 \\
2.031 \\
2.013 \\
1.995 \\
1.977 \\
1.960 \\
1.942 \\
1.925 \\
1.908 \\
1.891 \\
1.875 \\
1.860 \\
1.844 \\
1.829 \\
1.813 \\
1.798 \\
1.783 \\
1.787 \\
1.752 \\
1.736 \\
1.721 \\
1.705 \\
1.689 \\
1.673 \\
1.656 \\
1.640 \\
1.624 \\
1.607 \\
1.591 \\
1.574 \\
1.558 \\
1.541 \\
1.525 \\
1.509\end{array}$ & $\begin{array}{l}110.0 \\
109.0 \\
108.0 \\
107.0 \\
106.0 \\
105.0 \\
104.0 \\
103.0 \\
102.0 \\
101.0 \\
100.0 \\
99.0 \\
98.0 \\
97.0 \\
96.0 \\
95.0 \\
94.0 \\
93.0 \\
92.0 \\
91.0 \\
90.0 \\
89.0 \\
88.0 \\
87.0 \\
86.0 \\
85.0 \\
84.0 \\
83.0 \\
82.0 \\
81.0 \\
80.0 \\
79.0 \\
78.0 \\
77.0 \\
76.0 \\
75.0 \\
74.0 \\
73.0 \\
72.0 \\
71.0\end{array}$ & $\begin{array}{l}1.493 \\
1.477 \\
1.461 \\
1.446 \\
1.430 \\
1.416 \\
1.401 \\
1.387 \\
1.373 \\
1.359 \\
1.345 \\
1.331 \\
1.317 \\
1.303 \\
1.289 \\
1.274 \\
1.260 \\
1.245 \\
1.230 \\
1.215 \\
1.199 \\
1.183 \\
1.167 \\
1.151 \\
1.134 \\
1.118 \\
1.102 \\
1.085 \\
1.069 \\
1.053 \\
1.036 \\
1.020 \\
1.005 \\
0.989 \\
0.974 \\
0.959 \\
0.944 \\
0.929 \\
0.915 \\
0.900\end{array}$ & $\begin{array}{l}70.0 \\
69.0 \\
68.0 \\
67.0 \\
66.0 \\
65.0 \\
64.0 \\
63.0 \\
62.0 \\
61.0 \\
60.0 \\
59.0 \\
58.0 \\
57.0 \\
56.0 \\
55.0 \\
54.0 \\
53.0 \\
52.0 \\
51.0 \\
50.0 \\
49.0 \\
48.0 \\
47.0 \\
46.0 \\
45.0 \\
44.0 \\
43.0 \\
42.0 \\
41.0 \\
40.0 \\
39.0 \\
38.0 \\
37.0 \\
36.0 \\
35.0 \\
34.0 \\
33.0 \\
32.0 \\
31.0\end{array}$ & $\begin{array}{l}0.886 \\
0.872 \\
0.857 \\
0.843 \\
0.829 \\
0.815 \\
0.801 \\
0.787 \\
0.772 \\
0.758 \\
0.744 \\
0.730 \\
0.716 \\
0.702 \\
0.689 \\
0.675 \\
0.661 \\
0.647 \\
0.634 \\
0.620 \\
0.606 \\
0.593 \\
0.579 \\
0.566 \\
0.553 \\
0.539 \\
0.526 \\
0.513 \\
0.500 \\
0.487 \\
0.475 \\
0.462 \\
0.449 \\
0.436 \\
0.423 \\
0.411 \\
0.398 \\
0.385 \\
0.373 \\
0.360\end{array}$ & $\begin{array}{r}30.0 \\
29.0 \\
28.0 \\
27.0 \\
26.0 \\
25.0 \\
24.0 \\
23.0 \\
22.0 \\
21.0 \\
20.0 \\
19.0 \\
18.0 \\
17.0 \\
16.0 \\
15.0 \\
14.0 \\
13.0 \\
12.0 \\
11.0 \\
10.0 \\
9.0 \\
8.0 \\
7.0 \\
6.0 \\
5.0\end{array}$ & $\begin{array}{l}0.347 \\
0.335 \\
0.323 \\
0.310 \\
0.298 \\
0.286 \\
0.273 \\
0.261 \\
0.249 \\
0.237 \\
0.225 \\
0.213 \\
0.201 \\
0.189 \\
0.177 \\
0.166 \\
0.154 \\
0.143 \\
0.131 \\
0.120 \\
0.109 \\
0.097 \\
0.086 \\
0.075 \\
0.063 \\
0.052\end{array}$ \\
\hline
\end{tabular}


WHC-EP-0680

This page intentionally left blank. 
WHC-EP-0680

DISTRIBUTION

Number of Copies

OFFSITE

2

\begin{tabular}{l} 
U.S. Environmental Protection \\
\hline Agency/Region 10 \\
1200 Sixth Avenue \\
Attention: AT-002 \\
Seattle, Washington 98101
\end{tabular}

R. W. Poeton

Science Applications International

Corporation

1845 Terminal Drive, Suite 202

Richland, Washington 99352

J. L. Kenoyer

ONSITE

5

U.S. Department of EnergyRichland Operations Office

G. J. Bracken

R3-81

J. E. Mecca

R3-81

J. E. Rasmussen

A5-15

S. D. Stites

A5-15

Public Reading Room Al-65

Pacific Northwest Laboratory

D. L. Klages P7-79

PNL Technical Files K1-11

14

Westinghouse Hanford Company

L. P. Diediker T1-30

J. J. Dorian H6-30

B. G. Erlandson H6-20

K. A. Hadley R3-56

D. B. Jensen H6-30

J. Lohrasbi S6-19

J. H. Mizner, Jr T3-28

R. D. Weissenfels $\quad 56-70$

C. D. Wollam S6-19

Central Files L8-04

Document Processing \& Distribution L8-15

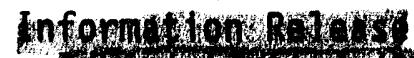

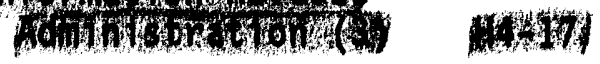

Distr-1 
WHC-EP-0680

This page intentionally left blank. 


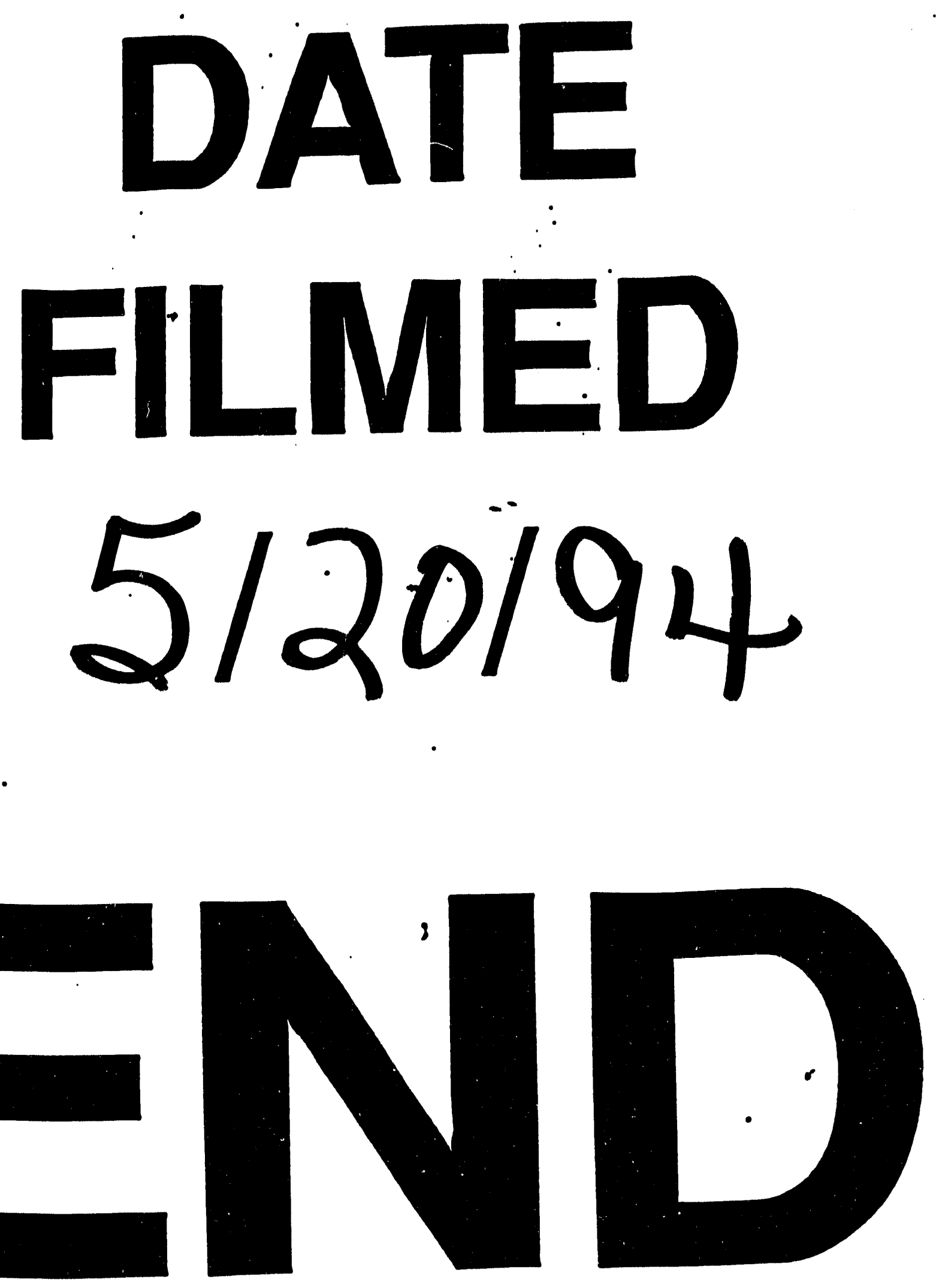


